\title{
TESORILLOS DEL S. III d.C. EN LA PENÍNSULA IBÉRICA ${ }^{1}$
}

\author{
ISIDRO MARTÍNEZ MIRA
}

Universidad de Alicante

\begin{abstract}
Este trabajo tiene como finalidad recopilar todos los tesorillos numismáticos del siglo III d.C. hallados y publicados en la Península Ibércia. Sus datos se han reunido en fichas tipo resumen sus características principales y permiten una rápida consulta. La base es el listado publicado por Pereira et alii, 1974, del que se hace también una revisión crítica.

The aim of this work is to gather all the coin hoard of the III Century AD found and published in the Iberian Peninsula. Their data and its principal characteristics have been collected in records, which provides a faster consultation. The base is the listing published by Pereira et alii, 1974, of which we also make a critical revision.
\end{abstract}

En el presente artículo recogemos los tesorillos numismáticos aparecidos, y publicados, en la Península Ibérica pertenecientes al S. III d.C.. Para ello nos hemos basado en la relación publicada por Pereira et alii ${ }^{2}$, relación a la que hemos añadido los nuevos tesorillos publicados desde 1974 hasta estos momentos más alguno publicado anteriormente y no

\footnotetext{
' Este artículo constituye una actualización del Apéndice III de nuestra Tesina de Licenciatura denominada: «Fuentes para el estudio de las supuestas invasiones del siglo III d.C. en la Península Ibérica». Universidad de Alicante. Diciembre, 1992. Dirigida por J.M. Abascal Palazón.

2 PEREIRA, I., BOST, J.-P., HIERNARD, J.; 1974: Fouilles de Conimbriga III. Les Monnaies. París, 232-233.
}

recogido en la referida relación. Asimismo hemos efectuado también una comprobación de los tesorillos de dicha relación excluyendo los que a nuestro entender no pertenecen a este período.

Para el estudio individual de los tesorillos hemos confeccionado una ficha que cumplimentamos en función de sus datos conocidos.

Los diferentes apartados de la ficha son:

( ) = Número asignado en nuestra relación.

[ ] = Número de la relación de Pereira et alii.

Hall.= Lugar y circunstancias del hallazgo del tesorillo, número de numismas hallados, etc.

Inv. = En el caso de conocer la composición del tesorillo, la resumiremos en un cuadro sinóptico, con referencias a: -Emperadores representados. 
-Cronología de la emisión de los numismas, en el caso de que se conozca; en el caso contrario nos remitiremos a la cronología global del emperador.

-Ceca de emisión de los numismas, cuya lectura se hará mediante las siguientes abreviaturas:

Ant= Antioquía
Asi $=$ Asia
Biz= Bizancio
Col= Colonia
Cae $=$ Caesaraugusta
Cel $=$ Celsa
Cal= Calagurris
Cyz= Cyzicus
Dud= Dudosas
Eme= Emesa
Fru=Frustras
Gal $=$ Galia
Ile= Ilegible
Ina $=$ Inatribuible
Inc= Incierta

Lug= Lugdunum

Med $=$ Mediolanum

Moe $=$ Moesia

Ori $=$ Oriente

Occ $=$ Occidente

Reg=Taller regional

RoL= Roma o local

Rom $=$ Roma

Sam $=$ Samosata

Ser= Sérdica

Sis $=$ Siscia

Tic $=$ Ticinum

Tur $=$ Turiaso

Tre $=$ Tréveris

Vim= Viminacium

Por último, señalaremos los porcentajes, tanto de las cecas como de los emperadores, con relación al total de numismas del hallazgo o, en el caso de que no esté completo, de los que conozcamos.

Ult. Num. $=$ Descripción del último numisma conocido del tesorillo, que sirve de «terminus post quem» para su ocultación, con referencia a:

1) Emperador (tipo de numisma)

2) Anverso

3) Reverso

4) Ceca. Cronología

5) Peso. Módulo

6) Referencia del RIC, Elmer o Cunetio.

Ref. $=$ Referencias bibliográficas.

ABREVIATURAS USADAS EN LAS REFERENCIAS

ANSMuN: The American Numismatic Society Museum Notes. New York.

ANum: Acta Numismática. Barcelona.

AP: O Arqueologo Portugués. Lisboa.

BAR Supp. Ser.: British Archaeological Reports Supplementary Series. Oxford.

BCMHALugo: Boletín de la Comisión provincial De Monumentos Histórico-Artísticos de Lugo. Lugo.

BIDEA: Boletín del Instituto de Estudios

BJ: Asturianos. Oviedo.

Bonner Jahrbücher des Rheinischen Landesmuseums in Bonn. Bonn.
BMZ:

Bol. Arq.:

BRAG:

BRSVAP:

BSEAA:

BSFN:

CENB:

CNA:

CPAC:

CTEEHAR:

Cunetio:

CuPAUM:

EAE:

EClás:

Elmer:

GN:

HAnt:

MCV:

$\mathrm{NAH}$ :

NC:

$\mathrm{NH}$ :

NL:

PITTM:

PV:

Rev. Arq.:

RG:

RIC IV-1:
Boletín del Museo de Zaragoza. Zaragoza.

Boletín Arqueológico de Real Sociedad Arqueológica de Tarragona. Tarragona. Boletín de la Real Academia Gallega. La Coruña.

Boletín de la Real Sociedad Vascongada de Amigos del País. San Sebastián.

Boletín del Seminario de Estudios de Arte y Arqueología. Valladolid.

Bulletin de la Société Française de Numismatique. París.

Cercle d'Etudes Numismatiques. Bulletin. Brussels.

Congreso Nacional de Arqueología. Zaragoza.

Cuadernos de Prehistoria y Arqueología Castellonenses. Castellón.

Cuadernos de Trabajo de la Escuela Española de Historia y Arqueología de Roma. Roma.

BESLY, E., BLAND, R., 1983: The Cunetio Treasure. Roman Coinage of the Third Century AD. London.

Cuadernos de Prehistoria y Arqueología de la Universidad Autonoma de Madrid. Madrid.

Excavaciones Arqueológicas de España. Madrid.

Estudios Clásicos. Madrid.

ELMER, G., 1941: «Die Münzpragung der gallischen kaiser in Köln, Trier und Mailand.» BJ 146, 1-106.

Gaceta Numismática. Barcelona.

Hispania Antiqua. Valladolid.

Mélanges de la «Casa de Velázquez».

Madrid.

Noticiario Arqueológico Hispánico.

Madrid

Numismatic Chronicle. London.

Numario Hispánico. Madrid.

Numismatic Literature. The American

Numismatic Society. New York.

Publicaciones de la Institución «Tello

Téllez de Meneses».Palencia.

Príncipe de Viana. Pamplona.

Revista de Arqueologia. Madrid

Revista de Guimaraes. Guimaraes.

MATTINGLY, H., SYDENHAM, E.A., 1936: Roman Imperial Coinage IV-1, Pertinax to Geta. London. 
RIC IV-2:

MATTINGLY, H., SYDENHAM, E.A., SUTHERLAND, C.H.V.,1938: Roman Imperial Coinage IV-2, Macrinus to Pupienus.London.

RIC IV-3: MATTINGLY, H., SYDENHAM, E.A. SUTHERLAND, C.H.V, 1949: Roman Imperial Coinage IV-3, Gordian III to Uranius Antoninus. London.

RIC V-1: $\quad$ WEBB, P.H., 1927: Roman Imperial Coinage V-1, Valerian to Florian.London. RIC V-2: $\quad$ WEBB, P.H., 1933: Roman Imperial Coinage V-2, Probus to Amandus. London.

RN: Revue Numismatique. París.

SNB: $\quad$ Symposium Numismatic de Barcelona. Barcelona. 1979. Vol. 1 y 2.

TAN: $\quad$ Trabajos de Arqueología Navarra. Pamplona.

\section{TESORILLOS DEL SIGLO III D.C. EN LA PENÍNSULA IBÉRICA}

\section{(1) [6] GRANADA}

Hall. En la Provincia de Granada, sin especificar un lugar determinado. Constaba de unos 20.000 numismas, entre los cuales había algunos del Emperador Probo, a flor de cuño. No se especifican más datos, por lo que lo incluimos en este siglo, aunque no tenemos la seguridad de que pueda pertenecer al siglo III o al IV d.C.

Ref. BALIL, A. 1959: «Hispania en los años 260-300 d.C.», Emerita, 27, 282 y nota 4.

\section{(2) [16] VALHASCOS (SANTAREM, PORTUGAL)}

Hall. M. de Castro Hipólito nos refiere dos noticias sobre el hallazgo de monedas romanas aparecidas en Valhascos, Concelho de Sardoal, Distrito de Santarem (Portugal), que pone en relación con un mismo tesorillo:

-En Sardoal, apareció un vaso de bronce con monedas de plata del s. III, de las que 12 ingresaron en el Museo Etnológico.

-En Abrantes, se adquirieron, para el Museo Etnológico, 190 monedas de plata del s. III, que formaban parte de un tesoro aparecido en la década de 1880, en Sardoal.

Ref. LEITE DE VASCONCELLOS, J. 1910: «Crónica», AP, 15, 250.; LEITE DE VASCONCELLOS, J. 1927: De Terra em Terra, vol. I, 158-59; DE CASTRO HIPÓLITO, M. 1960-61: «Dos tesouros de moedas romanas em Portugal», Conimbriga, $23,78, \mathrm{n}^{\circ} 106$.

\section{(3) [31] LUGO-1}

Hall. Aureos romanos hallados al construir el edificio del Banco de España en Lugo, en 1928-29, compuesto por un áureo de cada uno de los emperadores siguientes:
Inv.

\begin{tabular}{|l|c|}
\hline \multicolumn{1}{|c|}{ Emperador } & Cronología \\
\hline Vespasiano & $69-79$ d.C. \\
\hline Domiciano & $79-82$ d.C. \\
\hline Faustina & $105-140$ d.C. \\
\hline Marco Aurelio & $160-180$ d.C. \\
\hline Septimo Severo & $193-211$ d.C. \\
\hline
\end{tabular}

Ref. VÁZQUEZ SEIJAS, M.; 1949: Monumentos arqueológicos-numismáticos en Lugo y su provincia. Libro de Oro. Lugo, 114; MATEU Y LLOPIS, F. 1951: «Hallazgos monetarios 6», Ampurias, 13, 235, $\mathrm{n}^{\circ} 421$.

\section{(4) [19] BORRALHEIRA, BARROCA DA LAJE (POR- TUGAL)}

Hall. Se halló casualmente el 10-XII-1953, en un lugar de Borralheira, Feligresia de Teixoso, Concelho de Covilhâ (Portugal). Del total hallado sólo se lograron recuperar 40 aureos, 1 collar de oro, 1 par de pendientes de oro, 4 anillos de oro y 4 fragmentos de collares de plata.

Además de los numismas que se describen, se tiene constancia de la existencia de otros aureos de los Emperadores: Lucio Vero y Lucilla, Adriano y Septimio Severo que no se pudieron recuperar.

Inv.

\begin{tabular}{|l|c|c|}
\hline Emperador & Cronología & Ejemplares \\
\hline Nerón & $54-68$ d.C. & 1 \\
\hline Tito & $79-81$ d.C. & 2 \\
\hline Trajano & $98-117$ d.C. & 2 \\
\hline Adriano & $117-138$ d.C. & 12 \\
\hline Antonino Pío & $138-161$ d.C. & 6 \\
\hline Faustina I & & 6 \\
\hline Marco Aurelio & $161-180$ d.C. & 5 \\
\hline Faustina II & & 3 \\
\hline Septimio Severo & $193-211$ d.C. & 1 \\
\hline Iulia Domna & & 1 \\
\hline Geta & $209-212$ d.C. & 1 \\
\hline
\end{tabular}


Ult. Num.

Emperador: Geta (Aureo).

A/ P SEPTIMIVS GETA CAES.

R/ PONTIF COS.

Ceca: Roma, 203-208 d.C.

Peso, Mód.: --,--

Ref: RIC IV-1, 33.

Ref. HELENO, M. 1953: «O tesouro da Borralheira (Teixoso)», AP, Nova Serie II, 213-26; DE CASTRO HIPÓLITO, M. 1960-61: «Dos tesouros de moedas romanas em Portugal», Conimbriga, 23, 63-64; D'ENCARNAÇAO, J., GERALDES, F. 1982: «Júpiter Supremo Sumo», Conimbriga, 21, 138.

\section{(5) [--] COCA (SEGOVIA)}

Hall. Se encontró al realizar unas obras en una calle de Coca (Segovia) a unos $200 \mathrm{mts}$. de la muralla, en 1949-50. Parece ser el contenido de una bolsa hoy desaparecida.

El número de numismas encontrados estaría en torno a los 80-100 ejemplares, de los que sólo se conservan 2 áureos y 16 denarios, faltando 1 denario de Marco Aurelio desaparecido.

Al estudiar el material se comprueba que las piezas han sido claramente seleccionadas, pues todas son diferentes.

Inv.

\begin{tabular}{|c|c|c|c|c|c|}
\hline Emperador & Cronol. & Rom & Eme? & Total & $\%$ \\
\hline Trajano & 106 & $1 *$ & & 1 & 5,55 \\
\hline Adriano & $134-138$ & $1 *$ & & 1 & 5,55 \\
\hline Marco Aurelio & $\begin{array}{c}145-147 \\
161\end{array}$ & $\begin{array}{l}1 \\
1\end{array}$ & & 2 & 2,11 \\
\hline Antonio Pío & $153-154$ & 1 & & 1 & 5,55 \\
\hline Faustina II & $161-176$ & 2 & & 2 & 11,11 \\
\hline Septimio Severo & $\begin{array}{c}194-195 \\
201-210 \\
202-211 \\
207\end{array}$ & $\begin{array}{l}1 \\
1 \\
2\end{array}$ & 1 & 5 & 27,79 \\
\hline Iulia Domna & $196-211$ & 1 & & 1 & 5,55 \\
\hline Geta & 205 & 1 & & 1 & 5,55 \\
\hline \multirow[t]{3}{*}{ Caracalla } & $\begin{array}{l}205 \\
207 \\
214\end{array}$ & $\begin{array}{l}1 \\
2 \\
1 \\
\end{array}$ & & 4 & 22,24 \\
\hline & TOTAL & 17 & 1 & 18 & \\
\hline & $\%$ & 94,44 & 0,55 & & 100 \\
\hline
\end{tabular}

(*) Aureos

$\%:$ Aureos $=11,11$

$\%:$ Denarios $=88,89$

\section{Ult. Num.}

Emperador: Caracalla (Denario).

A/ ANTONINVS PIVS AVG GERM, Cabeza laureada a derecha.

R/ PM TR P XVII COS IIII PP, Serapis en pie a izq.; mano derecha levantada sosteniendo cetro transversalmente.

Ceca: Roma. 214 d.C.

Peso. Módulo: 3,79 gr. 20/18 mm.

Ref: RIC IV-1, 244.

Ref. SAGREDO SAN EUSTAQUIO, L. 1981: «Posible tesorillo del siglo III d.C.», Numisma, 31, $\mathrm{n}^{\circ}$ 168-173, 73-88. BLANCO, F.J. 1988: Moneda y circulación monetaria en Coca. Segovia.

\section{(6) [--] BOLIBAR (VIZCAYA)}

Hall. En el término municipal de esta villa fue localizado, en 1923, un tesorillo de monedas de bronce en circunstancias desconocidas. Parece ser que el hallazgo se componía de unas 30 monedas, de las que sólamente se han podido describir 3, al haber sido fotografiadas con anterioridad a la dispersión del tesorillo. Las tres monedas descritas son sestercios, lo cual, parece indicar que estaría compuesto muy problablemente por sestercios de los siglos II-III d.C.; no siendo su ocultación muy posterior a la última de las monedas descritas:

Inv.

\begin{tabular}{|l|c|c|c|}
\hline Emperador & Cronología & Ceca & Total \\
\hline Diva Faustina I & Post. 161 d.C. & Roma & 1 \\
\hline Faustina II & $161-176$ d.C. & Roma & 1 \\
\hline Severo Alejandro & 231 d.C. & Roma & 1 \\
\hline
\end{tabular}

\section{Ult. Num.}

Emperador: Severo Alejandro (sestercio).

A/ IMP SEV ALEXANDER AVG.

R/ IOVI CONSERVATORI, SC.

Ceca: Roma, 231 d.C.

Peso, Módulo: --,--

Ref: BMC 694.

Ref. CEPEDA OCAMPO, J.J. 1990: Moneda y circulación monetaria en el País Vasco durante la Antiguiedad (siglo II a.C.-V d.C.), Bilbao, 39-40, 171; BALPARDA, G. 1924: Historia crítica de Vizcaya y de sus fueros, I, Madrid, 96 ss.

\section{(7) [--] TORRE LLAUDER (MATARO, BARCELONA)}

Hall. En un espacio intermedio del terreno, entre los restos de la villa romana de Torre Llauder (Mataró, Barcelona) y los hornos de vidrio de esta misma villa, se descubrió un peque- 
ño escondrijo compuesto por 188 anillas de bronce, que estaban agrupadas y 8 medianos bronces romanos.

Inv.

\begin{tabular}{|l|c|c|c|c|}
\hline Emperador & Cronol. & Rom & Ile & Total \\
\hline Domiciano & - & & 3 & 3 \\
\hline Faustina I ó Il & -- & & 1 & 1 \\
\hline Plautilla & 2 22 d.C. & 2 & & 2 \\
\hline Alejandro Severo & 228 d.C. & 1 & & 1 \\
\hline Iulia Mamaea & 235 d.C. & 1 & & 1 \\
\hline & TOTAL & 4 & 4 & 8 \\
\hline
\end{tabular}

\section{Ult. Num.}

Emperador: Iulia Mamaea (Sestercio).

A/ IVLIA MAMAEA AVGVSTAE, Busto diademado a derecha.

\section{R/ FECVNDITAS AVGVSTAE, S C.}

Ceca: Roma, 235 d.C.

Peso, Módulo: 12,83 gr. 27,05 mm.

Ref: RIC IV-2, 669.

Ref. GURT, J.M. 1978: «Hallazgo de un tesorillo del siglo III en la villa romana de Torre Llauder (Mataró)», GN, 50, 10-15; MARTI, C., BONAMUSA, J. 1976: «La numismática de la vil.la romana d'Iluro de Torre Llauder (Mataró)», Miscel.lànies arqueológiques de Mataró i El Maresme, I, 87-116.

\section{(8) [14] ARRUDA DOS VINHOS (LISBOA, PORTUGAL)}

Hall. Hallazgo de un tesorillo con monedas de Julia Mamea (235 d.C.) y de Maximino (235-238 d.C.).

Ref. MATEU Y LLOPIS, F. 1947-48: «Hallazgos monetarios 5», Ampurias, 9-10, 68.

\section{(9) [17] POLVARINHO (CASTELO BRANCO, PORTU-} GAL)

Hall. Tesorillo formado por numismas de Faustina (141 d.C.) y de Maximino (23538 d.C.).

Ref. MATEU Y LLOPIS, F. 1947-48: «Hallazgos monetarios 5", Ampurias, 9-10, 68.

\section{(10) [--] "DOMUS A" DE ROMEU (SAGUNTO, VALEN-} CIA)

Hall. Se halló en el transcurso de las excavaciones que se llevaban a cabo durante 1993 en un solar de Sagunto, situado entre las calles Huertos, Alorco y Plaza de la morería Vella, donde se ubicaba antiguamente el campo de fútbol del Romeu.

Las excavaciones revelaron la existencia de una domus de época imperial. El depósito monetal apareció en la denomina- da estancia E, identificada como una dependencia de la parte noble de la domus.

Los 11 sestercios que componen el hallazgo aparecieron formando un cilindro, estando las monedas pegadas unas a otras. Muy probablemente, estarían en el interior de una bolsa o saquito de material perecedero y de la que no se ha conservado ningún resto. Aparece en un estrato de destrucción.

\section{Ult. Num.}

Emperador: Balbino (Sestercio)

A/ IMP CAES D CAEL BALBINVS AVG. Busto laureado, drapeado y con coraza a derecha.

R/ CONCORDIA AVGG, SC. Concordia sentada a izq. Manteniendo una pátera y una cornucopia.

Ceca: Roma. 238 d.C.

Peso. Módulo: 22,48 g; --

Ref: RIC IV-2, 22; BMC VI, 18.

Inv.

\begin{tabular}{|l|c|c|}
\hline Emperador & Cronología & Total \\
\hline Domiciano & & 1 \\
\hline Antonino Pío & $151-152$ & 1 \\
\hline Faustina II & & 1 \\
\hline Marco Aurelio & $170-171$ & 1 \\
\hline Lucilla & 181 & 1 \\
\hline Comodo & 186 & 1 \\
& -- & 1 \\
\hline Severo Alejandro & $222-231$ & 1 \\
\hline Maximino I & $236-238$ & 11 \\
\hline Balbino & 238 & TOTAL \\
\hline
\end{tabular}

Ref: LLORENS FORCADA, M $M^{a}$ DEL MAR, RIPOLLÉS ALEGRE, P.P.; 1995: "El depósito monetal de la Domus A de Romeu: nuevas aportaciones a la circulación de moneda de bronce en Sagunto durante el siglo III d.C.", Saguntum, 28, 217-228.

\section{(11) [--] PETAVONIUM (SANSUEÑA, ZAMORA)}

Hall. A principios de siglo, en las ruinas de Sansueña, se halló un tesorillo que superaba inicialmente los 500 numismas y de los que solamente se han descrito 16 denarios. Se desconocen los detalles del hallazgo. 
Ult. Num.

Emperador: Gordiano II (Denario)

A/ IMP M ANT GORDIANVS AFR AVG, Busto laureado, drapeado y con coraza a derecha.

R/ PROVIDENTIA AVGG, Providencia de pie a izq. apoyada en una columna; vara en mano derecha y en la izq. cuerno de la abundancia; a los pies globo terráqueo.

Ceca: Roma, Marzo-Abril 238 d.C.

Peso, Módulo: 3,07 gr. $21 \mathrm{~mm}$.

Ref: RIC IV-2, 1.

Inv.

\begin{tabular}{|l|c|c|c|c|}
\hline Emperador & Cronol. & Rom & Total & $\%$ \\
\hline Vespasiano & $70-72$ & 1 & & \\
& $\begin{array}{c}72-73 \\
74\end{array}$ & 1 & & \\
$75-79$ & 1 & 4 & 25,00 \\
\hline Nerva & 97 & 1 & 1 & 6,25 \\
\hline Trajano & $114-117$ & 1 & 1 & 6,25 \\
\hline Faustina I Diva & 141 & 3 & 3 & 18,75 \\
\hline Antonino Pío & $150-151$ & 1 & & \\
& Divo & & 2 & 12,50 \\
\hline Marco Aurelio & $170-181$ & 1 & 1 & 6,25 \\
\hline Comodo & 189 & 1 & 1 & 6,25 \\
\hline Septimio Severo & $194-195$ & 1 & & \\
\hline Gordiano II & $202-210$ & 1 & 2 & 12,50 \\
\hline & 238 & 1 & 1 & 6,25 \\
\hline
\end{tabular}

Damos como último numisma el perteneciente a Gordiano II, pero existen noticias que confirman la existencia en el tesorillo de numismas pertenecientes a los emperadores Tiberio, Trajano, Geta y Filipo. Por tanto la fecha de ocultación del tesorillo nos llevaría como mínimo hasta el 249 d.C.

Ref. MARTÍN VALLS, R., DELIBES DE CASTRO, G. 1982: «Atesoramiento de denarios imperiales en Petavonium. Hallazgos arqueológicos en la provincia de Zamora $9 »$, BSEAA, $48,54-62$.

\section{(12) [15] SAO MIGUEL (SANTAREM, PORTUGAL)}

Hall. Sin precisar. Tesorillo comprendiendo un bronce de Severo Alejandro y otros numismas que se podrían datar en la primera mitad del siglo III d.C.

Ref. X,1960-61: AP, Nova Serie, 3, 249: referencia tomada de PEREIRA, I., BOST, J.P., HIERNARD, J. 1974: Fouilles de Conimbriga III. Les Monnaies, París, 232, $\mathrm{n}^{\circ} 15$.

\section{(13) [50] TALAMANCA (IBIZA)}

Hall. Se halló en la finca Can Benet de Dalt, término municipal de Talamanca (Ibiza). Dentro de una vasija o ánfora. Existen discrepancias en cuanto al número total de numismas hallados, su número oscilaría entrelos 550 y los 600 , de los que sólamente se conservan 515 sestercios y 1 mediano bronce de Sabina.

Inv.

\begin{tabular}{|c|c|c|c|}
\hline Emperador & Cronología & Rom & $\%$ \\
\hline Tito & $79-81$ & 1 & 0,19 \\
\hline Domiciano & $81-96$ & 9 & 1,74 \\
\hline Trajano & $98-117$ & 24 & 4,65 \\
\hline Adriano & $117-138$ & 51 & 9,88 \\
\hline Sabina & & $3^{*}$ & 0,58 \\
\hline Aelio & $136-138$ & 2 & 0,39 \\
\hline Antonino Pío & $138-161$ & 57 & 11,05 \\
\hline Faustina I & & 20 & 3,88 \\
\hline Faustina II & & 4 & 0,78 \\
\hline Marco Aurelio (Caes) & & 3 & 0,58 \\
\hline Marco Aurelio & $161-193$ & 52 & 10,08 \\
\hline Antonino Pío (Divo) & & 1 & 0,19 \\
\hline Faustina II & & 27 & 5,23 \\
\hline Lucio Vero & $161-169$ & 4 & 0,78 \\
\hline Lucilla & & 11 & 2,13 \\
\hline Comodo (Caes) & & 3 & 0,58 \\
\hline Comodo & $180-193$ & 37 & 7,17 \\
\hline Marco Aurelio (Divus) & & 3 & 0,58 \\
\hline Crispina & & 2 & 0,39 \\
\hline Manlia Scantilla & 193 & 1 & 0,19 \\
\hline Septimio Severo & $193-211$ & 8 & 1,55 \\
\hline Caracalla & $211-217$ & 3 & 0,58 \\
\hline Iulia Domna & & I & 0,19 \\
\hline
\end{tabular}

(*) Dos sestercios y un mediano bronce de Sabina. 


\begin{tabular}{|l|c|c|l|}
\hline Emperador & Cronología & Rom & $\%$ \\
\hline Geta & $209-212$ & 1 & 0,19 \\
\hline Heliogabalo & $218-222$ & 1 & 0,19 \\
\hline Iulia Soaemias & & 1 & 0,19 \\
\hline Iulia Maesa & & 1 & 0,19 \\
\hline Severo Alejandro & $222-235$ & 97 & 18,79 \\
\hline Iulia Mamaea & & 22 & 4,26 \\
\hline Maximino & $235-238$ & 26 & 5,04 \\
\hline Maximo & & 2 & 0,39 \\
\hline Pupieno & 238 & 1 & 0,19 \\
\hline Gordiano III & $238-244$ & 27 & 5,23 \\
\hline Inciertas & & 10 & 1,94 \\
\hline & TOTAL & 516 & 100,00 \\
\hline
\end{tabular}

Inv.

\begin{tabular}{|l|l|c|}
\hline Emperador & Tipo & Total \\
\hline Trajano & Bronces & 2 \\
\hline Adriano & Sestercio & 1 \\
\hline Sabina & Sestercio & 1 \\
\hline Faustina II & Sestercio & 1 \\
\hline Antonio Pío & Bronce & 1 \\
\hline Antonino & Bronces & 1 \\
\hline Septimio Severo & Sestercio & 1 \\
\hline Maximino & Bronce & 1 \\
\hline Gordiano III & Bronce & 1 \\
\hline
\end{tabular}

\section{(15) [49] VALENCIA}

\section{Ult. Num.}

Emperador: Gordiano III (Sestercio).

A/ IMP GORDIANVS PIVS FEL AVG.

R/ SECVRIT PERPET, $S$ C.

Ceca: Roma, 243-244 d.C.

Peso, Módulo: 18,19 gr., --

Ref: RIC IV-3, 335.

Ref. CAMPO, M., FERNÁNDEZ, J.H. 1977: «El tesoro de Talamanca: sextercios de Tito a Gordiano III», ANum, 7, 89101.

\section{(14) [--] CUEVA DE LA ZORRA (SOSCAÑO, CARRAN- ZA-VIZCAYA)}

Hall. El 2 de julio de 1903, apareció un lote de monedas dentro de una olla o ánfora, al parecer de hierro, en la cueva de La Zorra, Soscaño, Carranza (Vizcaya). El número total de monedas halladas parece ser de 90 , aunque existen noticias que indican la cantidad de 107 , pareciendo más verosímil la primera cifra. Todas eran de bronce, de unos 25-35 mm. de módulo. Del total sólamente poseemos noticias de las siguientes monedas (Cuadro columna derecha)

Ref. AGUIRRE, A. 1955: Materiales arqueológicos de Vizcaya, Bilbao, 200-202; YBARRA, J. 1958: Catálogo de monumentos de Vizcaya, Bilbao, 82-83; CEPEDA OCAMPO, J.J. 1990: Moneda y circulación monetaria en el País Vasco durante la Antigüedad (siglos II a.C.-V d.C.), Bilbao, 28-30, 171-172; GORROCHOTEGUI, J., YARRITU, M.J. 1984: «Carta arqueológica de Vizcaya. Segunda parte, materiales de superficie», Cuadernos de Arqueología de Deusto, 9, 149.

Hall. Se desconocen las circunstancias del hallazgo. «Monedas de Gordiano (III ?) en una ampolla de vidrio que pasó a la colección Amatller de Barcelona».

Ref. MATEU Y LLOPIS, F. 1960: «Hallazgos monetarios $18 \gg, \mathrm{NH}, 9,192, \mathrm{n}^{\circ} 1071$.

\section{(16) [--] EL MASNOU (BARCELONA)}

Inv.

\begin{tabular}{|c|c|c|c|c|c|}
\hline Emperador & Cronol. & Rom & Ile & Total & $\%$ \\
\hline Domiciano &.- & 1 & & 1 & 5,88 \\
\hline Tito o Domiciano & -- & & 1 & 1 & 5,88 \\
\hline Trajano & $112-117$ & 1 & & & \\
\hline & $\ldots$ & 1 & 1 & 3 & 17,65 \\
\hline Adriano & $134-138$ & 3 & & 3 & 17,65 \\
\hline Marco Aurelio & $171-172$ & 2 & & 2 & 11,77 \\
\hline Maximino & $235-236$ & 1 & & 1 & 5,88 \\
\hline Maximo (Caes) & $236-238$ & 1 & & 1 & 5,88 \\
\hline Gordiano III & $241-242$ & 3 & & 3 & 17,65 \\
\hline Filipo I & $\ldots$ & 1 & & 1 & 5,88 \\
\hline \multirow[t]{3}{*}{ Filipo II } & $244-246$ & 1 & & 1 & 5,88 \\
\hline & TOTAL & 14 & 3 & 17 & 100 \\
\hline & $\%$ & 82,35 & 17,65 & & \\
\hline
\end{tabular}


Hall. Este conjunto monetal apareció en el transcurso de las obras de la Autopista A-19, en el término municipal de Masnou (Barcelona), se hallaron, los numismas, ocultos por tres losas a modo de cubierta o señal, no apareciendo ningún resto del recipiente que los contenía. El total de ejemplares hallados es de 17 sestercios, siendo muy bueno el estado de conservación de los acuñados en último lugar.

\section{Ult. Num.}

Emperador: Filipo II (Caesar) (Sestercio).

A/ M IVL PHILIPPVS CAES. Busto descubierto y drapeado a derecha.

R/ PRINCIPI IVVENT. SC. Filipo II a izquierda sosteniendo cetro y globo.

Ceca: Roma. 244-246 d.C.

Peso, Módulo: 18,44 gr. 29,7/26,6 mm.

Ref: RIC IV-3, 256 (a).

Ref. GURT, J.M. 1977: «Un tesorillo del s. III en Masnou (Barcelona)», GN, 44, 81-89; MATEU Y LLOPIS, F. 1971: «Hallazgos numismáticos 21, Numisma, 21, n 108-113, 197, $n^{\circ} 1.348$.

\section{(17) [--] EL MIRADOR (DENIA, ALICANTE)}

Hall: Conjunto monetal hallado a comienzos de los años cuarenta dentro de un recipiente cerámico del que se desconoce cualquier característica. El conjunto fue adquirido por el Museo Arqueológico Provincial de Alicante a un particular y aparentemente se conserva el total de las monedas halladas. Se descubrió en un lugar o partida de "El Mirador" o el "Molí del Mirador" situada entre las poblaciones alicantinas de Denia y Javea. Sin embargo, dichos topónimos no se han podido identificar con garantias. El conjunto está compuesto de un total de 669 monedas, todas ellas sestercios menos un dupondio (*). Roma es la ceca de acuñación de todas las monedas excepto una perteneciente a Adriano acuñada en la Koinon de Bithynia (**)

\section{Ult. Num.:}

Emperador: Gordiano III (Sestercio).

\section{A/ IMP CAES M ANT GORDIANVS AVG}

R/ CONCORDIA, SC. Concordia sentada a izq.

Ceca: Roma, 240 d.C.

Peso. Módulo: 22,15g; $30 \mathrm{~mm}$.

Ref: RIC IV.3, 268

Ref: ABASCAL, J.M.; OLCINA, M.; RAMÓN, J., 1995: Un tesoro de sestercios romanos procedentes del territorium de Dianium (Hispania Citerior). Alicante.
Inv.

\begin{tabular}{|c|c|c|c|}
\hline Emperador & Cronología & Rom & $\%$ \\
\hline Vespasiano & 69-79 & 4 & 0,59 \\
\hline Domiciano & $84-96$ & 12 & 1,79 \\
\hline Nerva & $96-98$ & 4 & 0,59 \\
\hline Trajano & $98-117$ & 46 & 6,87 \\
\hline Adriano & $117-138$ & $112 * *$ & 16,74 \\
\hline Sabina & & 5 & 0,75 \\
\hline L. Aelio César & & 1 & 0,15 \\
\hline Ant. Pío César & & 1 & 0,15 \\
\hline Antonino Pío & $139-161$ & 103 & 15,40 \\
\hline Faustina I & & 41 & 6,12 \\
\hline M. Aurelio César & & 19 & 2,84 \\
\hline Faustina II & & 13 & 1,94 \\
\hline Marco Aurelio & $161-180$ & 86 & 12,85 \\
\hline Ant. Pío Divus & & 1 & 0,15 \\
\hline Lucio Vero & & 13 & 1,94 \\
\hline L. Vero Divus & & 1 & 0,15 \\
\hline Cómodo César & & 15 & 2,24 \\
\hline Faustina II & & 43 & 6,42 \\
\hline Faustina II Diva & & 12 & 1,79 \\
\hline Lucilla & & 29 & 4,33 \\
\hline Comodo & $180-192$ & 63 & 9,42 \\
\hline M. Aurelio (Divus) & & 6 & 0,90 \\
\hline Crispina & & 8 & 1,19 \\
\hline Septimio Severo & $195-196$ & 2 & 0,29 \\
\hline Iulia Domna & & 1 & 0,15 \\
\hline Alejandro Severo & $223-235$ & 13 & 1,94 \\
\hline Iulia Mamaea & & 2 & 0,29 \\
\hline Maximino & $235-236$ & 3 & 0,44 \\
\hline Gordiano III & 240 & 1 & 0,15 \\
\hline \multirow[t]{2}{*}{ Indeterminadas } & & $9^{*}$ & 1,34 \\
\hline & TOTAL & 669 & 100,00 \\
\hline
\end{tabular}


(18) [16 bis] SAO JOAO BAPTISTA, MONTE REAL (LEIRIA, PORTUGAL)

Hall. En 1807, a 1 km. al oeste de Monte Real (Leiria, Portugal) en una colina que desciende sobre los pantanos de la margen izquierda del río Liz, se halló un recipiente, cubierto por un ara dedicada a la diosa Fontana, conteniendo varias monedas de cobre y latón, que se dispersaron en el Gabinete de Numismática de la Biblioteca Nacional Portuguesa. Parece un lugar de culto siendo las monedas ofrendas de los fieles. Solamente se describen 4 numismas, que presentan un estado de conservación muy deficiente.

Inv.

\begin{tabular}{|l|c|l|}
\hline Numisma & Emperador & Cronología \\
\hline $\begin{array}{l}\text { A/...INA } \\
\text { R/........ }\end{array}$ & Faustina ? & $105-141$ \\
\hline $\begin{array}{l}\text { A/....AVRELIVS } \\
\text { R/........ }\end{array}$ & Marco Aurelio ? & $161-180$ \\
\hline $\begin{array}{l}\text { A/IMPALEXANDER PIVS AVG } \\
\text { R/PROVIDENTIA AVG S.C. }\end{array}$ & Alejandro Severo* & $231-235$ \\
\hline $\begin{array}{l}\text { A/PHILIPPVS CAESAR } \\
\text { R/......... }\end{array}$ & Filipo II & $244-246$ \\
\hline
\end{tabular}

(*) Sestercio.

Ref. ANÓNIMO. 1921-1922: «Antigüidades lusitano romanas», AP, 25, 8-15.

\section{(19) [--] SANTA POLA (ALICANTE)}

Hall. En la zona del castillo de Santa Pola (Alicante), se hallaron 52 numismas, pertenecientes a los emperadores Filipo I y II, sin determinar la cantidad correspondiente a cada uno de ellos ni el tipo de numismas, sin precisar más datos.

Ref. RIPOLLES, P.P. 1980: La circulación monetaria en las tierras valencianas durante la Antigüedad, Barcelona, 160; ABASCAL, J.M. 1989: La circulación monetaria del Portus Ilicitanus. Estudis Numismàtics Valencians 4, Valencia, 43.

\section{(20) [--] VALERIA (VALERA, CUENCA)}

Hall. Se halló en las excavaciones de la ciudad romana de Valeria (Valera, Cuenca), en el corte realizado al este del ninfeo. Todas sus monedas aparecieron juntas, con restos de madera carbonizada adherida a las piezas. Se trata de 15 grandes bronces divididos entre: 7 sestercios, 2 dupondios y 5 monedas frustras. Su conservación es mala.
Inv.

\begin{tabular}{|l|c|c|c|c|c|c|}
\hline Emperador & Cronol. & Sest. & Dupond. & Inclas & Total & $\%$ \\
\hline Antonino Pío & $138-161$ & 4 & 2 & & 6 & 40,00 \\
\hline Commodo & $176-192$ & 1 & & & 1 & 6,67 \\
\hline Iulia Mamaea & $222-235$ & 1 & & & 1 & 6,67 \\
\hline Filipo I ó II & $244-249$ & 1 & & & 1 & 6,67 \\
\hline Herennia Etrus. & 249 & & 1 & & 1 & 6,67 \\
\hline Frustras & --- & & & 5 & 5 & 33,33 \\
\hline & Total & 7 & 3 & 5 & 15 & 100 \\
\hline & $\%$ & 46,67 & 20,00 & 33,33 & & \\
\hline
\end{tabular}

\section{Ult. Num.}

Emperador: Herennia Etruscilla, esposa de Trajano Decio (Dupondio).

A/ HERENNIA ETRVSCILLA, cabeza de la emperatriz a derecha.

R/ Figura femenina con el cuerno de la abundancia, a los lados S.C. Leyenda ilegible.

Ceca: Roma. 249 d.C.

Peso. Módulo.: 18,5 grs., $33 \mathrm{~mm}$.

Conservación: regular.

Ref. OSUNA, M., SUAY, F., FERNÁNDEZ, J.J., GARZÓN, J.L., VALIENTE, S., RODRÍGUEZ COLMENERO, A. 1978: Valeria Romana I, Cuenca, 76-79.

\section{(21) [--] POLLENTIA-1 (LA ALCUDIA, MALLORCA)}

Hall. Apareció durante las excavaciones de 1957-1963, en una gran casa situada en el sector de Sa Portella, en La Alcudia (Palma de Mallorca).

En la misma casa apareció otro tesorillo perteneciente al s. IV, por lo que la casa ha pasado a denominarse: «Casa de los dos tesoros».

El tesorillo está compuesto por 17 sestercios, que han sido estudiados por Mattingly que sólo describe 12; los 5 restantes sospechamos que puedan ser frustros, habida cuenta del mal estado de conservación que presentan los descritos; estado por el que Mattingly conjetura su posible ocultación con posterioridad al 270 d.C.

\section{Ult. Num.}

Emperador: Trajano Decio (Sestercio).

A/ IMP C M Q TRAIANVS DECIVS AVG.

R/ VICTORIA AVG S.C.

Ceca: Roma. 249-251 d.C. 
Peso. Módulo:---,--

Ref: RIC IV-3, $126 \mathrm{~d}$.

Ref. TARRADELL, M. 1977: «Primeres noticies de la crisi del segle III d.C. a Mallorca». Memoria de l'Institut d'Arqueologia i Prehistoria de la Universitat de Barcelona, 28; MATTINGLY, H.B. 1983: «Roman Pollentia: coinage and history», en ARRIBAS, A.(ed.). 1983: Pollentia. Estudio de los materiales I. Sa Portella, excavaciones de 1957-63, Palma de Mallorca, 269.

Inv.

\begin{tabular}{|c|c|c|c|c|c|}
\hline Emperador & Cronol. & Rom & Inc & Total & $\%$ \\
\hline Trajano & $98-117$ & 1 & & 1 & 5,88 \\
\hline Marco Aurelio & $161-180$ & 1 & & 1 & 5,88 \\
\hline Faustina Diva & $\begin{array}{l}141-147 \\
147-161\end{array}$ & $\begin{array}{l}1 \\
1\end{array}$ & & 2 & 11,76 \\
\hline Caracalla & 213 & 1 & & 1 & 5,88 \\
\hline Alejandro Severo & $\begin{array}{c}235-231 \\
229\end{array}$ & $\begin{array}{l}1 \\
1\end{array}$ & & 2 & 11,76 \\
\hline Gordiano III & $243-244$ & 2 & & 2 & 11,76 \\
\hline Filipo I & $\begin{array}{l}244 ? \\
245 ?\end{array}$ & $\begin{array}{l}1 \\
1\end{array}$ & & 2 & 11,76 \\
\hline Trajano Decio & $249-251$ & 1 & & 1 & 5,88 \\
\hline Inciertas & --- & & 5 & 5 & 29,42 \\
\hline & TOTAL & 12 & 5 & 17 & 100 \\
\hline
\end{tabular}

\section{(22) [--] MUSEO DIOCESANO DE MALLORCA}

Hall. Incluimos en nuestra lista este hallazgo publicado por Mateu y Llopis sin saber a ciencia cierta si se trata en realidad de un tesorillo o no, pues las referencias que facilita no nos lo permiten saber:

«Un hallazgo de bronces pertenecientes a: Antonino Pío, Faustina, Marco Aurelio, Gordiano III, Filipo I, Trajano Decio y otros, hallados en las inmediaciones de Palma, se hallan depositados en el Museo Diocesano de Mallorca».

Ref. MATEU Y LLOPIS, F. 1952: «Hallazgos monetarios 7》, NH 1, 229.

\section{(23) [--] LOS TORREJONES (YECLA, MURCIA)}

Hall. Este depósito monetal se halló durante las excavaciones que en 1985 se llevaron a cabo en la villa romana de Los Torrejones situada a $3 \mathrm{~km}$ al este de Yecla (Murcia) en el sec- tor II, nivel IIC, cuadrante D4 a una profundidad de $1,8 \mathrm{~m}$, en un estrato de destrucción.

El hallazgo se produjo en el espacio vacío existente entre el muro corto del perfil a y el rebanco paralelo al mismo. Las monedas se encontraban mezcladas con la tierra sin ningún recipiente que las contuviera quizá estaban en una bolsa de material orgánico que desapareción con el tiempo. El conjunto se compone de 8 sestercios y 1 as.

Inv.

\begin{tabular}{|l|c|c|}
\hline Emperador & Cronología & Total \\
\hline Calígula & 39 & $1\left(^{*}\right)$ \\
\hline Faustina I Diva & post 141 & 1 \\
\hline Faustina II Diva & post 176 & 1 \\
\hline Cómodo & $187-188$ & 1 \\
\hline Septimio Severo & $201-202$ & 1 \\
\hline Gordiano III & $241-242$ & 1 \\
\hline Filipo II & $246-249$ & 1 \\
\hline Trajano Decio & $249-251$ & 1 \\
\hline
\end{tabular}

(*) As de la ceca de Cartago Nova.

\section{Ult. Num.}

Emperador: Trajano Decio (Sestercio).

A/ [I]MP C M Q TRAIANVS DECIV[S], Busto laureado y drapeado a der.

R/ [PAN]NON[IAE], SC, Las dos Panonias de pie, vestidas, sosteniendo estandartes.

Ceca: Roma, 249-251 d.C.

Peso, Módulo: 17,86g, 29,15 mm.

Ref: RIC IV-3, 124c.

Ref.: AMANTE SÁNCHEZ, M; LECHUGA GALINDO, M., 1986: "Un conjunto de bronces del s. III d.C. procedente del yacimiento romano de los Torrejones (Yecla, Murcia)". I Jornadas de Historia de Yecla, 51-61. BOST, J.-P., CAMPO, M., COLLS, D., GUERRERO, V. 1992: L'Epave Cabrera III (Majorque), París, 102-103 nota 9 y 104.

\section{(24) [--] BENICATÓ (NULES, CASTELLÓN)}

Hall.: En las excavaciones de la villa romana de Benicató (Nules, Castellón). El conjunto monetal se encontró en un estrato de destrucción, las monedas se hallaban dispersas sobre el suelo de una habitación ya amortizada, junto con utensilios de laboreo agrícola. 
Inv.: El hallazgo consta de 16 monedas: 11 sestercios y 5 ases. Su cronología abarca desde Antonino Pío hasta Valeriano pero las monedas no han sido descritas aunque algunas de ellas han sido publicadas (1) aunque sin individualizarlas del resto de monedas aparecidas de forma dispersa en el yacimiento.

Ult. Num.: Sería un sestercio de Valeriano (253-260 d.C.)

Ref.: (1) RIPOLLÉS, P.P.; 1977: “Estudio numismático en la villa de Benicató (Nules, Castellón) CPAC, 4, 145-154. LLORENS FORCADA, Ma DEL MAR; RIPOLLÉS ALEGRE, P.P.; 1995: "El depósito monetal de la domus A de Romeu: Nuevas aportaciones a la circulación de moneda de bronce en Saguntum durante el siglo III d.C.". Saguntum, 28, p. 221, cuadro $\mathrm{n}^{\circ} 1$ y p. 225 nota 8.

\section{(25) [--] LUGO-2}

Hall.: Apareció el 23 de diciembre de 1923, cuando se llevaba a cabo la pavimentación de la calle San fernandi, en el interior de las murallas de Lugo. Se hallaba en el interior de un puchero de cerámica burda, negruzca, y tenía la apariencia de una masa compacta ferruginosa. Consta de 47 radiados.

Inv. (al final del artículo).

Ult. Num.

Emperador: Valeriano I (radiado)

A/ IMP VALERIANVS PF AVG, Busto con coraza, cabeza radiada a derecha.

R/ VICT PA[--], Victoria alada andando a izq. Lleva corona a izq. y palma a der. A sus pies y a izq. Un cautivo.

Ceca: Roma, 259 d.C.

Peso, Módulo: 2,11g; 20-23 mm.

Ref.: RIC V-1, 262.

Ref. CAVADA, M. 1984: «Dos tesorillos monetarios aparecidos en Galicia». II Congreso Galaico Minhoto, Santiago, 191. CAVADA, M. 1994: La crisis económico-monetaria del s. III: ¿un mito historiográfico?. Avance del resultado de los análisis metalográficos sobre dos tesorillos de la Provincia de Lugo. Santiago 78-89. CAVADA, M. 1995: "Resultado de los análisis metalográficos y estadísticos de dos tesorillos de la provincia de Lugo" en GARCÍA Y BELLIDO, M.P.; SOBRAL CENTENO, R.M. /eds.): La moneda hispánica. Ciudad y territorio. Actas I Encuentro Peninsular de Numismática Antigua. Madrid, 25-27.

\section{(26) [--] PORTUGAL 1967}

Hall. Recogemos su existencia transcribiendo una cita de J.-P. Bost et alii (1):

«4 monnaies vendues à Monte-Carlo: vente hôtel Loews, 2324 avril $1976 \%$.

Los autores lo dan como compuesto por bronces, sin especificar su número total de monedas, aunque señalando la pre- sencia de monedas de Maximino I, Filipo I, Valeriano y Galieno. Desconocemos cualquier otro dato de su procedencia, circunstancias de hallazgo, etc.

Ref. (1) BOST, J.-P., CAMPO, M., COLLS, D., GUERRERO, V. 1992: L'Epave Cabrera III (Majorque), París, 102-103 nota 9 y 104.

\section{(27) [--] PECIO "CABRERA III" (PUERTO DE CABRE-} RA, BALEARES)

Hall. Fue hallado en el interior de una ánfora Dressel 23, durante la campaña de excavaciones submarinas llevada a cabo en 1986, en el pecio denominado «Cabrera III», en el puerto de Cabrera (isla de Cabrera, Baleares). El total de monedas que lo componen es de 967 , siendo todas ellas sestercios menos dos radiados y ocupando un espacio cronológico que va desde el $81-96$ d.C. hasta mediados del siglo III d.C..

Inv.

Radiados:

\begin{tabular}{|l|c|c|c|}
\hline Emperador & Cronología & Ceca & Total \\
\hline Filipo I & $244-249$ & Roma & 1 \\
\hline Valeriano & $254-256$ & Roma & 1 \\
\hline
\end{tabular}

Sestercios:

\begin{tabular}{|l|c|c|c|}
\hline Emperador & Cronología & Rom & $\%$ \\
\hline Domiciano & $81-96$ & 4 & 0,41 \\
\hline Trajano & $98-117$ & 4 & 0,41 \\
\hline Adriano & $117-138$ & 1 & 0,11 \\
\hline Antonino Pío & $138-161$ & 9 & 0,93 \\
\hline Faustina I & & 3 & 1,35 \\
\hline Faustina II & & 5 & 0,52 \\
\hline Marco Aurelio (Caes) & & 3 & 0,31 \\
\hline Marco Aurelio & $161-180$ & 4 & 0,41 \\
\hline Faustina II & & 20 & 2,07 \\
\hline Lucio Vero & $161-169$ & 1 & 0,11 \\
\hline Lucilla & & 18 & 1,86 \\
\hline Antonino (Divus) & & 1 & 0,11 \\
\hline
\end{tabular}

Continúa 


\begin{tabular}{|c|c|c|c|}
\hline Emperador & Cronología & Rom & $\%$ \\
\hline Vero (Divus) & & 1 & 0,11 \\
\hline Comodo (Caes) & & 6 & 0,62 \\
\hline Comodo & $180-192$ & 39 & 4,04 \\
\hline Antonino Pío (Divus) & & 6 & 0,62 \\
\hline Crispina & & 5 & 0,52 \\
\hline M.Aurelio, Vero o M. Anto. & & 6 & 0,62 \\
\hline Divus Anto., Vero o M. Anto & & 1 & 0,11 \\
\hline Antonino, M. Aur., Vero o Comodo & & 2 & 0,21 \\
\hline Faustina II, Lucilla o Crispina & & 6 & 0,62 \\
\hline Manlia Scantilla & 193 & 1 & 0,11 \\
\hline Septimio Severo & $193-211$ & 11 & 1,14 \\
\hline Caracalla (Caes) & & 1 & 0,11 \\
\hline Iulia Domna & & 6 & 0,62 \\
\hline Caracalla & $211-217$ & 2 & 0,21 \\
\hline Iulia Maesa & $218-222$ & 2 & 0,21 \\
\hline Severo Alejandro & $222-235$ & 119 & 12,33 \\
\hline Orbiana & & 1 & 0,11 \\
\hline Iulia Mamaea & & 31 & 3,21 \\
\hline Maximino I & $235-238$ & 52 & 5,39 \\
\hline Paulina (Diva) & & 1 & 0,11 \\
\hline Maximo & & 3 & 0,31 \\
\hline Gordiano I ó II & 238 & 1 & 0,11 \\
\hline Balbino & 238 & 3 & 0,31 \\
\hline Pupieno & 238 & 3 & 0,31 \\
\hline Maximo Caes o Gord. III Caes. & & 1 & 0,11 \\
\hline Gordiano III & $238-244$ & 136 & 14,08 \\
\hline Filipo I & $244-249$ & 77 & 7,98 \\
\hline Otacilia Severa & & 14 & 1,45 \\
\hline Filipo II (Caes) & & 11 & 1,14 \\
\hline Filipo II & $247-249$ & 9 & 0,93 \\
\hline Trajano Decio & $249-251$ & 29 & 3,00 \\
\hline Herennia Etruscilla & & 7 & 0,72 \\
\hline
\end{tabular}

\begin{tabular}{|l|c|c|c|}
\hline Emperador & Cronología & Rom & $\%$ \\
\hline H. Etrusco & & 4 & 0,41 \\
\hline Treboniano Galo & $251-253$ & 19 & 1,97 \\
\hline Volusiano & $251-253$ & 17 & 1,76 \\
\hline T. Galo, Volusiano o Emiliano & & 2 & 0,21 \\
\hline Valeriano & $253-260$ & 9 & 0,93 \\
\hline Galieno & $253-260$ & 4 & 0,41 \\
\hline Salonina & & 3 & 0,31 \\
\hline Ilegible & & 164 & 16,99 \\
\hline & TOTAL & 965 & 100,00 \\
\hline
\end{tabular}

\section{Ult. Num.}

Emperador: Valeriano (sestercio).

A/ IMP C P LIC VALERIANVS P F AVG.

R/ VICT[ORIA] GERM, S.C.

Ceca: Roma. 256-257 d.C.

Peso. Módulo: 21,3 g., 29-25 mm.

Ref: RIC V-1, 181.

Ref. GUERRERO, V.M., COLLS, D., MAYET, F. 1987: «Arqueología submarina: el navío romano «Cabrera III»». Rev. Arq., 74, 14-24; BOST, J.-P., CAMPO, M., COLLS, D., GUERRERO, V., MAYET, F. 1992: L'Epave Cabrera III (Majorque), París.

\section{(28) [--] VILAUBA (CAMOS, GERONA)}

Hall. Se halló durante las excavaciones llevadas a cabo en la villa romana de Vilauba (Gerona) en la habitación denominada XXX, situada al extremo noroeste del edificio, siendo la estancia de mayores dimensiones siendo su función la de cocina-almacén. Su construcción presenta una banqueta adosada, encima de la cual se hallaban las monedas depositadas dentro de una olla de cerámica común oxidada; por efecto de la caida del techo de la construcción, las monedas, se hallaron diseminadas en un área de diámetro inferior a un metro.

Inv. El total de monedas halladas es de 47 ejemplares, siendo su distribución la siguiente: 1 As, 44 Sestercios y 2 radiados.

Radiados:

\begin{tabular}{|l|c|c|c|}
\hline Emperador & Cronología & Ceca & Total \\
\hline Valeriano & $258-259$ & Lugdunum & 1 \\
\hline Mariniana & $255-257$ & Roma & 1 \\
\hline
\end{tabular}


Sestercios:

\begin{tabular}{|l|c|c|c|c|c|}
\hline Emperador & Cronol. & Rom & Alexandria & Total & $\%$ \\
\hline Antonino Pío & $151-152$ & 2 & & 2 & 4,44 \\
\hline Faustina I & $141-145$ & 2 & & & 4,44 \\
\hline Marco Aurelio & $161-162$ & 2 & & 2 & 4,44 \\
\hline Faustina II & post 145 & $4 *$ & & 4 & 8,88 \\
\hline Sept. Severo & $193-211$ & 3 & & 3 & 6,66 \\
\hline Iulia Domna & $193-194$ & & 1 & 1 & 2,22 \\
\hline Caracalla & 211 & 1 & & 1 & 2,22 \\
\hline Alej. Severo & $222-235$ & 4 & & 4 & 8,88 \\
\hline Maximino I & $235-236$ & 1 & & 1 & 2,22 \\
\hline Gordiano III & $240-243$ & 5 & & 5 & 11,00 \\
\hline Filipo I & $244-249$ & 3 & & 3 & 6,66 \\
\hline Traj. Decio & $249-251$ & 1 & & 1 & 2,22 \\
\hline Galieno & 254 & 1 & & 1 & 2,22 \\
\hline Inatribuibles & & 15 & & 15 & 33,33 \\
\hline & Total & 44 & 1 & 45 & \\
\hline & & 97,78 & 2,22 & & \\
\hline I. 3 Sestercios & & & & & \\
\hline
\end{tabular}

$(*): 3$ Sestercios y 1 As.

\section{Ult. Num.}

Emperador: Valeriano (Radiado).

A/ VALERIANVS P F AVG.

R/ OR[IENS] AVGG.

Ceca: Lugdunum, circa 258-259 d.C.

Peso. Módulo: 3,20 g, $22 \mathrm{~mm}$.

Ref: RIC V-1, 12.

Ref. ROURE,A., TREMOLEDA, J. CASTANYER, P., 19881989: «Troballa d'un conjunt monetari a Vilauba (Camós, Pla de l'Estany)». Empúries 48-50, vol. II, 268-281; TREMOLEDA, J., CASTAÑER, P, ROURE, A., 1989: «Vilauba: estudi preliminar del larari de la vil.la». Cypsela 7, 57; CASTAÑER,P., TREMOLEDA, J., ROURE, A.; 1990: «Un conjunt cerámic de finals del segle III d. C. a Vilauba (Camòs, Plá de l'Estany)», Cypsela 8, 189. NL 132, 1994, 0273.

\section{(29) [--] ZONA DE CHANTADA (ORENSE)}

Hall. El hallazgo se produjo en la zona de Chantada (Orense), en un momento anterior a 1986, cuando unos vecinos trataban de desbrozar de maleza una finca. Se desconoce el número inicial de monedas hallado aunque se sabe que eran «un gran número», de las cuales solamente 49 radiados han podido ser estudiados.

Inv. (al final del artículo)

Ult. Num.

Emperador: Galieno (radiado).

A/ GALLIENVS AVG.Busto con coraza, cabeza radiada a der. R/ VICTORIA AVG III, T-//-.

Ceca: Roma, 267-268 d.C.

Peso, Módulo: 3,3 g., $22 \mathrm{~mm}$.

Ref: RIC V-1, 84; Cunetio 950-958.

Ref. CAVADA NIETO, M. 1992: «Monedas de un tesorillo del s. III hallado en tierras lucenses», Finis Terrae. Estudios en lembranza do prof. Dr. Alberto Balil, Santiago.CAVADA, M. 1994: La crisis económico-monetaria del s. III: ¿ un mito historiográfico?. Avance del resultado de los análisis metalográficos sobre dos tesorillos de la Provincia de Lugo. Santiago 78-89. CAVADA, M. 1995: "Resultado de los análisis metalográficos y estadísticos de dos tesorillos de la provincia de Lugo" en GARCÍA Y BELLIDO, M.P.; SOBRAL CENTENO, R.M. leds.): La moneda hispánica. Ciudad y territorio. Actas I Encuentro Peninsular de Numismática Antigua. Madrid,25-27.

\section{(30) [--] POLLENTIA-3 (L'AlCUdiA, PALMA DE} MALLORCA)

Hall. En Pollentia, aparecido en el nivel de destrucción de una de las habitaciones de la casa de Polymnia, entre grandes capas de cenizas y cerámicas en buen estado. La única noticia que poseemos es:

«La serie empieza con una pieza de Domiciano, sigue con unas pocas de emperadores del siglo II y una mayor representación de la primera mitad del siglo III: la pieza más moderna corresponde a Galieno (253-268)» (1).

Ref. (1) ARRIBAS, A., TARRADELL, M, 1987: «El foro de Pollentia. Noticias de las primeras excavaciones», Col. Los Foros romanos de las Provincias Occidentales, Valencia, 135.

\section{(31) [33] BARES-1 (LA CORUÑA)}

Hall. Entre junio y agosto de 1942, frente al morro de la escollera del puerto de Bares (La Coruña), a unos $45 \mathrm{~cm}$. de profundidad, entre la capa de arena que forma el suelo se halló un puchero de barro tapado con una losa, dentro del cual se hallaron de 50 a 60 monedas de cobre y bronce.

Analizadas 13 de ellas, se apreció que 3 ó 4, mejor conservadas, correspondían a pequeños bronces imperiales romanos de Valeriano y Salonina.

Ref. MATEU Y LLOPIS, F.1953: «Hallazgos monetarios 8», NH 2, 279, n 646; BALIL, A. 1957: «Las invasiones germánicas en Hispania durante la segunda mitad del siglo III d.C.», CTEEHAR 9, 128, n 73; VÁZQUEZ SEIJAS,M., 1953: «Hallazgo de denarios romanos en Bares», BCMHA Lugo 5, 
40, 308; MACIÑEIRA, F., 1947: Bares. Puerto hispánico de la primitiva navegación occidental, Madrid.

\section{(32) [34] BARES-2 (LA CORUÑA)}

Hall. En diciembre de 1948 entró en el Museo Provincial de Lugo un lote de monedas romanas (unas 700 piezas) procedentes de un tesorillo hallado el año anterior en Bares (Ortigueira), cerca de la escollera del puerto.

El número de ejemplares hallados superaba el millar. De los cerca de 700 ingresados en el Museo solamente se pudieron individualizar unos 100 , debido a su fuerte estado de oxidación, y de éstos, a su vez, sólo se pudieron clasificar 42, es decir, aproximadamente un 5\% del total hallado.

Inv. (al final del artículo)

\section{Ult. Num.}

Debido a los problemas de clasificación de los ejemplares pertenecientes a Galieno y Salonina, no podemos precisar cuál es el último numisma descrito, aunque creemos que se fecharía con posterioridad al 260 d.C. ya que existen diversos anversos con la leyenda GALLIENVS AVG, que se comenzó a usar a partir del 259 d.C.

Ref. VÁZQUEZ SEIJAS, M. 1953: «Hallazgo de denarios romanos en Bares», BCMHALugo 5, 40, 304-308; CAVADA NIETO, M., 1973: «Circulación monetaria en la provincia de La Coruña», CNA 12, 755.

\section{(33) [--] COLECCION CRUIXENT (BARCELONA)}

Hall. Bajo el título «Cincuenta retratos del emperador Galieno y su esposa Salonina en monedas acuñadas en Tarragona» fueron expuestos en la I Exposición Nacional de Numismática 50 numismas pertenecientes al emperador Galieno y a su esposa Salonina.Las piezas fueron adquiridas en el comercio y parecen proceder de Tarragona o sus alrededores (podrían pertenecer al tesorillo de Altafulla). Según A. Balil de su homogeneidad parece deducirse su pertenencia a un tesorillo.

Ref. BALIL, A. 1957: «Las invasiones germánicas en Hispania durante la segunda mitad del siglo III d.C.», CTEEHAR 9, 141 y nota 110.

\section{(34) [ 3] VALVERDE DEL CAMINO (HUELVA)}

Hall. Los únicos datos publicados de este tesorillo nos indican que se halló en Valverde del Camino (Huelva) y que estaba formado por unos 800 radiados que cronológicamente abarcaban a los emperadores comprendidos entre Gordiano III y Galieno, ambos inclusive.

Ref. BALIL, A., 1957: «Las invasiones germánicas en Hispania durante la segunda mitad del siglo III d.C.», CTEEHAR 9, 142 y nota 111 .

\section{(35) [51] SERRA ? (PORTUGAL)}

Hall. Este tesorillo no tiene una localización geográfica clara, está compuesto por bronces de varios emperadores, el más moderno de los cuales era Galieno.

Ref. BALIL, A., 1957: «Las invasiones germánicas en Hispania durante la segunda mitad del siglo III d.C.», CTEEHAR 9, 142; DE CASTRO HIPÓLITO, M. 1960-1961: «Dos tesouros de moedas romanas em Portugal», Conimbriga, 12-3, $92 \mathrm{n}^{\circ} 139$ y $111,7$.

\section{(36) [30] PONTEVEDRA}

Hall. Sólo poseemos la referencia, que sobre su hallazgo, da Mateu y Llopis:

«413. Hallazgo de denarios del emperador Galieno, en la comarca de Pontevedra. Referencia de don José Filgueira Valverde, en 1948».

Ref. MATEU Y LLOPIS, F., 1951: «Hallazgos monetarios 6», Ampurias 13, 234, $\mathrm{n}^{\circ} 413$.

\section{(37) [--] ECIJA (SEVILLA)}

Hall. Sólamente poseemos la escueta noticia siguiente: «Hallazgo en esta zona (Ecija) de un tesorillo de un centenar de monedas de época de Galieno».

Ref. ORDÓÑEZ AGULLA, S., 1988: Colonia Augusta Firma Astigi, Ecija, 61, 78 y nota 161 .

\section{(38) [--] CERRO DE JUDAS, LLANOS DEL CIEGO (CAZORLA, JAÉN)}

Hall. Según noticia transmitida por la Dra. C. Fernández Chicarro a M. Tarradell; se trata de un escondrijo de monedas de Galieno (más de un millar) halladas en una vasija, en 1920. No se consignan más datos.

Ref. TARRADELL, M.1955: «Sobre las invasiones germánicas del siglo III d.C. en la Península Ibérica», EClás. 3, I05 y nota 23.

\section{(39) [--] BAÑOS DE RÍO CALDO (ORENSE)}

Hall. El tesorillo fue hallado durante la campaña de excavaciones llevada a cabo en 1990, en una villa romana descubierta en Baños de Río Caldo (Orense) e identificada con la «mansio Aquis Originis» de la «via item alio itinere Bracara Asturica».

El tesorillo consta de 9 radiados, hallados en el interior de un vaso imitación de los de paredes finas. Los emperadores representados son: Gordiano, T. Galo, Valeriano, Galieno y Salonina. No habiéndose descrito ninguna de las monedas.

Ref. XUSTO RODRÍGUEZ, M., 1991: «Galicia. Romanización en el valle del río Caldo», Rev. Arq. 126, 31

\section{(40) [25] PANOIAS (DIST. GUARDA O BRAGA, POR-} TUGAL)

Hall. Sólo tenemos la referencia del hallazgo de un tesorillo de Salonina, sin más precisiones. 
Ref. MATEU Y LLOPIS, F., 1947-1948: «Hallazgos monetarios 5», Ampurias 9-10, 68.

\section{(41) [--] MAS D'ARAGÓ (CERVERA DEL MAESTRAT, CASTELLÓN)}

Hall. Apareció en el Sector I de las excavaciones llevadas a cabo en el Mas d'Aragó (Cervera del Maestrat, Castellón), dentro de un recinto termal. En total se hallaron 53 numismas, agrupados en una bolsa de tela, de la que se recuperó un pequeño fragmento. Los numismas se dividen en 38 radiados y 15 sestercios, de los cuales, no se describe ninguno.

Inv.

\begin{tabular}{|c|c|c|c|}
\hline Emperador & Cronología & Total & $\%$ \\
\hline Adriano & $117-138$ & 2 & 3,77 \\
\hline Faustina I & $138-141$ & 1 & 1,88 \\
\hline Faustina Diva & post. 141 & 1 & 1,88 \\
\hline Marco Aurelio & $161-180$ & 2 & 3,77 \\
\hline Faustina II & & 1 & 1,88 \\
\hline Alejandro Severo & $222-235$ & 1 & 1,88 \\
\hline Maximino Pio & $235-238$ & 1 & 1,88 \\
\hline Gordiano III & $238-244$ & 1 & 1,88 \\
\hline Filipo I & $244-249$ & $1 *$ & 1,88 \\
\hline T. Decio & $249-251$ & 1 & 1,88 \\
\hline Valeriano & $253-260$ & 1 & 1,88 \\
\hline & $253-260$ & $3^{*}$ & 5,65 \\
\hline Galieno & $253-268$ & $25^{*}$ & 47,17 \\
\hline Salonina & & $6^{*}$ & 11,30 \\
\hline Quieto & $261-262$ & $3 *$ & 5,65 \\
\hline \multirow[t]{2}{*}{ Frustros } & & 3 & 5,65 \\
\hline & TOTAL & 53 & 100,00 \\
\hline
\end{tabular}

$*$ = radiados.

$\%$ radiados $=72 \%$

$\%$ sestercios $=28 \%$

Ref. BORRÀS I QUEROL, C., 1989: «Mas d'Aragó. Cervera del Maestrat. Baix Maestrat», Memòries Arqueològiques a la Comunitat Valenciana 1984-85, Valencia, 148; BORRÀS I QUEROL, C., 1987-1988: «Avance de las excavaciones en la villa romana del Mas d'Aragó (Cervera del Maestrat)», CPAC 13, 392-93.

\section{(42) [48] CASTELLÓN DE LA PLANA}

Hall. Se desconocen las circunstancias del hallazgo, que se produciría con anterioridad a 1951. Mateu y Llopis, que lo describe, afirma que está compuesto por 32 denarios, pero son radiados y solamente pasa a describir 27 , los 5 restantes creemos que deben ser ilegibles.

Debido a su defectuosa descripción (faltan las titulaturas del anverso, faltan las indicaciones sobre marcas de oficina y ceca) optamos por reproducir el listado que da el citado Mateu y Llopis:

Inv.

\begin{tabular}{|c|c|c|c|c|}
\hline Emperador & Cronol. & Reverso & Ejem & Total \\
\hline Gordiano III & 242 & PM TR P V COS II PP & 1 & 1 \\
\hline Filipo I & $244-249$ & $\begin{array}{l}\text { SALVS AVGVSTA } \\
\text { LAETITIA FVNDAT } \\
\text { LIBERALITAS AVG }\end{array}$ & $\begin{array}{l}1 \\
1 \\
1\end{array}$ & 3 \\
\hline Ota Severa & & CONCORDIA AVGG & 1 & 1 \\
\hline Filipo II & $246-249$ & SAECVLARES AVG COS III & 1 & 1 \\
\hline T. Decio & $249-251$ & GENIVS EXERCIT ILLYRIC & 1 & 1 \\
\hline Etruscilla & & FECVNDITAS AVG & 2 & 2 \\
\hline T. Galo & $251-253$ & $\begin{array}{l}\text { LIBERTAS AVG } \\
\text { FELICITAS PVBL }\end{array}$ & $\begin{array}{l}1 \\
1\end{array}$ & 2 \\
\hline Volusiano & $251-253$ & PIETAS AVG & 1 & 1 \\
\hline Emiliano & 253 & $\begin{array}{l}\text { PACI AVG } \\
\ldots \text { VICTRIX }\end{array}$ & $\begin{array}{l}1 \\
1\end{array}$ & 2 \\
\hline Valeriano & $253-258$ & $\begin{array}{l}\text { FELICITAS AVGG } \\
\text { APOLINI PROPVGNAT } \\
\text { PIETAS AVGG } \\
\text { RESTITVTORI ..ENTIS } \\
\text { VICTORIA AVG } \\
\text { VIRTVS AVG } \\
\text { ORIENS AVG }\end{array}$ & $\begin{array}{l}2 \\
1 \\
2 \\
1 \\
1 \\
1 \\
1\end{array}$ & 9 \\
\hline Galieno & $253-261$ & $\begin{array}{l}\text { VICTORIA AVG } \\
\text { VICT GALLI }\end{array}$ & $\begin{array}{l}1 \\
1\end{array}$ & 2 \\
\hline Salonina & & FELICITAS PVBLICA & 1 & 1 \\
\hline Salonino & & SPES PVBLICA & 1 & 1 \\
\hline \multirow[t]{2}{*}{ Ilegibles? } & & & 5 & 5 \\
\hline & & & TOTAL & 32 \\
\hline
\end{tabular}

Ref. MATEU Y LLOPIS, F., 1952: «Hallazgos monetarios 7》, NH 1, 244-245, no 535. 


\section{(43) [32] ALGARA (LA CORUÑA)}

Hall. En 1916, en el sitio denominado Algara, lugar de Bermaño, parroquia de Perbes del Ayuntamiento de Castro (La Coruña), con ocasión de unas operaciones de labranza se halló un recipiente de barro que contenía más de mil quinientas monedas romanas.

Del total hallado solamente se describen: 47 numismas por A. Martínez Salazar y 30 por M. Aulló Costilla. En total 77 ejemplares que representan, aproximadamente, un 5\% del total del tesorillo.

Inv. (al final del artículo)

\section{Ult. Num.}

Emperador: Valeriano (radiado).

A/ VALERIANVS P F AVG.

R/ ORIENS AVGG.

Ceca: Lugdunum. 258-259 d.C..

Peso. Módulo: ---, ---,

Ref: RIC V-1, 12.

Ref. MARTÍNEZ SALAZAR, A, 1916: «Del tesoro de monedas de Algara», BRAG, año XI, n $106,217-230$ y BRAG, año XI, n 107, 1916, 249-253; AULLÓ COSTILLA, M., 1955: «Contribución al conocimiento del tesorillo de monedas de Algara (La Coruña) y noticia sobre una hallazgo en San Tirso de Abres (Oviedo)», Numisma 17, 9-23.

\section{(44) [--] HONCALADA (VALLADOLID)}

Hall. En el Otoño de 1974, al efectuarse unas labores agrícolas en la finca de «Las Cañadas», término municipal de Honcalada-Salvador de Zapardiel,(Valladolid) apareció un conjunto de monedas en bastante buen estado de conservación, de las que se recuperaron 22 radiados, siendo muy probable que ésta no sea la cantidad total del depósito, aunque parece que no fueron muchas más las que se descubrieron.

Inv. (al final del artículo)

Ult. Num. Pueden ser dos monedas:

Emperador: Galieno (radiado).

A/ GALLIENVS AVG, Cabeza radiada a der.

R/ VICTORIAAET, Victoria de pie a Izq. con corona y palma. Ceca: Siscia. 264-266 d.C.

Peso. Módulo: 3,81 g.; 22/24 mm.

Ref: RIC V-1, 183, nº 586.

Emperador: Salonina (radiado).

A/ CORN SALONINA AVG. Busto diademado y drapeado a der. sobre creciente lunar.

R/ VESTA. Vesta de pie a izq. con pátera y cetro transversal. Ceca: Mediolanum. 264-266 d.C.

Peso. Módulo: 2,58 g. 22/24 mm.

Ref: RIC V-1, 112, $\mathrm{n}^{\circ} 39$.

Ref. BALIL, A., MARTÍN VALLS, R., 1979: «Tesorillos de Antoninianos de Honcalada (Valladolid)». Monografías del Museo Arqueológico de Valladolid, Vol. 4, Valladolid.

\section{(45) [--] VAREIA (LOGROÑO)}

Hall. Fue hallado oculto, debajo de tres tegulae, en el suelo de una vivienda romana durante las excavaciones llevadas a cabo en el llamado «Sector Siberia» de la ciudad romana de Vareia, en 1989.

El conjunto se compone de 182 radiados.

Inv. (al final del artículo)

\section{Ult. Num.}

Emperador: Salonina (radiado).

A/ SALONINA AVG.

R/ VENVS.

Ceca: Roma. $5^{\text {a }}$ emisión, $4^{\text {a }}$ Oficina, 266 d.C.

Peso. Módulo: 2,40 g., $22 \mathrm{~mm}$.

Ref: RIC V-1, 30, Cunetio 990.

Ref. ESPINOSA, U., 1990: Vareia. Enclave romano en el Valle del Ebro, Logroño, 17; ABASCAL, J.M., TIRADO, J.A., MARTÍNEZ, I., 1994: «Circulación monetaria posterior al 193 d.C. en Vareia». Historia de la ciudad de Logroño, Logroño, Ed. U. ESPINOSA, Tomo I, 333-338. MARTÍNEZ, I. TIRADO, J.A., ESPINOSA, U., ABASCAL, J.M.,: «El tesorillo de Vareia del Sector Siberia», en prensa.

\section{(46) [--] D'EULA (CREVILLENTE, ALICANTE)}

Hall. Apareció en el paraje denominado La D'Eula, término municipal de Crevillente (Alicante) cuando se efectuaban trabajos agrícolas.

Los numismas aparecieron en compañia de los restos fracturados de un vaso de cerámica común de pasta ocre-anaranjada, que presumiblemente los contendría.

El conjunto está compuesto de 7 radiados y 55 sestercios, de los cuales 13 son frustros.

Sestercios:

\begin{tabular}{|l|c|c|c|c|c|}
\hline Emperador & Cronol. & Rom & Ile & Total & $\%$ \\
\hline Neron & $54-68$ & 1 & & 1 & 1,82 \\
\hline Domiciano? & $81-96$ & 1 & & 1 & 1,82 \\
\hline Antonino Pio & $138-161$ & 6 & & 6 & 10,91 \\
\hline Marco Aurelio & 161 & 3 & & 3 & 5,45 \\
\hline Faustina II & 161 & 2 & & 2 & 3,64 \\
\hline Lucio Vero & 161 & 1 & & 1 & 1,82 \\
\hline Alej.Severo & 225 & 1 & & & \\
\hline Iulia Marnaea & $231-235$ & 3 & & 3 & 5,45 \\
\hline Maximino I & $235-236$ & 1 & & 1 & 1,82 \\
\hline
\end{tabular}

Continúa 


\begin{tabular}{|c|c|c|c|c|c|}
\hline Emperador & Cronol. & Rom & Ile & Total & $\%$ \\
\hline Maximo & $236-238$ & 1 & & 1 & 1,82 \\
\hline Gordiano III & $\begin{array}{c}240 \\
241 \\
240-244 \\
241-243\end{array}$ & $\begin{array}{l}1 \\
1 \\
1 \\
1\end{array}$ & & 4 & 7,27 \\
\hline Filipo I & $\begin{array}{c}244-249 \\
247-249 \\
248\end{array}$ & $\begin{array}{l}1 \\
3 \\
1\end{array}$ & & 5 & 9,09 \\
\hline Ota. Severa & $244-249$ & 1 & & 1 & 1,82 \\
\hline Filipo II & $247-249$ & I & & 1 & 1,82 \\
\hline T. Galo & 253 & 4 & & 4 & 7,27 \\
\hline Emiliano & 253 & 1 & & 1 & 1,82 \\
\hline Valeriano & $256-257$ & 1 & & 1 & 1,82 \\
\hline Galieno & 253 & 1 & & 1 & 1,82 \\
\hline Ilegibles & & & 13 & 13 & 23,64 \\
\hline & TOTAL & 42 & 13 & 55 & 100 \\
\hline & $\%$ & 76,37 & 23,63 & & \\
\hline
\end{tabular}

Radiados:

\begin{tabular}{|l|c|c|c|c|c|c|}
\hline Emperador & Cronol. & Rom & Ant. & Asia & Total & $\%$ \\
\hline Gordiano III & $\begin{array}{c}240-244 \\
242\end{array}$ & 1 & & & & \\
\hline Filipo I & $244-247$ & 2 & & & 2 & 28,58 \\
\hline T. Galo & $251-253$ & & 1 & & 1 & 14,28 \\
\hline Valeriano & $253-254$ & 1 & & & 1 & 14,28 \\
\hline Salonina & $258-259$ & & & 1 & 1 & 14,28 \\
\hline & Total & 5 & 1 & 1 & 7 & 100 \\
\hline & $\%$ & 71,40 & 14,28 & 14,28 & & \\
\hline
\end{tabular}

\section{UIt. Num.}

Emperador: Salonina (radiado).

A/ SALONINA AVG, Busto diademado a der.

R/ IVNO REGINA, Juno de pie, sosteniendo una pátera y un cetro.

Ceca: Asia. 258-259 d.C.

Peso. Módulo: 3,3 g., 23,9 mm.

Ref: RIC V-1, 64.
Ref. GONZÁLEZ PRATS, A.; ABASCAL PALAZÓN, J.M., 1987: «La ocultación monetal de la D'Eula, Crevillente (Alicante) y su significación para el estudio de las invasiones del siglo III», Lucentum, 6, 183-196.

\section{(47) [44] ALTAFULLA (TARRAGONA)}

Hall. En 1905 se halló este tesorillo en las ruinas de la villa romana de Els Munts (Altafulla, Tarragona).

Tradicionalmente se venían describiendo 227 radiados(1) que eran considerados como $1 / 3$ del total de monedas halladas; pero posteriormente Hiernard(2) eleva a 230 el número total de monedas recuperadas, que describe considerando que son $1 / 4$ del total hallado. Es decir, para este investigador, el tesorillo tendría en origen unas 1000 monedas.

Por su parte, Sagredo San Eustaquio (3) situa en 231 monedas el número de las conservadas al añadir a los 230 de Hiernard la última moneda que publica Balil(4) como numisma terminal del tesorillo y que no consta en la relación dada por Hiernard.

Inv. Debido a la ya comentada disparidad de cifras en cuanto a las monedas conservadas, aparecen unas leves diferencias en cuanto a la composicióbn general del tesorillo según consideremos la de Hiernard o la de Mateu y Llopis.

\begin{tabular}{|l|l|c|}
\hline Emperador & Lista & $N^{\circ}$ Ejemplares \\
\hline Filipo I y II & Mateu y Llopis & 19 \\
& Hiernard & 20 \\
\hline Treboniano Galo & Mateu y Llopis & 24 \\
& Hiernard & 25 \\
\hline Valeriano II & Mateu y Llopis & 1 \\
& Hiernard & 2 \\
\hline
\end{tabular}

Apareciendo también diferencias en cuanto al número total de monedas conservadas:

- Mateu y Llopis (7): 227 (En los totales del cuadro $=* *$ ).

- Hiernard (6): 230 (En los totales del cuadro $={ }^{*}$ )

(ver cuadro al final del artículo).

\section{Ult. Num.}

Tradicionalmente se venía considerando como último numisma el perteneciente a Póstumo, con reverso HERCVLI DEVSONENSI (8) y su cronología no se especificaba dándose por buena la del reinado de Póstumo: 260-68 d.C..

Con la revisión del tesorillo han surgido dos cronologías terminales diferentes:

-La sustentada por Hiernard (9), basada en el estudio de los calcos de las monedas, da como monedas terminales a tres ejemplares pertenecientes a Salonina datados en 263-64 d.C. (RIC 25 -2 ej.- y RIC 68).

-La representada por Balil (10), basada en los reversos 
publicados por Mateu y Llopis (11), alarga la cronología del tesorillo hasta el 266 d.C. con una emisión de Galieno perteneciente a la denominada del «Séptimo Consulado» acuñada en Roma, reverso SECVRIT PERPET, RIC 280, y otro numisma perteneciente a Salonina, ceca de Roma, emisión del 266 d.C., reverso FECVNDITAS, RIC 5.

Ref. BALIL, A., 1979: «Sobre el tesorillo de Antoninianos de Altafulla (Tarragona)», ANum., 9, 1979, 97-99; HIERNARD, J., 1978: «Recherches numismatiques sur Tarragone au III eme siécle aprés Jesus-Christ», Numisma, 150-155, 28, 307321; MATEU Y LLOPIS, F., 1950: «El hallazgo de denarios romanos de Altafulla», Bol. Arq., Año 50, Época IV, Fasc. 30, 53-58; MATEU Y LLOPIS, F., 1951: «Hallazgos Monetarios 6», Ampurias 13, $\mathrm{n}^{\circ}$ 449; MATEU Y LLOPIS, M., 1958: «Hallazgos monetarios 16», NH 7, 1958, Apéndice, addenda al no 449 .

\section{Notas:}

1.- F. Mateu y Llopis, 1950, Bol. Arq., Año 50, Ep. IV, Fasc. $30,53-58$.

2.- J. Hiernard, 1978, Numisma 28, n 150-155, 308, nota 1.

3.- L. Sagredo San Eustaquio, HAnt. 1981-85, Vol. 11-12,91-

92 (Las invasiones del siglo III d.C. en Hispania a la luz de los tesorillos monetales).

4.- A. Balil, ANum. 9, 1979, 98.

5.- J. Hiernard, Numisma 28, 1978, 313-314.

6.- J. Hiernard, 1978, op.cit. en nota 2, 314.

7.- F. Mateu y Llopis, 1950, op.cit. en nota 1, 54-58.

8.- A. Balil, op.cit. en nota 4, 99 ELMER 124, J. Hiernard, op.cit. en nota 2, 314 ELMER 123.

9.- J. Hiernard, 1978, op.cit. en nota 2.

10.- A. Balil, 1979, op.cit. en nota 4.

11.- F. Mateu y Llopis, 1950, op.cit. en nota 1, 54-58.

\section{(48) [1] JIMENA DE LA FRONTERA-1 (CÁDIZ)}

Hall. Fue hallado, en 1935 ó 36, en un lugar denominado Las Mesas, a $8 \mathrm{~km}$. de Jimena de la Frontera (Cádiz), cuando se realizaban las estructuras de una casa de campo, a unos $50 \mathrm{~cm}$. de profundidad, en una orza o tinaja.

Gallwey (1) describe 29.858 numismas a los que considera como $2 / 3$ ó $3 / 4$ del total hallado. Por su parte Christol y Nony (2) incrementan en 23 ejemplares más el total conocido del tesorillo, quedando en 29.881 numismas, de los que todos son radiados, excepto 3 denarios pertenecientes a Paulina, Galieno y Salonina.

Inv. (al final del artículo)

Ult. Num.

Tradicionalmente se fijaba la última acuñación del tesorillo en el 267-68 d.C. con las emisiones de Galieno denominadas del Bestiario. Pero con su revisión aparecen algunos ejem- plares de la ceca de Siscia acuñados en el 268 d.C.. Uno de éstos es:

Emperador: Galieno (radiado).

A/ GALLIENVS AVG.

R/ AETERNITATI AVG.

Ceca. Siscia, 268 d.C.

Peso. Módulo. ------.

Ref: RIC V-1, 555.

Ref. (I) GALLWEY, H.D., 1962: «A Hoard of third-century antoniniani from Southern Spain», NC 7, Serie II, 335-406; (2) CHRISTOL, M., NONY, D., 1970: «Le trésor de Jimena de la Frontera (Cádiz): antoniniani du III siécle», BSFN 5, 526-528. TYLER, PH.; 1975: The Persian wars of the 3rd Century A.D. and Roman Imperial Monetary Policy, A.D. 253-68. Wiesbaden.

\section{(49) [45] TARRAGONA-1888}

Hall. Hallado en 1888, lo conservado es una fracción del tesoro descubierto al abrir el portillo de la muralla que va desde el baluarte de San Pablo a la derruida puerta de Lérida, y al extremo occidental de la calle del Gobernador González.

Se conservan 105 radiados, lo descubierto sumaba varios centenares de numismas. El tesorillo está reconstruido hipotéticamente por Hiernard (1).

Inv. (al final del artículo)

UIt. Num. Pueden ser 2 ejem.

Emperador: Galieno (radiado).

A GALLIENVS AVG.

R/ INDVLGENTIA AVG.

Ceca. Roma, 17 emisión, 267-268 d.C.

Peso. Módulo. 2,38 gr. $21 / 19 \mathrm{~mm}$.

Ref: RIC V-1, 206.

Emperador: Salonina (radiado).

A/ SALONINA AVG.

R/ VENVS VICTRIX.

Ceca. Siscia. 267 d.C.

Peso. Módulo. 2,78 gr. 21/20 mm.

Ref: RIC V-1, 31 .

Ref. (1) HIERNARD, J., 1978: «Recherches numismatiques sur Tarragone au III eme siécle aprés Jesus-Christ», Numisma 28, n 150-155, 307-321; HIERNARD, J., 1978: «Monedas del s. III en el Museo Arqueológico Provincial de Tarragona», ANum. 8, 98-133.

\section{(50) [21] SERRA DO CONDAO (FREG. POMARES,} CONC. ARGANIL. PORTUGAL)

Hall. Fue hallado por un pastor, dentro de un escondrijo efectuado en una roca. Según los halladores el emperador más reciente de las monedas que vieron eran de Póstumo. No se cita el número total de numismas hallados y solamente se describen 14 de ellos: 
- 4 Aureos.

-10 Radiados.

Inv.

Aureos

\begin{tabular}{|c|c|c|}
\hline Emperador & Anverso & Reverso \\
\hline Galieno & $\begin{array}{l}\text { GALLIENVS AVG } \\
\text { IMP C ...IENUS AVG } \\
\text { IMP C P LIC GALLIENVS PF AVG } \\
\text { GALLIENVS AVG }\end{array}$ & $\begin{array}{l}\text { AETERNITAS AVG } \\
\ldots \ldots \ldots \ldots \ldots \ldots \\
\text { FORT }(\text { VNA R)ED(UX) } \\
\ldots \ldots \ldots \ldots \ldots \ldots\end{array}$ \\
\hline
\end{tabular}

Radiados

\begin{tabular}{|l|l|l|}
\hline Emperador & Anverso & Reverso \\
\hline Filipo II & M IVL PHILIPPVS CAES & IOVI CONSERVAT \\
\hline Ota. Severa & MARCIA OTACILIA SEVERA AVG & PVDICITIA AVG \\
\hline Galieno & $\begin{array}{l}\text { IMPC P LIC GALLIENVS PF AVG } \\
\text { GALLIENVS PF AVG }\end{array}$ & $\begin{array}{l}\text { ORIENS AVG } \\
\text { GERMANICVS MAX V }\end{array}$ \\
\hline Salonina & $\begin{array}{l}\text { CO SALONINAAVG } \\
\text { SALONINA AVG }\end{array}$ & $\begin{array}{l}\text { CONCORDIA AVG } \\
\text { PVDICITIA }\end{array}$ \\
\hline Macriano I & MARC TVL MARCRIANVS AVG & IOVI CONSERVATORI \\
\hline Macriano II & IMP C FVL MACRIANVS PF AVG & ROMAE AETERNAE \\
\hline Quieto & IMP C FVL QUIETVS PF AVG & ROMAE AETERNAE \\
\hline Postumo & IMPC POSTVMVS PF AVG & VICTORIAAVG \\
\hline
\end{tabular}

Ref. DE CASTRO HIPÓLITO, M., 1960-196I: «Dos tesouros de moedas romanas em Portugal», Conimbriga 2-3, 109 110 y nota 255 .

\section{(51) [42] SANGÜESA (NAVARRA)}

Hall. Se encontró en el término de Santa Eulalia (Santa Olalla), en el siglo XIX, dentro de una vasija de barro cuyo contenido eran más de 2.000 monedas de «cobre, vellón y plata».

Inv. En la memoria redactada por P. Ilarregui, secretario de la Comisión de Monumentos Histórico-Artísticos de Navarra, se citan los siguientes emperadores:

- Gordiano Pío - Filipo - Trajano Decio - Treboniano Galo Volusiano - Galieno - Salonino (Caesar) - Salonino (Emperador) -Póstumo.

Del conjunto total hallado se remitieron a la Real Academia de la Historia 10 monedas de plata de cada uno de los anteriores emperadores.

Ref. ALTADILL, J., 1928: «De Re Geographico-Histórica.
Vías y vestigios romanos en Navarra», Homenaje a Carmelo Echegaray, San Sebastián, 518-519; TARACENA, B., VÁZQUEZ DE PARGA, L., 1946: «Excavaciones en la villa de Liédena», PV, año VII-2, n 24, 437; LABEAGA, J.C., 1987: «Carta arqueológica del término municipal de Sangüesa (Navarra)», TAN 6, 65.

\section{(52) [--] GRISÉN (ZARAGOZA)}

Hall.: Apareció casualmente en Grisén (Zaragoza) en diciembre de 1966. Se desconocen los detalles de su hallazgo.

Inv.: El conjunto monetal se compone de 914 radiados:

\begin{tabular}{|l|c|c|}
\hline Emperador & Cronología & Total \\
\hline Valeriano & $253-260$ & 1 \\
\hline Valeriano II Divus & & 2 \\
\hline Salonino & & 2 \\
\hline Galieno & $253-268$ & 746 \\
\hline Salonina & & 64 \\
\hline Póstumo & 260-268 & 2 \\
\hline Claudio II & 268-270 & 88 \\
\hline
\end{tabular}

Al no haberse descrito los anversos de las monedas no podemos atribuir con seguridad las cecas en las que se acuñaron las monedas.

Ult. Num.: Correspondería a las monedas de Claudio II con fecha 269-270 d.C. dado que el conjunto no presenta ninguna moneda del tipo DIVO CLAVDIO.

Ref.: BELTRÁN, A. 1966-68: "Informe de actividades en 1966. Delegación de Excavaciones Arqueológicas del distrito universitario de Zaragoza», NAH, 10-11 y 12, 328, $\mathrm{n}^{\circ} 11$. BELTRÁN, A. 1992: "El tesorillo bajoimperial de Grisén". BMZ 11, 117-127

\section{(53) [--] ROSAS (GERONA)}

Hall. Pequeño grupo de monedas (7 radiados) pertenecientes al Emperador Póstumo. Que se presentan como parte integrante de un tesorillo o, como hipótesis, podría tratarse de un tesorillo propiamente dicho, puesto que las monedas pertenecen a una colección, desconociéndose cualquier tipo de información respecto a su procedencia y circunstancias del hallazgo.

\section{Ult. Num.}

Emperador: Póstumo (radiado).

A/ IMP C POSTVMVS PF AVG.

R/ PA-X A-VG P. 
Ceca: Colonia, 267 d.C., 21 emisión.

Peso, Módulo: 2,87 gr., ----.

Conserv.: ----

Ref: Elmer, 566.

Inv.

\begin{tabular}{|l|c|c|c|}
\hline Emperador & Cronología & Col & Total \\
\hline Postumo & 261 & 1 & \\
& 263 & 3 & \\
& 264 & 2 & \\
& 267 & 1 & 7 \\
\hline
\end{tabular}

Ref. GURT ESPARRAGUERA, J.M., 1977: «Comentarios sobre un lote de monedas de Póstumo», GN 45, 10-13.

(54) [--] MUSEO DE LA PORCIÚNCULA (MALLORCA)

Hall. Este tesorillo, conservado en el Museo de la Porciúncula de Palma, es de procedencia mallorquina, aunque se desconoce el lugar exacto de su hallazgo.

Su número de ejemplares parece que asciende a 18 , estando presentes numismas de Maximiano y Galieno, aunque el lote más abundante y el que además cierra la serie pertenece a Claudio II (268-70 d.C.). Se desconocen más detalles respecto a éste tesorillo.

Ref. MANERA, E., 1983: «Circulación monetaria en Mallorca», Symposium de Arqueología: Pollentia y la romanización de las Baleares, Palma de Mallorca, 138; TARRADELL, M., 1977: «Primeres noticies de la crisi del segle III d.C. a Mallorca», Memòria de l'Institut d'Arqueologia i Prehistòria de la Universitat de Barcelona, 32.

\section{(55) [--] MUSEO DE ARTA (MALLORCA)}

Hall. Tesorillo del mismo tipo que el de la Porciúncula, se supone que procede de la misma comarca de Artá. No se dan más detalles.

Ref. TARRADELL, M., 1977: «Primeres noticies de la crisi del segle III d.C. a Mallorca», Memòria de l'Institut d'Arqueologia i Prehistòria de la Universitat de Barcelona, 32.

\section{(56) [--] PROVINCIA DE PONTEVEDRA}

Hall. Se halló en la provincia de Pontevedra, sin poderse precisar el año ni el lugar, dentro de una cista formada por pequeñas piedras y, prácticamente, a flor de tierra. Se desconoce el número total de numismas hallados, solamente se han podido estudiar 6 piezas: 5 denarios y un as, con un desfase cronológico importante entre la primera y la última pieza: 172-151 a.C. $-264-65$ d.C.
Ult. Num.

Emperador: Póstumo (Denario).

A/ POSTVMVS AVG, Busto yelmado, con coraza, a izda. R/ ...TR P V COS III P.P. Emperador de pie, a izda. lleva globo y lanza, es coronado por la victoria que lleva palma, larga. Ceca: Lugdunum, 264 d.C.

Peso, Módulo: 3,78 gr., $19 \mathrm{~mm}$.

Ref: RIC V-2, 345, nळ 97.

Inv.

\begin{tabular}{|r|l|l|c|c|}
\hline Cant. & Tipo & Emperador & Cronol. & Ceca \\
\hline 1 & Denario & L. Sempronivs Pitio & $172-151$ a.C. & Roma \\
\hline I & Denario & C. Abvrivs Geminvs & $124-103$ a.C. & Roma \\
\hline I & Denario & $--\ldots-\ldots-$ & $93-92$ a.C. & Italiana \\
\hline 1 & Denario & Tiberio & $15-16$ d.C. & Lugdunum \\
\hline I & As & Tiberio & $14-37$ d.C. & Turiaso \\
\hline I & Denario & Postumo & 264 d.C. & Lugdunum \\
\hline
\end{tabular}

Ref. CAVADA NIETO, M., 1984: «Dos tesorillos monetarios aparecidos en Galicia», II Congreso Galaico-Minhoto, 181191.

\section{(57) [--] POLLENTIA-2}

Hall. Apareció en el área de las ruinas de Pollentia (1), aunque se desconoce el lugar exacto de su aparición puesto que fue hallado por un particular, siendo donado en 1973 al Museo de la Alcudia. Se trata de 19 radiados de Claudio II aunque Mattingly (2) notifica que en la parte recuperada del tesorillo y vista por él solamente aparecen 18 ejemplares, desconociéndose cualquier dato sobre el ejemplar que falta.

Inv.

\begin{tabular}{|c|c|c|}
\hline Emperador & Cronología & Roma \\
\hline Claudio II & 268 & 2 \\
& 269 & 14 \\
& $269-270$ & 2 \\
\hline & TOTAL & 18 \\
\hline
\end{tabular}

Ult. Num. Pueden serlo 2 ejemplares:

Emperador: Claudio II (radiado).

A/ IMP C CLAVDIVS AVG.

R/ FORTVNA REDVX.

Ceca: Roma, 269-270 d.C. 
Peso. Módulo: ----, ----.

Cons.: Buena.

Ref: RIC V-1, 41.

Emperador: Claudio II (radiado).

A/ IMP C CLAVDIVS AVG.

R/ MARTI PACIFERO.

Ceca: Roma, 269-270 d.C.

Peso. Módulo: ----, ----.

Cons.: Buena.

Ref: RIC V-1, 68.

Ref. (1) TARRADELL, M., 1977: «Primeres noticies de la crisi del segle III d.C. a Mallorca», Memòria de l'Institut d'Arqueologia i Prehistòria de la Universitat de Barcelona, 31. (2) MATTINGLY, H.B., 1983: «Roman Pollentia: coinage and history», Pollentia. Estudio de los materiales I. Sa Portella, Excavaciones de 1957-63, Palma de Mallorca, 285.

\section{(58) [--] BELO (BOLONIA, CÁDIZ)}

Hall. En octubre de 1973, durante la VIII campaña de excavaciones en Belo (Bolonia, Cádiz), se encontraron 13 radiados apilados, uno sobre otro, y apoyados contra un bloque de gres.

Inv.

\begin{tabular}{|l|c|c|c|c|}
\hline Emperador & Cronol. & Rom & Total & $\%$ \\
\hline Galieno & $262-263$ & 1 & & \\
& $263-264$ & 1 & & \\
& $266-267$ & 2 & & \\
& $267-268$ & 2 & 6 & 46,1 \\
\hline Salonina & $266-267$ & 2 & 2 & 15,4 \\
\hline Claudio II & $268-270$ & 4 & & \\
& 269 & 1 & 5 & 38,5 \\
\hline & TOTAL & 13 & 13 & 100 \\
\hline & $\%$ & 100 & & \\
\hline
\end{tabular}

\section{Ult. Num.}

Emperador: Claudio II (radiado).

A/ [IMP C] CLAVDIVS AVG, Busto radiado y drapeado a derecha.

R/ IOVI VIC[TORI].

Ceca: Roma, 269 d.C.

Peso. Módulo: 2,10 g, $21 \mathrm{~mm}$

Ref: RIC V-1, 54.

Ref. DUPRE, N.,1974: «La huitieme campagne de fouilles á Belo-Bolonia (Cadix)», MCV 10, 525-558; DUPRE, N.,
1975: «Un lot de antoniniani decouvert á Belo en 1973», MCV 11, 535-543.

\section{(59) [--] SON HEREU-2 (LLUCMAJOR, PALMA DE} MALLORCA)

Hall. En Son Hereu, lugar y circunstancias desconocidos.

Inv. 32 pequeños bronces (¿radiados?):

- Galieno $=20$. Reversos: SOLI CONS AVG, DIANAE CONS AVG, VBERITAS AVG, ORIENS AVG, ANONA, VICTORIA SC, MART PACIFER, PAX. Otros frustros.

-Claudio II $=12$. Reversos: FIDES MILITVM SC, FIDES EXER, SPES AVG. Otros frustros.

Ref. MANERA, E., 1983: "Circulación monetaria en Mallorca», Symposium Pollentia y la romanización de las Baleares, Alcudia, 1977, Palma de Mallorca, 134; TARRADELL, M., 1983: «La romanització de Mallorca: alguns aspectes i un programa, Primeres noticies de la crisi del segle III d.C. a Mallorca», Symposium Pollentia y la romanización de las Baleares, Alcudia 1977, Palma de Mallorca, 127.

\section{(60) [37] VALSADORNIN (PALENCIA)}

Hall. Fue encontrado casualmente en 1937, en el lugar conocido como Valdiquecho, situado en el camino viejo de Valsadornin a Gramedo.

Las monedas se hallaban en el interior de un caldero de cobre con un peso total de unos $45 \mathrm{~kg}$.. Rápidamente se dispersaron las monedas, estudiándose solamente 2.421 ejemplares que corresponden en peso a un $14 \%$ del total que se acercaría a las 10.000 monedas, de las cuales se encuentra un numeroso lote en el MAN, depositadas sin haber sido estudiadas.

Inv. El cuadro que damos al final del artículo está tomado de M.V. Calleja, advirtiendo en él algunos errores, como el de atribuir las acuñaciones de Póstumo a Roma (las hemos considerado como emisiones de Colonia), o también las de los usurpadores Macriano y Quieto a la misma ceca de Roma (las atribuimos a Antioquía). Por tanto, es necesario mantener algunas reservas a la hora de juzgar la procedencia de las acuñaciones.

Ref. CALLEJA GONZÁLEZ, M.V., 1979: «El tesoro romano de Valsadornin». PITTM, 42, 7-25; MATEU Y LLOPIS, F., 1952: «Hallazgos monetarios 17», NH 1, n 537; BALIL, A.1957: «Las invasiones germánicas en Hispania durante la segunda mitad del siglo III d.C.», CTEEHAR 9, 143; SAGREDO SAN EUSTAQUIO, L., 1979-1980: «La presencia romana en la provincia de Palencia durante el siglo III d.C.», HAnt. 9-10, 31-56.

\section{(61) [20] ALDEIA DAS DEZ (CONC. DE OLIVEIRA DO} HOSPITAL, PORTUGAL)

Hall. En 1910, en una especie de gruta junto a las ruinas de 
una casa abandonada, debajo de una losa se halló una vasija de barro con un peso entre $12-15 \mathrm{~kg}$.

Se desconoce el número total de numismas que componían el tesorillo, sólo se conservan 257 unidades a las que Castro Hipólito (1) añadió otras 13 que pudo estudiar, resultando un total de numismas estudiados de 270 , todos ellos radiados.

Inv. (al final del artículo)

\section{Ult. Num.}

Emperador: Claudio II (radiado).

A/ IMP CLAVDIVS AVG.

R/ MARTI PACIF. - -// X.

Ceca: Roma. 4 emisión, 269-70 d.C.

Peso. Módulo: ----, ----.

Ref: RIC V-1, 68.

Ref. DE CASTRO HIPÓLITO, M., 1960-1961: «Dos tesouros de moedas romanas em Portugal», Conimbriga 2-3, 107 108 y 114.

(62) [4] QUINTA DA TORRE DE ARES (ALGARVE, PORTUGAL)

Hall. En las excavaciones realizadas a principios de siglo en la Quinta da Torre de Ares (Algarve, Portugal), aparecieron 300 monedas pertenecientes a Claudio II, junto con anillos y piedras grabadas de anillos, dentro del encauzamiento general designado en la excavación como H'. No se tienen más referencias.

Ref. AFFONSO DOS SANTOS, M.L., 1971: Arqueología romana do Algarve, Lisboa, 233.

\section{(63) [--] TERRA CHA (LUGO)}

Hall. Se halló en un lugar indeterminado de la Terra Chá, pero en la zona de Castro de Riberas de Lea. El número de monedas que lo formaban era muy elevado, pero el tesorillo se dispersó, pudiendo localizarse solamente los 12 radiados que se estudian.

Inv. (al final del artículo)

\section{Ult. Num.}

Emperador: Claudio II (radiado)

A IMP CLAVDIVS AVG, cabeza radiada a derecha.

B/ FORTVNA REDVX, Fortuna de pie a izquierda, ramo en mano derecha y en la izda. sujeta el manto.

Ceca: Roma, 269-70 d.C.

Peso. Módulo: ----, 18/19 mm.

Cons.: Mala.

Ref: RIC V-1, 2I4, $n^{\circ} 41$.

Ref. ARIAS, F., CAVADA, M., 1976: «Antoninianos de un tesorillo hallado en la Terra Chá (Lugo)», BCMHALugo $9, \mathrm{n}^{\circ}$ 85-86, 257-63.

\section{(64) [--] GRANDAS DE SALIME (ASTURIAS)}

Hall. En el Concejo de Grandas de Salime (Asturias), hace más de cuarenta años, cuando se realizaban talas de árboles en un monte de dicho concejo, se produjo la exhumación de una vasija, al parecer metálica, en cuyo interior se hallaban las monedas. Del total de las monedas halladas se conservan 23, todas ellas radiados, habiéndose vendido las que faltan en Lugo. El estado de conservación es en general bueno.

Inv. (al final del artículo)

Ult. Num.

Emperador: Divo Claudio (radiado).

A/ DIVO C[LA]VDIO, Cabeza radiada a derecha.

R/ CONSECRATIO. Altar.

Ceca: Mediolanvm, 270 d.C.

Peso. Módulo: 2,50 gr. 21/22 mm.

Cons.: Buena.

Ref: RIC V-1, 233, n² 261.

Ref. VEGA DE LA TORRE, J.R., 1980: «Un tesorillo de Grandas de Salime», BIDEA 34, $n^{\circ}$ 99, 279-294.

(65) [--] SON HEREU-1 (LLUCHMAJOR, MALLORCA)

Hall. Fue hallado casualmente en el interior de una pequeña vasija de cerámica, en la finca de Son Hereu, término municipal de Lluchmajor, Mallorca. Se compone de 102 radiados.

Inv. (al final del artículo)

Ult. Num.

Emperador: Divo Claudio (radiado).

A/ DIVO CLAVDIO.

R/ CONSECRATIO, Pira funeraria.

Ceca: Galia, 270 d.C. o post.

Peso, Módulo: 3,62 gr.,--

Ref.: RIC V-1, 256.

Ref. MANERA, E., 1979: «Un tesorillo de Antoninianos hallado en Son Hereu», Butlletí de la Societat Lluliana, $\mathrm{n}^{\circ}$ 830-31, T. 37, 77-103.

\section{(66) [47] REUS (TARRAGONA)}

Hall. Monedas halladas formando un tesorillo en una quinta romana de Reus (Tarragona), antes de 1879. Se conservaban 119 radiados de los que actualmente sólo restan 109 en el Museo Arqueológico Provincial de Tarragona, los 10 que faltan se perdieron en las sucesivas remodelaciones del Museo. Los 119 numismas no eran el total de ejemplares hallados.

\section{Ult. Num.}

Emperador: Divo Claudio (radiado).

A/ DIVO CLAVDIO.

R/ CONSECRATIO, altar (3), águila (5).

Ceca: Roma, 270 d.C. o post.

Peso. Módulo:-- ,--

Ref.: RIC V-1, 266 (Altar), 261 (Águila).

Ref. HIERNARD, J., 1978: «Monedas del siglo III en el Museo Arqueológico Provincial de Tarragona», ANum. 8, 97- 
133; HIERNARD, J., 1978: «Recherches numismatiques sur Tarragone au III eme siécle aprés Jesus-Christ», Numisma 28, n $150-151,307-332$; SÁNCHEZ REAL, J., 1957: «Las invasiones germánicas», Bol. Arq., $\mathrm{n}^{\circ}$ 57-60, 11, nota 15; HERNÁNDEZ, B.; DEL ARCO Y MOLINERO, D.A., 1894: Catálogo del Museo Arqueológico de Tarragona, Tarragona, 236.

Inv.

- La primera división del tesorillo era:

*Galieno, 80 numismas

*Claudio II y Divo Claudio, 39 numismas

-La división actual es:

\begin{tabular}{|l|c|c|c|c|c|c|}
\hline Emperador & Cronol. & Rom & Sis & Ind & Total & $\%$ \\
\hline Galieno & 261 & 1 & & & & \\
& $262-263$ & 2 & & & & \\
$264-266$ & & 1 & & & \\
265 & 33 & & & & \\
& $266-267$ & 12 & & & & \\
& $267-268$ & 21 & & & & \\
268 & & 1 & & 74 & 67,89 \\
\hline Claudio II &.-- & 1 & & 2 & 74 \\
& 268 & 2 & & & & \\
& 269 & 22 & & & & \\
\hline Divo Claudio & pos 270 & & & & & \\
& Aguila & 3 & & & & \\
\hline & Altar & 5 & & & 8 & 7,34 \\
\hline & Total & 105 & 2 & 2 & 109 & 100 \\
\hline & $\%$ & 96,34 & 1,83 & 1,83 & & \\
\hline
\end{tabular}

(67) [23] CONIMBRIGA D (CONDEIXA A VELHA, PORTUGAL)

Hall. Se encontró en las excavaciones de 1965, escondido en el suelo de una casa y protegido por una teja de rebordes. Se trata de 29 radiados, que parecen ser el contenido de una bolsa. Inv. (al final del artículo)

\section{Ult. Num.}

Emperador: Divo Claudio (radiado).

A/ DIVO CL[avdio].

R/ CO[n]SE[cratio], Aguila.

Ceca: Roma o local. Post. 270 d.C.

Peso. Módulo: 2,51 gr., $18 \mathrm{~mm}$.

Ref.: RIC V-1, 266.

Ref. PEREIRA, I., BOST, J.-P., HIERNARD, J., 1974: Fouilles de Conimbriga III. Les Monnaies, París, 326-327.
(68) [43] BARBOLES (ZARAGOZA)

Hall. En 1856, se descubrieron en Bárboles (Zaragoza) cerca de 1.200 numismas, que en su mayoría pertenecían a los siguiente emperadores: Valeriano, Mariniana, Galieno, Salonina, Salonino y Claudio II. También incluía el tesorillo un numisma de Macriano (reverso SOLI INVICTO) y tres de Póstumo (reversos CONCORD EQVIT, MONETA AVG y PM TR P COS II PP). El último numisma es un DIVO CLAVDIO con reverso del águila, acuñado con posterioridad a la muerte de Claudio II (270 d.C.).

Ref. MOMMSEN, Th., 1863: «Sopra alcuni ripostigli di denari romani scoperti nella Spagna», Annali dell'Istituto di Corrispondencia Archeológica, 35, 76-77.

\section{(69) [41] LIEDENA (NAVARRA)}

Hall. Descubierto en las excavaciones de la villa romana de Liédena (Navarra) que efectuaban B. Taracena y L. Vázquez de Parga. Está compuesto por 105 radiados, de ellos 28 frustros.

Inv.

\begin{tabular}{|l|c|c|}
\hline Emperador & Cronología & Total \\
\hline Ota. Severa & $244-249$ & 1 \\
\hline T. Decio & & $*$ \\
\hline Valeriano & $253-260$ & 9 \\
\hline Galieno & $253-268$ & 42 \\
\hline Salonina & & 6 \\
\hline Quieto & $260-261$ & 2 \\
\hline Claudio II & $268-270$ & 13 \\
\hline Quintilo & 270 & 4 \\
\hline Fustras & & 28 \\
\hline & TOTAL & 105 \\
\hline
\end{tabular}

* No cuantificados.

Ult. Num. Sería uno de los radiados pertenecientes a Quintilo ( 270 d.C.).

Ref.: TARACENA, B., VÁZQUEZ DE PARGA, L., 19471951: «Excavaciones en la villa de Liédena», Excavaciones en Navarra II, 69-70; TARRADELL, M., 1955: «Problemas cronológicos de las invasiones germánicas del siglo III (d.de J.C.)», CNA 4, 237; BALIL, A., 1957: «Las invasiones germánicas en Hispania durante la segunda mitad del siglo III d.C.», CTEEHAR 491, 127 y nota 70. 
(70) [22] CONIMBRIGA B (CONDEIXA A VELHA, PORTUGAL)

Hall. En la campaña de excavaciones de 1967, escondidos en el ala occidental del criptopórtico se hallaron 56 radiados agrupados en un espacio muy reducido. No se sabe si esta cantidad corresponde al número total de numismas

Inv. (al final del artículo)

\section{Uit. Num.}

Tenemos varias monedas que nos indican la misma fecha: los radiados DIVO CLAVDIO, acuñados con posterioridad a la muerte de Claudio II, y un radiado del emperador Quintilo, acuñado en el año 270 d.C.

Emperador: Quintilo (radiado).

A/ IMP C M AVR CL QVINTILLVS AVG.

R/ MARTI PACIF.

Ceca: Roma, 270 d.C.

Peso. Módulo: 2,58 gr., 21/19 mm.

Ref.: RIC V-1 24.

Ref.: PEREIRA, I., BOST, J.-P, HIERNARD, J., 1974: Fouilles de Conimbriga III. Les monnaies, París, 323-324; ETIENNE, R., 1967: Trésor de monnaies romaines à Conimbriga, BSFN 22, 10, 221-222; RACHET, M., BOST, J.P., PEREIRA, I., 1970: A propos d'un trésor monétaire decóuvert à Conimbriga. Portugal. II Congreso Nacional de Arqueología, 543-557.

\section{(71) [--] JIMENA DE LA FRONTERA 2 (CÁDIZ)}

Hall. Se hallaron 13 radiados formando un conjunto, al realizar labores en los huertos que existen en el interior del castillo que se encuentra en el recinto de ruinas de la antigua Oba. Se encontraron aislados de cualquier resto cerámico o metálico que los pudiera haber contenido.

Inv.

\begin{tabular}{|l|c|c|c|c|c|c|}
\hline Emperador & Cronol. & Rom & Sis & Ind & Total & $\%$ \\
\hline Galieno & 261 & 1 & & & & \\
& $\begin{array}{c}263 \\
266\end{array}$ & 2 & & & & \\
& $267-268$ & 1 & 1 & & & \\
--- & & 1 & 1 & 9 & 69,24 \\
\hline Salonina & 266 & 1 & & & 1 & 7,69 \\
\hline Quintilo & 270 & 1 & & & 1 & 7,69 \\
\hline Ilegibles & & & & 2 & 2 & 15,38 \\
\hline & Total & 8 & 2 & 3 & 13 & 100 \\
\hline & $\%$ & 61,54 & 15,38 & 23,08 & & \\
\hline
\end{tabular}

Ult. Num.

Emperador: Quintilo (radiado).

A/(IMP) C M AVR CL QVINT(ILLVS AVG), Busto radiado a derecha.

R/ PROVIDENT AVG, Providencia en pie a izquierda, cetro en mano izquierda.

Ceca: Roma, 270 d.C.

Peso. Módulo: 3,12 gr., 18,5 mm.

Ref: RIC V-1, 29.

Ref.: DOMÍNGUEZ ARRANZ, A., 1980: «Tesorillo de Antoninianos de Jimena de la Frontera (Cádiz)», SNB II, Barcelona, 227-230.

\section{(72) [--] VILA CAIZ (AMARANTE, PORTUGAL)}

Hall. El hallazgo puede ser anterior a la década de 1940/50. Apareció en Vila Caiz, Concelho de Amarante (Portugal), en un muro, dentro de un recipiente de barro. Esta compuesto por 54 ejemplares: 52 radiados y 2 cuartos de radiado de Aureliano

Inv. (al final del artículo)

\section{Ult. Num.}

Emperador: Aureliano (radiado reformado).

A/ IMP AVRELI ANVS AVG.

R/ VICT O RI A AVG, - -//A.

Ceca: Roma, febrero o marzo del 274-275 d.C.

Peso. Módulo: 2,38 gr., 18,1/18,7 mm.

Ref.: RIC V-2, 73.

Ref. CENTENO, R.M.S., 1981-1982: «A circulaçao dos Divo Claudio na Peninsula Ibérica: notas sobre um tesouro do Concelho de Amarante». Portugalia, Nova Serie, vol. 2/3, 121-129.

\section{(73) [--] REGUENGO (VILA POUCA DE AGUIAR, POR-} TUGAL)

Hall. Fue hallado en 1977, dentro de un recipiente de barro enterrado a unos $40 \mathrm{~cm}$. de profundidad. El total de numismas hallados se acercaría a los 800 , de los que se han estudiado 749 radiados y un radiado reformado de Aureliano.

Inv. (al final del artículo)

Ult. Num.

Emperador: Aureliano (radiado reformado).

A/ IMP CAES L DOM AVRELIANVS AVG. Busto radiado con paludamentum a derecha.

R/ CONCORDIA MILI. Concordia sentada sosteniendo una enseña militar en cada mano, --//P.

Ceca: Siscia, 5 emisión. 274-275 d.C.

Peso. Módulo: 4,6 gr., 19/21,2 mm.

Ref: RIC V-1, 196.

Ref. PARENTE, J., 1982: «Tesouro numismático de Reguengo», RG 92, 231-313. 
(74) [--] CLUNIA-3 (CORUÑA DEL CONDE, BURGOS)

Hall. Fue hallado en el verano de 1974, durante las excavaciones practicadas en la habitación número 7 de la casa número 3 , en un estrato de cenizas de una potencia superior a los 50 $\mathrm{cm}$., al que se superponía otro estrato conteniendo la techumbre de la habitación.

El estrato del hallazgo es arqueológicamente el mismo que el que contiene al tesorillo Clunia-2, aparecido en la habitación número 10 de la misma casa.

El tesorillo está compuesto por:

-2 ases.

-2 sestercios.

-50 radiados.

Inv. (al final del artículo)

Ult. Num. Del monetario oficial, el último numisma corresponde a un radiado del emperador Tétrico II, acuñado en el 274 d.C., pero según Gurt Esparraguera (1), las monedas de imitación de Tetrico fueron acuñadas con posterioridad a su muerte, durante un período no inferior a diez años.

Emperador: Tétrico II (radiado).

A/ [C PIVS ESV] TETRICVS CAES.

R/ [PRINC IVVEN]T.

Ceca: Colonia, primera mitad 274 d.C. 7 emisión.

Peso. Módulo: 1,62 gr., 17,9 mm.

Ref: Elmer, 781.

Ref. (1) GURT, J.M., 1985: Clunia III. Hallazgos monetarios. La romanización de la Meseta norte a través de la circulación monetaria en la ciudad de Clunia, EAE 145, Madrid, 133-145.

(75) [5] MARGEM DO VASCAO (CONC. ALMODOVAR, BEJA, PORTUGAL)

Hall. Se halló de forma casual en la zona de Ameixial. El número de ejemplares alcanzaba los 5.000, de los que solamente se identificaron unos pocos que pertenecían a los siguientes emperadores: Galieno, Claudio II, Severina, Quintilo, Aureliano. Los numismas eran de plata de baja ley (radiados) y fueron vendidos.

Ref. LEITE DE VASCONCELLOS, J., 1908: «Antigualhas-3. Thesouros de moedas romanas», AP 13, 352; DE CASTRO HIPÓLITO, M., 1960-1961: «Tesouros de moedas romanas em Portugal», Conimbriga, 2/3, 89 n $^{\circ} 131$ y 109 IV y nota 254.

\section{(76) [13] BORBA (O EN SU REGIÓN, PORTUGAL)}

Hall. No se conocen las circunstancias de su hallazgo, ocurrido entre 1956 y 1957, en Borba o en su región.

El total de numismas hallados rondaba los 600 ejemplares, de los que sólo se han podido estudiar 268; el resto fue vendido.

Inv. (al final del artículo)
Ult. Num.

Emperador: Tétrico I (radiado).

A/ IMP C TETRICVS PF AVG.

R/ COMES AVG.

Ceca: Colonia, 5 ó 6 emisión, 273 d.C.

Peso. Módulo:--,--

Ref: Elmer, 774 ó 770.

Ref. DE CASTRO HIPÓLITO, M., 1961-1962: «Tesouros de moedas romanas em Portugal», Conimbriga 2/3, 100-107 y 157-165.

\section{(77) [--] SIERRA PITILLOS (VALDEPEÑAS, JAÉN)}

Hall.: El lugar del hallazgo de este conjunto monetal es la cima de la Sierra de Pitillos, término municipal de Valdepeñas de Jaén, junto al embalse del Quiebrajano.

Las monedas que componen el hallazgo no aparecieron en un lugar concreto dentro de una vasija o recipiente sino que lo fueron dispersas por la cima y algunas de las laderas de la Sierra. Las primeras noticias de su existencia surgen en 1993 a raíz del hallazgo de monedas empleando detectores de metales. Se desconoce el número inicial de monedas, aunque se sugiere que pudieran superar los 5.000 ejemplares, de los cuales solamente se han podido estudiar 251 que están en poder de un coleccionista local.

Para los autores de la publicación del depósito monetal los radiados que lo componen no estuvieron mezclados en la época de su ocultación-dispersión sino que estarían separados en varias bolsas ( 4 al menos) según la ley de las monedas lo que explicaría las concentraciones de los hallazgos.

Las 251 monedas que se han podido describir son 249 radiados y 2 denarios de Galieno(*).

Inv. (al final del artículo)

Ult Num.: Pese a que la publicación del depósito monetal da como última acuñación una moneda de Aureliano de la ceca de Roma del 271 d.C., creemos que la última moneda es una imitación de Tétrico I que sería posterior a la muerte de este usurpador galo:

Emperador: Tétrico I (Imitación radiado)

A/ IMP C TETRICVS PF AVG

R/ PAX AVG, Paz a izq. Con rama de olivo y cetro.

Ceca: Imitación, post. 273 d.C.

Peso. Módulo: 1,90 g, 16-19 mm

Ref.: Imitación Cunetio 2607

Ref.: HINOJOSA PAREJA, A.R., 1995: "El tesorillo de antoninianos de la segunda mitad del siglo III de Sierra Pitillos (Valdepeñas de Jaén)". Antiquitas, año V, nº 6, 92-119.

(78) [28] FRAGAS DO PIAGO (FREG. DE SALTO, CONC. DE MONTALEGRE, PORTUGAL).

Hall. Hallado el 11-II-1954 por unos buscadores de wolframio 
en la montaña conocida como Fragas do Piago, Freg. de Salto, en las proximidades de las minas de Borralha.

Se encontraron dos vasijas de barro groseros llenas de numismas, más los restos de una tercera vasija que contendría los primeros numismas hallados.

En total se han descrito:

-2.820 ejemplares por M. Ramíres (1).

-53 ejemplares por M. de Castro Hipólito (2) lo que suma 2.873 unidades, que no son el total de las halladas.

Inv. (al final del artículo)

Ult. Num. No se describe.

Emperador: Tácito (radiado reformado).

A/

R/

Ceca: Cyzicus, 275-276 d.C.

Peso. Módulo:

Ref: RIC V-1, 207.

Ref. (1) RAMÍRES, M., 1955: «O tesouro de Antoninianos das Fragas do Piago», Nummus, vol. 3, 2, nœ 9, 75-93; (2) DE CASTRO HIPÓLITO, M., 1960-1961: «Dos tesouros de moedas romanas em Portugal», Conimbriga 2/3, 103-105.

\section{(79) [--] CLUNIA-2 (CORUÑA DEL CONDE, BURGOS)}

Hall. Apareció en la habitacion número 10 de la casa número 3, durante las excavaciones del verano de 1974, en un estrato de cenizas similar al del tesorillo Clunia-3. Situado en un espacio considerado como jardín interior.

Lo componen 24 numismas:

-4 ases.

-1 sestercio.

-1 denario.

8 radiados.

Inv. (al final del artículo)

Ult. Num.

Emperador: Probo (radiado reformado).

A/ IMP C M AVR PROBVS PF AVG.

R/ CLEMENTIA TEMP. - B//XXI.

Ceca: Antioquía, 280 d.C.

Peso. Módulo: 3,42 gr., 21,6 mm.

Ref: RIC V-2, 922.

Ref. GURT, M., 1985: Clunia III. Hallazgos monetarios. La romanización de la Meseta Norte a través de la circulación monetaria en la ciudad de Clunia, EAE 145, Madrid, 133144.

(80) [29 bis] SANTULHAO (BRAGANÇA, PORTUGAL)

Hall. Según Pereira et alii ( $\mathrm{n}^{\circ} 29$ bis), tesorillo de más de 1.000 numismas que van desde Valeriano hasta Probo. Los emperadores representados son: Valeriano, Galieno, Claudio II, Quintilo, Divo Claudio, Imp. Galo, Aureliano y Probo.

Ref. PEREIRA, I., BOST, J.-P., HIERNARD, J., 1974:
Fouilles de Conimbriga III. Les monnaies, París, 233, nº 29 bis.

(81) [26] LAJE (FREG. VILARINHO, CONC. SANTO TIRSO, PORTUGAL)

Hall. En 1900, excavando en una cantera se encontró una gran vasija de barro dentro de la cual se encontraba otra llena de monedas romanas, formando una masa compacta que se calcula en unos 5.000 ejemplares.

Se procedió a la limpieza de unas 130, resultando ser de los emperadores Galieno y Probo, con un estado bueno de conservación.

Ref. AZEVEDO, P.A., 1900: «Noticias varias 7. Achado archeologico», AP, vol. 5, 342; DE CASTRO HIPÓLITO, M., 1960-1961: Dos tesouros de moedas romanas em Portugal, Conimbriga $2 / 3,110-111$, VI.

\section{(82) [11] PEAL DEL BECERRO (JAÉN)}

Hall. Creemos que los números 11 (Peal del Becerro) y 12 (Toya) de la lista de Pereira et alii, corresponden a un mismo tesorillo: encontrado por L. Ramos, en una finca de su propiedad hacia 1920. Se hallaron en el interior de una vasija 1.325 numismas.

De la composición general del tesorillo poseemos dos versiones:

Inv.: Maluquer $\left({ }^{*}\right)$

Fdez. Chicarro (**)

\begin{tabular}{|l|c|c|c|c|c|}
\hline Emperador & Cronol. & Total $^{*}$ & $\%$ & Total $^{* * *}$ & $\%$ \\
\hline Filipo & $244-249$ & 13 & 1,00 & 3 & 0,23 \\
\hline T. Galo & $251-253$ & 3 & 0,23 & 2 & 0,15 \\
\hline Valeriano I & $253-260$ & 20 & 1,54 & 20 & 1,51 \\
\hline Galieno & $253-268$ & 698 & 53,95 & 698 & 52,68 \\
\hline Salonina & & 73 & 5,65 & 73 & 5,51 \\
\hline Macriano & $260-261$ & 1 & 0,08 & 1 & 0,07 \\
\hline Postumo & $260-268$ & 2 & 0,15 & 3 & 0,23 \\
\hline Victorino & $269-271$ & 2 & 0,15 & 2 & 0,15 \\
\hline Claudio II & $268-270$ & 462 & 35,70 & 463 & 34,94 \\
\hline Aureliano & $270-275$ & 16 & 1,24 & 16 & 1,21 \\
\hline Quintilo & 270 & -- & -- & 32 & 2,41 \\
\hline Severina & & 3 & 0,08 & 1 & 0,07 \\
\hline Probo & $276-282$ & 1 & 0,08 & 1 & 0,07 \\
\hline Fustras & & -- & -- & 8 & 0,61 \\
\hline & Total & 1264 & 100 & 1325 & 100 \\
\hline
\end{tabular}


La manifiesta diferencia entre el total hallado y los ejemplares estudiados se salva, en el caso de Fernández Chicarro, al considerar fustras las ocho monedas que le faltan hasta 1.325. Por el contrario, Maluquer no hace ninguna observación sobre los 31 numismas que faltan en su estudio.

A pesar de estas diferencias, las concordancias son mayores: la identificación de los dos tesorillos viene apoyada porque en la bibliografía (3) se cite a L. Ramos Marín como expositor del citado tesorillo en la Segunda Exposición Nacional de Numismática, nombre que coincide con el de la persona que halló el tesorillo de Peal del Becerro. También coinciden: la zona y fecha de su hallazgo y el número total de ejemplares.

Ult. Num.:

Emperador: Probo (radiado).

A/ IMP C M PROBVS P F AVG.

R/ SOL IN VICTO.

Ceca: Roma, 281 d.C.

Peso. Módulo: ,

Ref: RIC V-2, 203.

Ref. (1) MALUQUER, J., 1954: «Un tesorillo de pequeños bronces del s. III en Peal del Becerro (Jaén)», Caesaraugusta 5, 125-127; (2) FERNÁNDEZ CHICARRO, C., 1955: «Noticiario numismático de Andalucía», NH 4, 166-179; (3) RAMOS MARÍN, L., 1951: «Monedas romanas del siglo III d.J.C. halladas en el campo de Tugia (Toya, Jaén)», Segunda Exposición Nacional de Numismática e Internacional de Medallas, Madrid, citado en NH 1, 1952, 269.

\section{(83) (--) MONTE DO CAVALEIRO}

(ALGARVE,PORTUGAL)

Hall. Su existencia se documenta en el registro de monedas pertenecientes al Museo de Santiago do Cacém, Alentejo; con fecha 2-Marzo-1938. Habiéndose hallado en la «Herdade do Monte Cavaleiro, Algarve», lugar perteneciente al concelho de Tavira, freguesia do Ameixial. Se desconoce cualquier otro dato sobre las circunstancias de su hallazgo. I. Pereira plantea su posible identificación con el tesorillo $n^{\circ} 51$ de la Lista de M. de Castro Hipólito ( $\mathrm{n}^{\circ} 35$ de nuestra lista) de imprecisa localización: Serra?. La citada autora plantea si dicho lugar de hallazgo podría ser la Serra divisoria de las provincias de Alentejo-Algarve, coincidente entonces con la zona de hallazgo del presente tesorillo. Sin embargo, las escasas noticias que sobre dicho tesorillo poseemos indican que el emperador más reciente de los representados en el conjunto monetal era Galieno lo que no coincide con el de Monte do Cavaleiro.

Inv. El conjunto monetal está compuesto de 87 monedas: 86 radiados y 1 denario (ver al final del artículo).

Ult. Num.

Emperador: Probo (Denario).
A/ PROBVS PF AVG.

R/ PM TR P COS V PP.

Ceca: Roma, 281 d.C.

Peso, Módulo:--,--

Ref: RIC V-2, 251.

Ref. PEREIRA, I., 1991-1993: «Tesoro do Monte do Cavaleiro, Algarve». Homenatge al Dr. Leandre Villaronga. ANum 21-23, 303-314.NL 132, 1994, 0267.

\section{(84) [9] SANTA ELENA (JAÉN)}

Hall. Se trata de un hallazgo de 6.000 monedas, de las cuales las más recientes eran de Probo. Abundan en él las acuñaciones de Galieno. Las de Probo parecen corresponder a los primeros tiempos de su reinado.

Aparecen también algunos denarios de época severiana, lo que lleva a A. Balil (1) a plantear que se trate de un tesorillo de tesaurización.

Ref.(1) BALIL, A., 1959: «Hispania en los años 260-300 d.C., Emérita 27, 283 y nota 3.

\section{(85) [--] CHAVES (PORTUGAL)}

Hall. Hallado, con anterioridad a 1929, en la región de Chaves (Portugal). Se desconocen: su lugar exacto de hallazgo, la fecha, las circunstancias y el número total de monedas que lo constituía. Se conservan 212 monedas, repartidas entre radiados, radiados reformados de Aureliano y 3 denarios de Severina.

Inv. (al final del artículo)

Ult. Num.

Emperador: Caro (radiado reformado).

A/ IMP CARVS PF AVG, Busto radiado con manto y coraza, de frente.

R/ ABVNDANT AVG, - - //TXXI.

Ceca: Ticinum, II emisión, 282-283 d.C.

Peso. Módulo: 3,64 grs., .

Ref: RIC V-2, 69.

Ref.CENTENO, R.M.S., 1988: «Tesouro monetario romano da regiao de Chaves», Nummus, 2 serie, Vol. 11, 99-120.NL $125,1991,0150$.

(86) [39] CLUNIA-1 (CORUÑA DEL CONDE, BURGOS) Hall. Apareció en 1933, durante las excavaciones que efectuó B. Taracena entre 1932 y 1935 en la casa número 1 (el llamado palacio romano de Clunia, según la terminología de Taracena) (1), dentro de la habitación 35. El tesorillo se compone de 32 numismas a flor de cuño.

Inv. En la primera noticia, dada por Taracena (1) se muestra una composición que difiere de la presentada por Gurt Esparraguera (2):

Taracena: 1 ejemplar de Aureliano

2 ejemplares de Numeriano 
Gurt: $\quad 2$ ejemplares de Aureliano

1 ejemplares de Numeriano

(cuadro al final del artículo)

Ult. Num.

Emperador: Magna Urbica (radiado reformado).

A/ MAGN VRBICA AVG.

R/ VENV S VI CTRIX, - -//KAS.

Ceca: Roma, 284-285 d.C.

Peso. Módulo: 3,02 gr., 24,5 mm.

Ref: RIC V-2, 343.

Ref. (1) TARACENA, B., 1946: «El palacio romano de Clunia», AEA 19, 43; (2) GURT, J.M., 1985: Clunia III. Hallazgos monetarios. La romanización de la Meseta Norte a través de la circulación monetaria en la ciudad de Clunia, EAE 145, 145-151; PALOL, P. DE, 1974: «Clunia 1974», Memòria del Institut d'Arqueologia i Prehistòria de la Universitat de Barcelona, 43; PALOL, P. DE, 1978: «Clunia 1978. Noves dades arqueológiques sobre el darrers segles de Clunia», Memòria del Institut d'Arqueologia i Prehistòria de la Universitat de Barcelona.

\section{(87) [18] EL GORDO (CÁCERES)}

Hall. La única información disponible es que se descubrió en 1950, siendo casi todos los numismas de Diocleciano y Maximiano, presentando un magnífico estado de conservación.

Ref. CALLEJO SERRANO, C., 1957: La colección monetaria del Museo de Cáceres, Cáceres, 5.

\section{(88) [8] LINARES (JAÉN)}

Hall. Tesorillo formado por 25.000 ejemplares, comprendidos entre Galieno y Diocleciano, de cronología parecida al tesorillo de Sevilla (n ${ }^{\circ}$ 92).

Ref. BALIL, A., 1957: «Las invasiones germánicas en Hispania durante la segunda mitad del siglo III d.C.», CTEEHAR, 9, 143.

\section{(89) [--] COIMBRA (PORTUGAL)}

Hall. Fue descubierto en la región de Coimbra, sin especificar, en 1977. Se desconoce el número total de numismas que constituían el tesorillo, pudiéndose estudiar solamente 79 ejemplares.

Inv. (al final del artículo)

\section{Ult. Num.}

Emperador: Diocleciano (radiado reformado).

A/ IMP DIOCLE TIANVS AVG.

R/ IOVI CON SERVAT AVGG. - -//XXI

Ceca: Roma, 292 d.C.

Peso. Módulo: 4,11 gr., 22,5/24,8 mm.

Ref: RIC , 166.

Ref. SALGADO DA ROCHA, M.F., 1979: «Alguns antoni- niani e aureliani de um tesouro da regiao de Coimbra», Nummus, 2 Serie, Vol. 2, 73-86.

\section{(90) [29] OHIMBRA (GALICIA)}

Hall. En el lugar de Ohimbra, en Galicia, junto a la frontera de Portugal, un labrador al levantar una piedra se encontró debajo 400 monedas de oro finísimo, con anversos y reversos de Diana, Diocleciano, Maximiano y otros emperadores romanos. Su hallador los vendió en el mercado, en 1744.

Ref. ALMEIDA, L.F., 1965: «Duas noticias sobre achados de moedas romanas en Tras-os-Montes no século XVIII», Conimbriga 4, 106; L. Montez Mattoso. Folheto de Lisboa, $\mathrm{n}^{\circ}$ 33, 15-Agosto-1744.

\section{(91) [52] SUR DE ESPAÑA}

Hall. Hallado en el Sur de España, en fecha y lugar indeterminados.

La composición general del hallazgo es imposible de determinar, posiblemente superara el millar de ejemplares de los que Guadán (1) vió unos 500 a flor de cuño o con muy buena conservación.

Ult. Num. No se describe, aunque se apunta que pertenece a Diocleciano siendo anterior a la reforma de este emperador.

Ref. GUADAN, A.M., 1964: «Acerca de los antoninianos de Aureliano de un hallazgos reciente», Estudios de Numismática Romana, Barcelona, 37-45.

Inv. Personalmente Guadán estudió unos 400 ejemplares, estando representados los siguientes emperadores:

\begin{tabular}{|l|c|}
\hline \multicolumn{1}{|c|}{ Emperador } & Cronología \\
\hline Claudio II & $268-270$ \\
\hline Aureliano* & $270-275$ \\
\hline Tacito & $275-276$ \\
\hline Floriano & 276 \\
\hline Probo** & $276-282$ \\
\hline Caro & $282-283$ \\
\hline Numeriano & $283-284$ \\
\hline Carino & $283-285$ \\
\hline Diocleciano & $284-305$ \\
\hline
\end{tabular}

(k): 80 ejemplares, de ellos 14 acuñados en Roma. (**): 200 ejemplares

\section{(92) [2] SEVILLA}

Hall. Se descubrió en Sevilla o en sus alrededores. Está compuesto por 691 numismas. No constan más datos. 
Inv. Sólo se especifican los emperadores y el total de numismas que se les atribuyen, sin precisar las cecas de emisión o cualquier otro dato.

\begin{tabular}{|l|c|c|c|}
\hline Emperador & Cronología & Total & $\%$ \\
\hline Galieno & $253-268$ & 47 & 6,80 \\
\hline Postumo & $260-268$ & 1 & 0,15 \\
\hline Claudio II & $268-270$ & 62 & 8,97 \\
\hline Quintilo & 270 & 5 & 0,72 \\
\hline Aureliano & $270-275$ & 95 & 13,75 \\
\hline Severina & & 6 & 0,87 \\
\hline Tetrico & $270-274$ & 2 & 0,29 \\
\hline Tacito & $275-276$ & 4 & 0,58 \\
\hline Floriano & 276 & 1 & 0,15 \\
\hline Probo & $276-282$ & 293 & 42,40 \\
\hline Caro & $282-283$ & 18 & 2,60 \\
\hline Carino & $283-285$ & 43 & 6,22 \\
\hline Magna Urbica & & 2 & 0,29 \\
\hline Nigriniano (Divvs) & & 1 & 0,15 \\
\hline Numeriano & $296-305$ & 35 & 5,06 \\
\hline Diocleciano & & 34 & 4,92 \\
\hline Maximiano & & 691 & 100 \\
\hline & & 6,08 \\
\hline & & & \\
\hline & & & \\
\hline
\end{tabular}

Ult. Num. No se describe pero se apunta que pertenece al emperador Diocleciano, siendo anterior a su reforma monetaria.

Ref. BALIL, A., 1957: «Las invasiones germánicas en Hispania durante la segunda mitad del siglo III d.C.», CTEEHAR 9, 142 y nota 113.

\section{(93) [10] SANTO TOMÉ (ÚBEDA, JAÉN)}

Hall. En el pueblo de Santo Tomé (Jaén), a $20 \mathrm{~km}$. de Ubeda, se descubrió casualmente una vasija conteniendo un tesorillo de monedas bajoimperiales, el conjunto superaba los 4000 ejemplares que pasaron rápidamente al comercio. El hallazgo tuvo lugar en 1957.

Mateu y Llopis (1) presenta la estadística de 161 ejemplares que pudo conocer, más la descripción de otros 5 , lo que hace un total de 166 numismas.

\begin{tabular}{|l|c|c|c|}
\hline Emperador & Cronología & Total & $\%$ \\
\hline Salonino & $258-260$ & 1 & 0,60 \\
\hline Aureliano & $270-275$ & 6 & 3,61 \\
\hline Severina & & 3 & 1,81 \\
\hline Tacito & $275-276$ & 4 & 2,41 \\
\hline Floriano & 276 & 4 & 2,41 \\
\hline Probo & $276-282$ & 13 & 7,83 \\
\hline Caro & $282-283$ & 19 & 11,44 \\
\hline Numeriano & $283-284$ & 16 & 9,64 \\
\hline Carino & $283-285$ & 47 & 28,32 \\
\hline Magna Urbica & & 1 & 0,60 \\
\hline Nigriniano & & 1 & 0,60 \\
\hline Diocleciano & $284-305$ & 19 & 11,44 \\
\hline Maximiano Hercules & $286-310$ & 11 & 6,63 \\
\hline Constancio Cloro & $292-306$ & 21 & 12,66 \\
\hline & TOTAL & 166 & 100 \\
\hline
\end{tabular}

Ult. Num. No se describe, el tesorillo podría pertenecer al s. IV d.C. dado que los últimoss emperadores reprentados en el conjunto prolongan su reinado en el primer decenio de este siglo.

Ref. MATEU Y LLOPIS, F., 1958: «Hallazgos Monetarios $16 », \mathrm{NH}, 7,181 \mathrm{n}^{\circ} 982$.

Por último debemos reseñar la existencia de dos posibles tesorillos en Sevilla y Evora (Portugal) según las noticias reseñadas por BOST,J.-P., CAMPO, M., COLLS, D., GUERRERO, V., MAYET, F., 1992: L'Epave Cabrera III (Majorque), París. 102-103 nota 9 y 104 .:

«Deux autres lots pourraient avoir appartenu à des trésors. Le premier est douteux, le second est vraisemblable. Il s'agit d'abord de 34 sesterces conservés au médaillier de 1'Université de Séville (de Caracalla à Dèce), dont nous devons la connaissance à l'aimable concours de F. Chaves. Le second ensemble se compose de 15 Sévère Alexandre et de 13 Gordien III «trouvés dans les fouilles de l'ancien couvent des Dominicains à Évora», selon une note conservée avec les monnaies dans le musée de cette ville».

Así como la existencia de un tercero hallado en los alrededores de Sevilla y puesto en ventas en Bruselas. Se trataría de un conjunto de 87 monedas del s. III d.C. de las que un 80\% son Divo Claudio. Ref.: SEVERS, L.; 1995: "A propos d'un petit lot de monnaies romains provenant de la région de Seville (Espagne)". CENB 32, 79-89. NL 137, 1997, 0239. 
«EXCLUSIONES DE LA RELACIÓN DE PEREIRA ET ALII»

\section{(1*) [7] JAÉN}

Hall. Según Mateu y Llopis (1):

«919. Linares. Lote de denarios de Galieno hallado en un tiesto. Pasaron al comercio en 1957.»

Pero, el mismo Mateu y Llopis corrige está información (2):

«919.Linares. Corrigenda. Este hallazgo, más identificado ahora, corresponde al número 982. Santo Tomé (Ubeda, Jaén).»

Ref. (1) MATEU Y LLOPIS, F., 1957: «Hallazgos Monetarios 15», NH 6, 73, no 919; (2) MATEU Y LLOPIS, F., 1958: «Hallazgos Monetarios 16», NH 7, 185. n 919. Corrigenda.

\section{(2*) [12] TOYA (JAÉN)}

Hall. Creemos que se trata del mismo tesorillo que el denominado tesorillo de Peal del Becerro, número 11 de la lista de Pereira et alii.

Las razones de la identificación están enumeradas en el apartado correspondiente a este tesorillo en nuestra lista.

Ref. RAMOS MARÍN, L.: «Monedas romanas del siglo III d. de J.C. halladas en el campo de Tugia (Toya, Jaén), Segunda Exposición Nacional de Numismática e Internacional de Medallas, Madrid, 1951. Citado en NH 1, 1952, 269.

\section{(3*) [24] CASTELO DE NUMAO (CON. VILA NOVA DE} FOZ COA., GUARDA, PORTUGAL)

Hall. En una exposición numismática realizada en Guarda, Portugal, en 1954, se presentaron una «quantidade de antoninianos provenientes do Castelo de Numao» (1) que parecen tener relación con una colección de 164 ejemplares procedentes de uno o más hallazgos efectuados en Numao o en Freixoso de Numao existentes en el Museo Regional de Guarda.

Una parte de los que Hipólito (2) pudo ver presentaban dificultades para su identificación debido a su mal estado, deficiente manufactura, descentrado de los cuños, cortes en las leyendas, etc. Debido a ello cree que pertenecen a un solo depósito, pero es imposible saber el origen exacto de la totalidad de los numismas.

Solamente se pudieron identificar los siguientes numismas: (cuadro columna de la derecha)

Además de ejemplares de Constantino I (306-337), Dalmacio (335-337), Constante (337-350), Constantino II (337-340) y Magnentio (306-312).

Por tanto, este tesorillo pertenece al siglo IV.

Ref. (1) VASCO RODRÍGUEZ, 1954: «Noticia sobre a primera exposiçao numismática de Guarda, Nummus, Vol. $2, \mathrm{n}^{\circ}$ 7, 205; (2) CASTRO HIPÓLITO, M., 1960-1961: «Dos tesou-

\begin{tabular}{|l|c|c|}
\hline Emperador & Cronología & Total \\
\hline Valeriano I & $253-260$ & 1 \\
\hline Mariniana & & 1 \\
\hline Galieno & $253-260$ & 21 \\
\hline Salonina & & 1 \\
\hline Claudio II & $268-270$ & 13 \\
\hline Tetrico I ó II & $271-274$ & 1 \\
\hline Probo & $276-282$ & 2 \\
\hline Numeriano & $283-284$ & 2 \\
\hline Diocleciano & $284-305$ & 2 \\
\hline Maximiano & $286-305$ & 2 \\
\hline Licinio I & $308-324$ & 3 \\
\hline
\end{tabular}

ros de moedas romanas em Portugal», Conimbriga 2/3, 56-57, $\mathrm{n}^{\circ} 76$.

\section{(4*) [27] BRAGA (PORTUGAL)}

Hall. Según la referencia periodística (1) recogida por L.F. Almeida (2) se trata de más de 300 monedas de oro de igual antiguiedad que las halladas en Ohimbra, se encontraron en el territorio de Braga y fueron vendidas en el mercado de Oporto, en 1744.

Por su parte, M. de Castro Hipólito (3), haciéndose eco de otra noticia periodística (4) del mismo año, transcribe los siguientes datos:

"No territorio de cidade de Braga se descobriram perto de trezentas moedas de ouro do tamanho de um tostao portugués com o peso de duas oitavas cada uma, que segundo a asseveraçao dos ourives tocam 24 quilates, e todas tao bem conservadas, como se agora saissem do cunho, no qual se admira a última perfeiçao romana.

Sao de vários imperadores antigos, como Nero, Galba, Vitelio, Vespasiano, Tito, Domiciano, Nerva, Trajano, Adriano, Antonino Pio, Marco Aurelio, e também de Lucio Vero, Faustina e Plautino; muitas dobradas destos mesmos imperadores, e com diversas empresas no reverso. Logo um negociante inglês comprou no Porto a um ouvires de Braga duzentas que mandou para Inglaterra a engrandecer os museus dos curiosos daquela naçao».

Debido a la coincidencia existente en la mayoría de los datos: lugar de hallazgo, fecha, tipo de numismas, cantidad, etc. nos hacen pensar que se trata del mismo tesorillo, y por tanto, pertenecería al siglo II d.C.

Ref. (1) Folheto de Lisboa, $\mathrm{n}^{\circ}$ 33, 15-agosto-1744; (2) ALMEIDA, L.F. DE, 1965: «Duas noticias sobre achados de 
moedas romanas en Tras-os-Montes no século XVIII», Conimbriga 4, 106; (3) Gaceta de Lisboa, 7-julio-1744; (4) CASTRO HIPÓLITO, M. DE, 1960-1961: «Dos tesouros de moedas romanas em Portugal, Conimbriga 2/3, 19, $n^{\circ} 14$.

\section{(5*) [35] SAN TIRSO DE ABRES (ASTURIAS)}

Hall. Se describen 3 radiados hallados en San Tirso de Abres (Asturias), en circunstancias desconocidas. Aunque en Pereira et alii aparezcan como tesorillo, la realidad es que esto no se puede afirmar pues en la bibliografía no se dice nada al respecto:

«... reproducimos los reversos de 3 antoninianos que llegaron a nuestro poder...» (1).

Inv.

\begin{tabular}{|l|c|c|c|c|}
\hline Emperador & Cronol. & Ceca & Reverso & Refer. \\
\hline Gordiano III & $241-243$ & Roma & LAETITIA AVG & RIC 86 \\
\hline Filipo I & $244-249$ & Roma & ROMAE AETERNAE & RIC 44 \\
\hline T. Decio & 249 & Roma & ADVENTVS AVG & RIC 11 \\
\hline
\end{tabular}

Ref. (1) AULLÓ COSTILLA, M., 1955: «Contribución al conocimiento del tesorillo de monedas de Algara (La Coruña) y noticia sobre un hallazgo en San Tirso de Abres (Oviedo)», Numisma 17, 10 y 19-20; FERNÁNDEZ OCHOA, C., 1977 : «La numismática romana de Asturias», CuPAUM 4, 139 y 163.

\section{(6*) [36] FOXO-TAMEZA (ASTURIAS)}

Inv.

\begin{tabular}{|l|c|c|}
\hline Emperador & Cronología & Total \\
\hline Diocleciano & $284-305$ & 38 \\
\hline Maximiano & $286-305$ & 50 \\
\hline Constancio Cloro & $292-306$ & 51 \\
\hline Galerio Maximiano & $292-311$ & 26 \\
\hline Maximiano Daza & $305-313$ & 3 \\
\hline Magnentio & $306-312$ & 1 \\
\hline Constantino & $306-337$ & 4 \\
\hline
\end{tabular}

Hall. Pereira et alii lo incluyen, con el $\mathrm{n}^{\circ} 36$, entre los tesorillos del siglo III, pero en realidad corresponde ya al siglo IV, su último numisma pertenece al emperador Constantino (306337).
Fue hallado en 1917, en Foxó, concejo de Tameza (Asturias), en el lugar denominado Canto de La Collada, dentro de una «cazuela». El número de ejemplares superaba el millar originalmente, de ellos solamente se han podido estudiar 173.

Ref. DIEGO SANTOS, F., 1966: «Tesorillo de monedas romanas halladas en Foxó-Tameza», Archivum T. 16, 293313; FERNÁNDEZ OCHOA, C.,1977: «La numismática romana de Asturias», CuPAUM 4, 134, 154-158.

\section{(7*) [38] PALENCIA}

Hall. Pereira et alii asignan a esta ciudad un tesorillo del siglo III d.C. ( $\left.n^{\circ} 38\right)$ basándose en una noticia de P. de Palol: «(depósitos monetarios)... del convento de las Madres Filipenses de la ciudad de Palencia» (1).

Realmente existe un depósito monetal hallado en el convento de las Madres Filipenses de Palencia, pero no pertence al siglo III d.C. sino al II a.C.. Se trata de un conjunto de joyas de oro y plata (torques, brazaletes, pendientes, fíbulas, etc.) y 51 denarios ibéricos del jinete lancero. Parte de este tesoro ingresó en 1956 en el M.A.N. (2). Fue hallado debajo de los niveles romanos, enterrado dentro de vasijas cerámicas, cuando se hacían las obras del nuevo convento.

Ref. (1) PALOL, P. DE, 1963: «El mosaico de tema oceánico de la villa romana del Cercado de San Isidro», BSEAA 29, 34; (2) BALMASEDA, L.J., 1984: «El territorio palentino en época romana». Historia de Palencia, vol. I. Edades Antigua y Media, Palencia, 83.

\section{(8*) [40] VERA DEL BIDASOA (GUIPÚZCOA)}

Hall. En la lista de tesorillos del siglo III d.C. aparecida en Pereira et alii, con el $n^{\circ} 40$ se da noticia de un tesorillo aparecido en Vera del Bidasoa. Revisada la bibliografía, las únicas noticias sobre tesorillos en Vera del Bidasoa son las siguientes:

«(20) Según ha tenido la amabilidad de participarme el señor Caro Baroja, en Vera se descubrió hace ya bastantes años un escondrijo a orillas del río con unas 200 monedas de bronce, que desgraciadamente se dispersaron. Tuvo ocasión de examinar unas 25, de los siglos I y II" (1).

«Algunas de las monedas imperiales (por lo general bien conservadas) son restos perdidos del tesoro ingente que afloró, según se dice, al abrir la zanja por la que discurre el canal que alimenta una de las centrales eléctricas de Vera de Bidasoa. Sucedió en los primeros años del siglo actual»(2).

Las únicas monedas, pertenecientes a este tesorillo, descritas pertenecen al monetario del Colegio de Lecároz(2) (cuadro en página siguiente):

Por tanto, se trataría de un tesorillo perteneciente al Siglo II d.C.

Ref. (1) MICHELENA, L., 1956: «Guipúzcoa en la época romana, BRSVAP, Año 12, Cuad. 1, 79, nota 20.; (2) ZUDAI- 


\begin{tabular}{|l|c|c|}
\hline Emperador & Cronología & Total \\
\hline Claudio & $41-54$ & 2 \\
\hline Neron & $54-68$ & 3 \\
\hline Domiciano & $81-96$ & 1 \\
\hline Nerva & $96-98$ & 1 \\
\hline Adriano & $117-138$ & 3 \\
\hline Antonino Pío & I58-161 & 3 \\
\hline
\end{tabular}

cas», Bol. Arq. 57-60, 11, nota 15; HIERNARD, J., 1978: «Monedas del s. III en el Museo Arqueológico Provincial de Tarragona», ANum. 8, 97-133; HIERNARD, J., 1978: «Recherches numismatiques sur Tarragone au IIIeme siécle aprés JesusChrist», Numisma 28, $\mathrm{n}^{\circ}$ 150-151, 307-321.

\section{(10*) [--] DOÑA PALLA (PRAVIA, ASTURIAS)}

Hall. Este tesorillo lo incluimos en las exclusiones pese a no estar presente en la lista de Pereira et alii debido a que son varios los autores que lo consideran como un tesorillo del siglo III d.C.

Fue hallado en el castro de Doña Palla, durante las obras

RE, E., 1979: «Monetario del Colegio de Lecároz», PV, $\mathrm{n}^{\circ}$ 154-155, 41-49.

\section{$(9 *)$ [46] TARRAGONA-1883}

Hall. Monedas descubiertas dentro de una casa romana de forma dispersa, durante la construcción de la plaza de toros de Tarragona en 1883.

\begin{tabular}{|c|c|c|c|c|}
\hline Emperador & Cronol. & Ceca & Tipo & Total \\
\hline Caracalla & & & Peq. Bronce & 1 \\
\hline Gordiano III & $\begin{array}{c}241 \\
242 \\
241-243 \\
242-244\end{array}$ & $\begin{array}{l}\text { Roma } \\
\text { Roma } \\
\text { Roma } \\
\text { Roma }\end{array}$ & $\begin{array}{l}\text { Denario } \\
\text { Radiado } \\
\text { Radiado } \\
\text { Radiado }\end{array}$ & $\begin{array}{l}1 \\
1 \\
1 \\
1\end{array}$ \\
\hline Filipo I & $244-249$ & Roma & Radiados & 3 \\
\hline Filipo II & $244-246$ & Roma & Radiado & 1 \\
\hline T. Decio & $249-251$ & Roma & Radiado & 1 \\
\hline Etruscilla & & Roma & Radiado & 1 \\
\hline T. Galo & $251-253$ & Antio. & Radiado & 1 \\
\hline Valeriano & $\begin{array}{l}254 \\
254 \\
255\end{array}$ & $\begin{array}{l}\text { Roma } \\
\text { Antio. } \\
\text { Sam. }\end{array}$ & $\begin{array}{l}\text { Radiado } \\
\text { Radiado } \\
\text { Radiado }\end{array}$ & $\begin{array}{l}1 \\
1 \\
1\end{array}$ \\
\hline Galieno & $\begin{array}{l}254-256 \\
257-258\end{array}$ & $\begin{array}{l}\text { Roma } \\
\text { Vim. }\end{array}$ & $\begin{array}{l}\text { Radiado } \\
\text { Radiado }\end{array}$ & 1 \\
\hline Salonina & 256 & Vim. & Radiado & 1 \\
\hline
\end{tabular}

Han sido varios los autores que lo han considerado como un tesorillo perteneciente al siglo III d.C., pero el conjunto monetal incluye 18 numismas del siglo III y otros 6 pertenecientes al siglo IV d.C.

La distribución de los ejemplares por emperadores, del siglo III d.C., es la que se refleja en el cuadro anterior.

Ref. SÁNCHEZ REAL, J.,1957: «Las invasiones germáni-

del ferrocarril Ferrol-Gijón, (concejo de Pravia, Asturias).

Su composición denota dos series de numismas bien diferenciadas cronológicamente:

Serie romano-republicana:

-3 denarios acuñados por Lucius Cupiennus, en la ceca de Roma, hacia el año 164 a.C.

Serie romano-imperial:

-3 denarios?:

Ult. Num.

\begin{tabular}{|l|c|c|c|}
\hline Emperador & Cronología & Ceca & Total \\
\hline Neron & $55-60$ & Roma & 1 \\
\hline Trajano & $104-110$ & Roma & 1 \\
\hline Postumo & 264 & Colonia & 1 \\
\hline
\end{tabular}

Emperador: Póstumo (denario).

A/ POSTVMVS AVG. Cabeza barbada con casco a izquierda. R/ VIC GERM PM TR P V COS III PP. Póstumo de pie a izquierda, llevando un globo y un asta, coronado.

Ceca: Lugdunum, 264 d.C.

Peso. Módulo: 3,75 gr., $19 \mathrm{~mm}$.

Ref: RIC V-2, 345, 97.

Las evidentes lagunas cronológicas y la nula homogeneidad del conjunto nos hacen dudar de que constituya un tesorillo, dudas que se acrecientan al no poseer ningún dato sobre si se hallaron juntas o por el contrario, efectivamente, formaban un conjunto monetal.

Ref. MALLO VIESCA, M., 1969: «Tesorillo de denarios de Doña Palla (Pravia)», Archivum T. 19, 93-97; FERNÁNDEZ OCHOA, C., 1977: «La numismática romana de Asturias», CuPAUM 4, 134, 152-153.

\section{(11*) [--] NUMARIO UNIVERSIDAD DE VALENCIA-1}

Hall.R. Arroyo Ilera, en su estudio sobre el numario de la Universidad de Valencia propone la existencia de tres tesorillos del siglo III en su composición. Este primer conjunto 
monetal, compuesto por radiados, es propuesto en base al paralelismo, que según el citado autor, existe entre el contenido del tesorillo de Altafulla y un grupo de monedas del s. III d.C. existente en el referido Numario:

\begin{tabular}{|l|c|}
\hline \multicolumn{1}{|c|}{ Emperador } & Cronología \\
\hline Gordiano III & 17 \\
\hline Filipo I & 14 \\
\hline Ota. Severa & 1 \\
\hline T. Decio & 5 \\
\hline Her. Etrusco & 2 \\
\hline T. Galo & 2 \\
\hline Volusiano & 1 \\
\hline Salonina & 25 \\
\hline Salonino & 4 \\
\hline Valeriano & 5 \\
\hline TOTAL & 76 \\
\hline
\end{tabular}

Se desconocen totalmente las circunstancias por las que las citadas monedas llegaron al Numario, el paralelismo en la composición no prueba o indica su existencia como depósito monetal, máxime cuando sólo se conoce 1/3 ó 1/4 del total hallado en Altafulla, por tanto la descartamos totalmente.

Ref. ARROYO ILERA, R., 1984: El Numario de la Universidad de Valencia, Valencia, 428-429.

\section{(12*) [--] NUMARIO UNIVERSIDAD DE VALENCIA-2}

Hall. El segundo de los supuestos tesorillos del Numario de la Universidad de Valencia está compuesto por 125 sestercios, su existencia se sustenta en la presencia de una pátina de color blanco que todos ellos presentan debida a la tierra del yacimiento del cual proceden. $\mathrm{R}$. Arroyo basándose en este tipo de tierra localiza su procedencia en la zona límite entre el sur de la provincia de Valencia y el norte de la de Alicante. Su composición es la reflejada en el cuadro siguiente.

Como en el caso anterior se desconoce cualquier detalle sobre su hallazgo y su procedencia. Las monedas en cuestión podrían pertenecer a una o varias excavaciones en yacimientos que presenten este tipo de tierra (Albarís). Por tanto, y con los datos que poseemos debemos descartar a este conjunto de monedas como integrantes de un tesorillo.

Ref. ARROYO ILERA, R., 1984: El Numario de la Universidad de Valencia, Valencia, 429.

\begin{tabular}{|l|c|}
\hline \multicolumn{1}{|c|}{ Emperador } & Cronología \\
\hline Alejandro Severo & 30 \\
\hline Iulia Mamaea & 10 \\
\hline Maximino I & 11 \\
\hline Maximo & 1 \\
\hline Gordiano I & 2 \\
\hline Gordiano III & 40 \\
\hline Filipo I & 16 \\
\hline T. Decio & 27 \\
\hline T. Galo & 8 \\
\hline TOTAL & 125 \\
\hline
\end{tabular}

(13*) [--] NUMARIO UNIVERSIDAD DE VALENCIA-3

Hall. R. Arroyo basándose en el número de piezas repetidas y el tipo de pátina identifica un tercer tesorillo compuesto por 143 radiados de Galieno y Claudio II exclusivamente: de Galieno 107 monedas y de Claudio II 36.

$\mathrm{Al}$ igual que en los dos conjuntos anteriores desconocemos cualquier dato sobre su procedencia y forma de hallazgo lo que unido al tipo de argumentos esgrimidos en defensa de su existencia nos hace tener que descartarlo como tesorillo numismático.

Ref. ARROYO ILERA, R., 1984: El Numario de la Universidad de Valencia, Valencia, 429-430.

\section{CARACTERÍSTICAS DE LOS TESORILLOS PENINSULARES DEL SIGLO III D.C.}

Tomando como modelo la encuesta realizada por A.S.Robertson ${ }^{3}$ sobre diversos aspectos de los tesorillos numismáticos de época romana hallados en el Reino Unido, hemos realizado un análisis semejante aunque ciñéndonos exclusivamente a los hallados en la Península y que pertenezcan al siglo III d.C.. Para ello hemos utilizado los 93 tesorillos recogidos en el presente artículo.

\section{a) Composición}

Nos encontramos ante tesorillos o depósitos monetales de composición uniforme y de composición mixta, en cuanto al tipo de metal:

ROBERTSON, A.S., 1974: «Romano-british coin hoards: their numismatic, archaelogiacal and historical signifiance», BAR Supp. Ser. 1, 4, 12-36. 
* Oro: son escasos los tesorillos formados por áureos exclusivamente $\left(\mathrm{n}^{\circ} 3\right.$ : Lugo-1, $\mathrm{n}^{\circ}$ 4: Barroca de Laje y $\mathrm{n}^{\circ} 90$ : Ohimbra). En cuanto al número de ejemplares que los componen también existen grandes diferencias.

Tesorillos mixtos, en cuya composición entren áureos y otras monedas, sólamente tenemos dos: $\mathrm{n}^{\circ}$ 5: Coca (áureos/denarios) y $\mathrm{n}^{\circ}$ 50: Serra do Condao (áureos/radiados).

Entre los áureos destaca la fuerte presencia de ejemplares pertenecientes a los siglos I-II d.C., con residuos de monedas del siglo I d.C. post-reforma de Nerón. Observamos la escasa presencia de monedas del siglo III d.C., estando solamente presentes algunas del primer tercio del siglo y 4 áureos de Galieno. Esta distribución se corresponde con los estudios sobre circulación de las monedas de oro en el siglo III d.C. ${ }^{4}$

* Plata: a este metal, en sus dos versiones numismáticas (denario y radiado más radiado reformado), corresponde el mayor número de tesorillos o depósitos de este período, siendo el radiado la moneda que predomina, de acorde con su papel dentro del sistema monetario de la época.

Dentro de los tesorillos mixtos, a los ya citados más arriba hemos de sumar los compuestos por radiados/sestercios: $\mathrm{n}^{\circ}$ 41 Mas d'Aragó y n ${ }^{\circ} 46$ D'Eula; radiados/sestercios/ases: $n^{\circ} 74$ Clunia-3; denarios/ases: $\mathrm{n}^{\circ} 56$ provincia de Pontevedra y radiados/denarios/sestercios/ases: $\mathrm{n}^{\circ} 79$ Clunia-2.

En la moneda de plata, la mayoría de denarios atesorados pertenecen al siglo II d.C. y en menor medida al siglo I d.C.. Su evolución corre pareja a la de su acuñación durante este siglo.

En cuanto a los radiados, aparecen con asiduidad a partir de Gordiano III, aunque existen dos radiados de Caracalla en el tesorillo $n^{\circ} 43$ de Algara (La Coruña).

Se observan dos cortes numismáticos:

+ Para la circulación monetaria del siglo III d.C. en general, vid.: CALLU, J.P., 1969: La politique monetaire des empereurs romains de 238 á 311. París.

CORBIER, M., 1980: «Remarques sur la circulation monetáire au III siècle». BSFN, diciembre, 793-797.

BUTTREY, T.V., 1972: «A Hoard of sestertii from Bordeaux and the problems of bronze circulation in the third century A.D.». ANSMUN, 18, 33-58.

LE GENTILHOME, P., 1943: «Les Aurei du trésor decóuvert a Rennes au 1774. Essai sur la circulatión de la monnaie dór au III siècle». RN, 5, 7, 11-33.

Para el caso del Península Ibérica:

SAGREDO SAN EUSTAQUIO, L., 1983: «La circulación y desaparición del bronce en la Hispania romana (193-285)», Estudios en Homenaje a Don Claudio Sánchez Albornoz, Vol. I, Buenos Aires, 173-222. IDEM, 1986: «La circulación del áureo en la Hispania del siglo III d.C.», Conimbriga, 25, 89-98. IDEM, 1988: «Circulación monetaria de la plata en la Hispania del Siglo III d.C.», Espacio, Tiempo y Forma, Serie II, Historia Antigua, Tomo I, 341-362. -si las monedas terminales pertenecen a Galieno o Claudio II, las primeras monedas del tesorillo son de Gordiano III.

-sin embargo, a partir de Claudio II-Aureliano, las monedas por las que comienzan los tesorillos pertenecerán a Galieno y se datarán alrededor del año 260 d.C.

Dentro de las monedas presentes en estos depósitos o tesorillos, hallaremos también radiados reformados y Divo Claudio aunque no en cantidades importantes. La moneda del Imperio Galo está escasamente representada: más de cien ejemplares de Póstumo, 16 de Victorino y 19 de los Tétricos, de ellas varias de imitación. También nos encontramos con un cuarto de Aurelianos.

* Bronce-vellón: el principal valor de este metal es el sestercio, con 10 tesorillos como único componente, apareciendo también en tesorillos mixtos con denarios y radiados, pero nunca con áureos. En cuanto a las monedas de bronce, los sestercios son mayoría. Sus acuñaciones pertenecen al siglo IIprimera mitad del siglo III d.C., aunque su período de circulación hace que resulte casi imposible fijar su cronología de pérdida u ocultación con un mínimo de aproximación.

Existen también ases del siglo I d.C. pero son meros representantes de una circulación residual, perteneciendo en su mayoría a conjuntos formados por la pérdida de monederos o bolsas de dinero.

Por último, existe un número elevado de tesorillos (más de 20) de los cuales desconocemos su tipo de monedas debido a las deficiencias que presentan las noticias que de ellos existen.

\section{b) Número de monedas.}

Dependiendo del límite que tomemos para clasificar un tesorillo o depósito monetal como grande o pequeño (500 ó 1.000 monedas), la distribución sería como se refleja en el cuadro de la página siguiente:

Tres son los hechos que resaltan:

- la gran cantidad de tesorillos de los que se desconoce su número original de monedas.

- la fuerte presencia de pequeños tesorillos de menos de 100 ejemplares.

- la débil representación de grandes tesorillos de más de 10.000 ejemplares.

En cuanto al número de tesorillos, hemos de apuntar que los recogidos hasta el año 1983 para el siglo IV d.C. superan a los del siglo III d.C.: 100 tesorillos, esta cifra es provisional, con su actualización se incrementarát.

\footnotetext{
${ }^{5}$ Sobre este tipo de monedas vid. BOON, G.C., 1978: «Les monnaies fausses de l'époque impériale et la valeur des espéces courantes», Colloq. Les Devaluations a Rome, Roma, 99-106.

' CALDERA DE CASTRO, M.P., VELÁZQUEZ, A., 1983: «El tesorillo de 'Torrecaños' Guareña (Badajoz)», Augusta Emérita I, Madrid, 175 ss.
} 


\begin{tabular}{|l|c|}
\hline No ejemplares & $\mathrm{N}^{\mathrm{o}}$ tesorillos \\
\hline $1-50$ & 29 \\
\hline $50-100$ & 9 \\
\hline $100-500$ & 12 \\
\hline $500-1000$ & 8 \\
\hline $1000-5000$ & 8 \\
\hline $5000-10000$ & 5 \\
\hline+10000 & 20 \\
\hline Desconocidos & 93 \\
\hline TOTAL & 2 \\
\hline
\end{tabular}

\section{c) Lugares de hallazgo.}

Se pueden dividir en:

- campamentos militares: Petavonium

- ciudades: Conimbriga, Clunia, Cauca, Pollentia, Baelo, Portus Ilicitanus, Lucus Augusti, Vareia, etc.

- establecimientos rurales: Reus, Mas d'Aragó, Liédena, etc.

- parajes naturales no habitados: más de quince tesorillos.

- indeterminados: dieciocho tesorillos.

\section{d) Receptáculos.}

Predominan las distintas variedades de recipientes de barro: vasijas, ollas, ánforas, etc. En menor medida aparecen recipientes metálicos de hierro, cobre o bronce. Por último, son contados los hallados en recipientes hechos con material perecedero: ampollas de vidrio, arcas de madera, bolsas de tela, etc.

En cuanto a su forma, considerando sólo los ocultados con una finalidad, responden a dos tipos diferentes:

- los hallados en casas se sitúan en los lugares más dispares: en el suelo de la vivienda, en su desagüe, protegidos por tejas de rebordes, en recinto termal, etc.

- los hallados sin conexión con edificaciones habitadas: destaca la ocultación en muros, parajes naturales fácilmente reconocibles como grutas, cuevas, montes, playas, etc., normalmente con una señal que permita su rápida identificación: debajo de una losa, en una cista de piedras, oculto en una roca determinada, etc.

\section{e) Tipos especiales.}

Se pueden considerar como depósitos monetales especiales pues su formación responde a otros parámetros:

- accidente, caso del pecio $\mathrm{n}^{\circ} 27$ «Cabrera III»

- ofrendas rituales, caso del no 18 Sao Joao Baptista.

\section{f) Objetos asociados.}

Son muy pocos los objetos hallados en asociación con tesorillos o depósitos monetales:

$N^{\circ} 4$ : Barroca de Laje: un collar, un pendiente, cuatro anillos de oro y cuatro fragmentos de collares de plata.

$N^{\circ} 7$ : Torre Llauder: 188 anillas de bronce.

$\mathrm{N}^{\circ}$ 62: Quinta da Torre de Ares: anillos y piedras grabadas.

En definitiva, sus características se asemejan bastante a las extraidas del estudio de A.S. Robertson para el conjunto de los tesorillos o depósitos monetales romanos hallados en el Reino Unido.

Pero pese a todo lo anteriormente expuesto, creemos que la principal característica que presentan la casi totalidad de estos tesorillos peninsulares del siglo III d.C. es su deficiente publicación que hace que en la práctica la mayoría de ellos no sean utilizables para realizar estudios histórico-cronológicos basados en ellos.

CORRESPONDENCIAS DE LOS NÚMEROS DEL ARTÍCULO 59 CON LA LISTA DE TESORILLOS DEL S. III D.C. PUBLICADA POR PEREIRA et ali ${ }^{*}$

(Art.)[Pereira] Nombre

(1) [6] Granada

(2) [16] Valhascos (Santarem, Portugal)

(3) [31] Lugo-1

(4) [19] Borralheira (Barroca da Laje, Portugal)

(5) [--] Coca (Segovia)

(6) [--] Bolibar (Vizcaya)

(7) [--] Torre llauder (Mataró, Barcelona)

(8) [14] Arruda dos Vinhos (Lisboa, Portugal)

(9) [17] Polvarinho (Castelo Branco, portugal)

(10) [--] Domus "A" de Romeu (Sagunto, Valencia)

(11) [--] Petavonium (Sansueña, Zamora)

(12) [15] Sao Miguel (Santarem, Portugal)

(13) [50] Talamanca (Ibiza)

(14) [-- Cueva de la Zorra (Soscaño, Carranza, Vizcaya)

(15) [49] Valencia

(16) [-- El Masnou (Barcelona)

(17) [--] El Mirador (Denia, Alicante)

(18) [16 bis] Sao Joao Baptista, Monte Real (Leiria, Portugal)

(19) [-] Santa Pola (Alicante)

* PEREIRA, I., BOST, J.P., hIERNARD, J. 1974: Fouilles de Conimbriga III. Les monnaies. París, 323-324. 
(20) [-- Valeria (Valera, Cuenca)

(21) [--] Pollentia-l (L'Alcúdia, Mallorca)

(22) [--] Museo Diocesano de Mallorca

(23) [-- Los Torrejones (Yecla, Murcia)

(24) [--] Benicató (Nules, Castellón)

(25) [-- Lugo-2

(26) [--] Portugal-1967

(27) [--] Pecio "Cabrera III" (Puerto de Cabrera, Baleares)

(28) [--] Vilauba (Camós, Gerona)

(29) [--] Zona de Chantada (Orense)

(30) [-- Pollentia-3 (L'Alcudia, Mallorca)

(31) [33] Bares-1 (La Coruña)

(32) [34] Bares-2 (La Coruña)

(33) [--] Colección Cruixent (Barcelona)

(34) [3] Valverde del Camino (Huelva)

(35) [51] serra? (Portugal)

(36) [30] Pontevedra

(37) [-- Ecija (Sevilla)

(38) [-- Cerro de Judas, Llanos del Ciego (Cazorla, Jaén)

(39) [-- Baños de Rio Caldo (Orense)

(40) [25] Panoias (Distrito de Guarda o Braga, Portugal)

(41) [--] Mas d’Aragó (Cervera del Maestrat, Castellón)

(42) [48] Castellón de la Plana

(43) [32] Algara (La Coruña)

(44) [-] Honcalada (Vailadolid)

(45) [--] Vareia (Logroño)

(46) [--] D’Eula (Crevillente, Alicante)

(47) [44] Altafulla (Tarragona)

(48) [1] Jimena de la Frontera-1 (Cádiz)

(49) [45] Tarragona- 1888

(50) [21] Serera do Condao (Arganil, Portugal)

(51) [42] Sangüesa (Navarra)

(52) [-- Grisén (Zaragoza)

(53) [--] Rosas (Gerona)

(54) [--] Museo de la Porciúncula (Mallorca)

(55) [--] Museo de Artá (Mallorca)

(56) [-- ] Provincia de Pontevedra

(57) [--] Pollentia-2 (L'Alcúdia, Mallorca)

(58) [--] Belo (Bolonia, Cádiz)

(59) [--] Son Hereu-2 ( Lluchmajor, Mallorca)

(60) [37] Valsadornín (Palencia)

(61) [20] Aldeia das dez (Oliveira do Hospital, Portugal)

(62) [4] Quinta da Torre da Ares (Algarve, Portugal)

(63) [--] Terra Chá (Lugo)

(64) [-- Grandas de Salime (Asturias)
(65) [--] Son Hereu-1 (Lluchmajor, Mallorca)

(66) [47] Reus (Tarragona)

(67) [23] Conimbriga-D (Condeixa a Velha, Portugal)

(68) [43] Bárboles (Zaragoza)

(69) [41] Liédena (Navarra)

(70) [22] Conimbriga-B (Condeixa a Velha, Portugal)

(71) [--] Jimena de la Frontera-2 (Cádiz)

(72) [-- $]$ Vila Caiz (Amarante, Portugal)

(73) [-- Reguengo (Vila Pouca de Aguiar Portugal)

(74) [-- Clunia-3 (Coruña del Conde, Burgos)

(75) [5] Margem do Vascao (Beja, Portugal)

(76) [13] Borba ( o en su Región, Portugal)

(77) [-- Sierra Pitillos (Valdepeñas, Jaén)

(78) [28) Fragas do Piago (Montalegre, Portugal)

(79) [-- Clunia-2 (Coruña del Conde, Burgos)

(80) [29 bis] Santulhao (Bragança, Portugal)

(81) [26] Laje (Santo Tirso, Portugal)

(82) [11] Peal del Becerro (Jaén)

(83) [-- Monte do Cavaleiro (Algarve, Portugal)

(84) [9] Santa Elena (Jaén)

(85) [-- Chaves (Portugal)

(86) [39] Clunia-1 (Coruña del Conde, Burgos)

(87) [18] El Gordo (Cáceres)

(88) [8] Linares (Jaén)

(89) [--] Coimbra (Portugal)

(90) [29] Ohimbra (Galicia)

(91) [52] Sur de españa

(92) [2] Sevilla

(93) [10] Santo tomé (Úbeda, Jaén)

\section{EXCLUSIONES}

$\left(1^{*}\right)$ [ 7] Jaén

( $\left.2^{*}\right)[12]$ Toya (Jaén)

( $\left.3^{*}\right)$ [24] Castelo de Numao (Guarda, Portugal)

( $4^{*}$ [27] Braga (Portugal)

( $5^{*}$ [35] Santo Tirso de Abres (Asturias)

( $\left.6^{*}\right)[36]$ Foxó-Tamez (Asturias)

( $7 *)$ [38] Palencia

$\left(8^{*}\right)[40]$ Vera del Bidasoa (Guipúzcoa)

(9*)[46] Tarragona-1883

$\left(10^{*}\right)$ [--] Doña Palla (Pravia, Asturias)

$\left(11^{*}\right)[--]$ Numario Univeridad de Valencia-1 (Valencia)

$\left(12^{*}\right)[-]$ Numario Universidad de Valencia-2 (Valencia

$\left(13^{*}\right)$ [--] Numario Universidad de Valencia-3 (Valencia) 
Inv. (25) [--] Lugo-2

\begin{tabular}{|l|c|c|c|c|c|c|c|}
\hline Emperador & Cronol. & Rom & Ant & Med & Col & Total & $\%$ \\
\hline Heliogábalo & $218-222$ & 1 & & & & 1 & 2,13 \\
\hline Gordiano III & $238-244$ & 9 & & & & 9 & 19,14 \\
\hline Filipo I & $244-247$ & 1 & & & & 1 & 2,13 \\
\hline Filipo II & & 1 & & & & 1 & 2,13 \\
\hline Otac. Severa & & 1 & & & & 1 & 2,13 \\
\hline Tra. Decio & $249-251$ & 4 & & & & 4 & 8,51 \\
\hline H. Etrusco & & 1 & & & & 1 & 2,13 \\
\hline H. Etruscilla & & 1 & & & & 1 & 2,13 \\
\hline Treb. Galo & $251-253$ & 1 & 2 & 1 & & 4 & 8,51 \\
\hline Volusiano & & 4 & & & & 4 & 8,51 \\
\hline Emiliano & 253 & 1 & & & & 1 & 2,13 \\
\hline Valeriano I & $253-260$ & 9 & 2 & 3 & & 14 & 29,79 \\
\hline Valeriano II & $253-258$ & 1 & & & 1 & 5 & 10,64 \\
\hline & Divus & 2 & & & 1 & & \\
\hline & Total & 37 & 4 & 4 & 2 & 47 & \\
\hline & & 78,72 & 8,51 & 8,51 & 4,26 & & \\
\hline & & & & & & & \\
\hline
\end{tabular}

Inv. (29) [--] Zona de Chantada (Orense)

\begin{tabular}{|l|c|c|c|c|c|c|c|}
\hline Emperador & Cronol. & Rom & Lug & Med & Ant & Total & $\%$ \\
\hline Gordiano III & $241-243$ & 2 & & & & 2 & 4,08 \\
\hline Filipo I & $244-247$ & 5 & & & & 5 & 10,20 \\
\hline T. Decio & $249-251$ & 2 & & & & 2 & 4,08 \\
\hline H. Etruscilla & & 2 & & & & 2 & 4,08 \\
\hline T. Galo & $251-253$ & 1 & & & & 1 & 2,04 \\
\hline Volusiano & $251-253$ & 2 & & & & 2 & 4,08 \\
\hline Valeriano I & $253-260$ & 9 & 1 & & 2 & 12 & 24,48 \\
\hline Valeriano II & $254-255$ & 1 & & & & & \\
\hline Galieno & $253-260$ & 9 & & 1 & 1 & & \\
\hline Salonina & $260-268$ & 9 & & & & 20 & 40,81 \\
\hline & $253-268$ & 1 & & & & 1 & 2,04 \\
\hline & Total & 44 & 1 & 1 & 3 & 49 & 100 \\
\hline
\end{tabular}


Inv. (32) [34] Bares-2 (La Coruña)

\begin{tabular}{|c|c|c|c|c|c|c|c|}
\hline Emperador & Cronol. & Rom & Rorn o Med & Ant. & Ileg & Ind & Total \\
\hline Gordiano III & 242 & 1 & & & & & 1 \\
\hline T. Decio & $\begin{array}{c}249-251 \\
\text { Consecratio }\end{array}$ & & 1 & & 1 & & 2 \\
\hline Etruscilla & $249-251$ & 1 & & & & & 1 \\
\hline T. Gallo & $251-253$ & 2 & 1 & & & & 3 \\
\hline Volusiano & $251-253$ & 3 & & & 1 & & 4 \\
\hline Valeriano & $\begin{array}{c}254 \\
256-257 \\
257-259 \\
253-260\end{array}$ & $\begin{array}{l}2 \\
1\end{array}$ & & 1 & 3 & & 7 \\
\hline Galieno* & $253-268$ & & & & & 11 & 11 \\
\hline Salonina** & $253-268$ & & & & 4 & 8 & 12 \\
\hline \multirow[t]{2}{*}{ Salonino } & 256 & & & 1 & & & 1 \\
\hline & Total & 10 & 2 & 2 & 9 & 19 & 42 \\
\hline
\end{tabular}

(*) En los numismas pertenecientes a Galieno nos hemos encontrado con descripciones de reversos que no aparecen en el RIC y también con titulaturas del anverso que no tienen correspondencia con los reversos. Por todo ello las consideramos como de fecha y ceca indeterminada.

(**) De los 12 ejemplares pertenecientes a Salonina, 4 son ilegibles y los 8 restantes se dividen en:

Reverso Ejemplar

IVNO REGINA = Reversos todos diferentes

FECVNDITAS AVG $=$ Dos reversos iguales y el tercero diferente.

VESTA $\quad=$ Sin especificar ningún detalle, lo que no permite asignarla a ninguna de las numerosas emisiones que con este reverso emitió Salonina.

Todos los reversos no se especifican, por lo que ante la imposibilidad de adscribirlas a alguna ceca y emisión determinada, hemos optado por recogerlas como ceca y fecha indeterminada. 
Inv. (43) [32] Algara (La Coruña)

\begin{tabular}{|c|c|c|c|c|c|c|c|}
\hline Emperador & Cronol. & Rom & Ant. & Lug & Rom o Med & Total & $\%$ \\
\hline Caracalla & 215 & 2 & & & & 2 & 2,60 \\
\hline Gordiano III & \begin{tabular}{|l|}
$238-239$ \\
$240-244$
\end{tabular} & $\begin{array}{l}5 \\
2\end{array}$ & & & & 7 & 9,09 \\
\hline Filipo I & $\begin{array}{c}244-247 \\
247-249 \\
247 \\
248-249\end{array}$ & $\begin{array}{l}1 \\
5 \\
3 \\
9\end{array}$ & 1 & & & 19 & 24,67 \\
\hline Ota. Severa & $\begin{array}{c}244-249 \\
248\end{array}$ & $\begin{array}{l}5 \\
2\end{array}$ & & & & 7 & 9,09 \\
\hline Filipo II & $\begin{array}{c}244-247 \\
247 \\
247-249\end{array}$ & $\begin{array}{l}2 \\
1 \\
5\end{array}$ & & & & 8 & 10,39 \\
\hline T. Decio & $\begin{array}{c}249-250 \\
\text { Consecratio }\end{array}$ & 4 & & & 4 & 8 & 10,39 \\
\hline Etruscilla & $249-251$ & 2 & & & & 2 & 2,60 \\
\hline Her. Etruscus & $250-251$ & 3 & & & & 3 & 3,90 \\
\hline Hostiliano & $250-251$ & 1 & & & & 1 & 1,30 \\
\hline T. Galo & $251-253$ & 3 & & & & 3 & 3,90 \\
\hline Volusiano & $\begin{array}{c}251 \\
251-253 \\
253\end{array}$ & $\begin{array}{l}1 \\
1 \\
2\end{array}$ & & & 1 & 5 & 6,49 \\
\hline Valeriano & $\begin{array}{c}253 \\
253-254 \\
256 \\
257 \\
258-259\end{array}$ & $\begin{array}{l}1 \\
1\end{array}$ & 1 & $\begin{array}{l}1 \\
1\end{array}$ & & 5 & 6,49 \\
\hline Mariana Diva & $256-257$ & 1 & & & & 1 & 1,30 \\
\hline Valeriano II & $\begin{array}{l}253-255 \\
258-259\end{array}$ & 1 & & 1 & & 2 & 2,60 \\
\hline \multirow[t]{3}{*}{ Galieno } & $\begin{array}{l}253-254 \\
254-255 \\
257-258\end{array}$ & $\begin{array}{l}2 \\
1 \\
1\end{array}$ & & & & 4 & 5,19 \\
\hline & Total & 67 & 2 & 3 & 5 & 77 & 100 \\
\hline & $\%$ & 87,01 & 2,60 & 3,90 & 6,49 & & \\
\hline
\end{tabular}


Inv. (44) [--] Honcalada (Valladolid)

\begin{tabular}{|c|c|c|c|c|c|c|c|}
\hline Emperador & Cronol. & Rom & Med & Sis & Asi & Total & $\%$ \\
\hline Gordiano III & $\begin{array}{c}239-240 \\
240\end{array}$ & $\begin{array}{l}1 \\
1\end{array}$ & & & & 2 & 7,70 \\
\hline Filipo I & $\begin{array}{c}245-247 \\
246 \\
247 \\
248\end{array}$ & $\begin{array}{l}2 \\
1 \\
2 \\
1\end{array}$ & & & & 6 & 23,08 \\
\hline Filipo II & $245-247$ & 1 & & & & 1 & 3,84 \\
\hline T. Decio & 250 & 1 & $\begin{array}{l}0 \\
1\end{array}$ & & & 1 & 3,84 \\
\hline T. Galo & $\begin{array}{l}251 \\
252 \\
253\end{array}$ & $\begin{array}{l}1 \\
3 \\
1\end{array}$ & & & & 5 & 19,23 \\
\hline Volusiano & $\begin{array}{l}251 \\
253\end{array}$ & $\begin{array}{l}1 \\
1\end{array}$ & & & & 2 & 7,70 \\
\hline Valeriano I & $\begin{array}{c}255-257 \\
255 \\
258-260\end{array}$ & $\begin{array}{l}1 \\
1\end{array}$ & $1 ?$ & & & 3 & 11,54 \\
\hline Galieno & $\begin{array}{c}253 \\
254-255 \\
256-257 \\
264-266\end{array}$ & $\begin{array}{l}2 \\
1\end{array}$ & & 1 & 1 & 5 & 19,23 \\
\hline \multirow[t]{3}{*}{ Salonina } & $264-266$ & 1 & & & & 1 & 3,84 \\
\hline & Total & 22 & 2 & 1 & 1 & 26 & 100 \\
\hline & $\%$ & 88,45 & 7,70 & 3,84 & 3,84 & & \\
\hline
\end{tabular}


Inv. (45) [--] Vareia (Logroño)

\begin{tabular}{|c|c|c|c|c|c|c|c|c|c|}
\hline Emperador & Cronol. & Rom & Med & Lug & $I^{\text {a }} \mathrm{Ceca}$ & Ant & $2^{a}$ Asia & Total & $\%$ \\
\hline Gordiano III & $238-244$ & 25 & & & & I & & 26 & 14,28 \\
\hline Filipo I & 244-249 & 26 & & & & & & 26 & 14,26 \\
\hline Ota. Severa & & 8 & & & & & & 8 & 4,20 \\
\hline Filipo II & & 4 & & & & & & 4 & 2,20 \\
\hline T. Decio & $249-251$ & 9 & & & & & & 9 & 4,94 \\
\hline H. Etruscilla & & 5 & & & & & & 5 & 2,75 \\
\hline H. Etrusco & & 2 & & & & & & 2 & 1,10 \\
\hline Hostiliano & & 1 & & & & & & 1 & 0,55 \\
\hline T. Galo & $251-253$ & 1 & & & & 5 & & 6 & 3,30 \\
\hline Volusiano & & 4 & & & & & & 4 & 2,20 \\
\hline Valeriano & $253-260$ & 7 & 2 & & & 3 & 13 & 25 & 13,73 \\
\hline Mariniana Diva & & 3 & & & & & & 3 & 1,65 \\
\hline Valeriano II & & 1 & & 4 & & & & 5 & 2,75 \\
\hline Salonino & & & 1 & 1 & & 2 & 2 & 6 & 3,30 \\
\hline Galieno & $\begin{array}{l}253-260 \\
260-268\end{array}$ & $\begin{array}{l}9 \\
4\end{array}$ & $\begin{array}{l}1 \\
1\end{array}$ & 8 & & 3 & $\begin{array}{l}3 \\
2\end{array}$ & 31 & 17,03 \\
\hline Salonina & $\begin{array}{l}253-260 \\
260-268\end{array}$ & $\begin{array}{l}1 \\
8\end{array}$ & 1 & 3 & & 1 & 5 & 19 & 10,44 \\
\hline \multirow[t]{3}{*}{ Postumo } & $260-262$ & & & & 2 & & & 2 & 1,10 \\
\hline & Total & 118 & 6 & 16 & 2 & 15 & 25 & 182 & 100 \\
\hline & $\%$ & 64,83 & 3,30 & 8,79 & 1,10 & 8,24 & 13,74 & & \\
\hline
\end{tabular}


Inv. (47) [44] Altafulla (Tarragona)

\begin{tabular}{|c|c|c|c|c|c|c|c|c|c|c|c|}
\hline Emperador & Cronol. & $\mathrm{Col}$ & Rom & Med & Vim & Sam & Ant & Tot* & $\%$ & $\operatorname{Tot}^{* *}$ & $\%$ \\
\hline Gordiano III & $238-244$ & & 21 & & & & 3 & 24 & 10,44 & 24 & 10,58 \\
\hline Filipo I & $244-249$ & & 13 & & & & 4 & 17 & 7,40 & & \\
\hline Filipo II & $244-249$ & & 3 & & & & & 3 & 1,30 & 19 & 8,37 \\
\hline T. Decio & $249-251$ & & 7 & & & & & 7 & 3,05 & 7 & 3,08 \\
\hline Divi Trajano & & & 1 & & & & & 1 & 0,43 & 1 & 0,44 \\
\hline Etruscilla & $249-251$ & & 1 & & & & & 1 & 0,44 & 1 & 0,44 \\
\hline T. Galo & $251-253$ & & 17 & & 5 & & 3 & 25 & 10,88 & 24 & 10,38 \\
\hline Volusiano & $251-253$ & & 4 & & 2 & & & 6 & 2,60 & 6 & 2,64 \\
\hline Emiliano & 253 & & 2 & & & & & 2 & 0,86 & 2 & 0,88 \\
\hline Valeriano I & $253-260$ & 8 & 51 & & 1 & 2 & 7 & 69 & 30,00 & 69 & 30,40 \\
\hline Galieno & $\begin{array}{l}253-260 \\
260-268\end{array}$ & 3 & $\begin{array}{c}26 \\
3\end{array}$ & 3 & 4 & & 5 & 44 & 19,14 & 44 & 19,38 \\
\hline Salonina & $\begin{array}{c}253-60 \\
260-268\end{array}$ & & $\begin{array}{c}12 \\
4\end{array}$ & 4 & & & 1 & 21 & 9,14 & 21 & 9,25 \\
\hline Valeriano II & $257-258$ & 1 & 1 & & & & & 2 & 0,86 & 1 & 0,44 \\
\hline Salonino & $258-260$ & & 6 & 1 & & & & 7 & 3,04 & 7 & 3,08 \\
\hline \multirow[t]{3}{*}{ Postumo } & $260-268$ & 1 & & & & & & 1 & 0,43 & 1 & 0,44 \\
\hline & Total & 13 & 172 & 8 & 12 & 2 & 23 & 230 & 100 & 227 & 100 \\
\hline & $\%$ & 5,64 & 74,78 & 3,47 & 5,21 & 0,86 & 10,00 & & & & \\
\hline
\end{tabular}


Inv. (48) [1] Jimena de la Frontera-1 (Cádiz)

\begin{tabular}{|c|c|c|c|c|c|c|c|c|}
\hline Emperador & Cronol. & Rom & Med & Col & Lug-Col & Sis & Ant & Moe \\
\hline Diva Paulina & $235-238$ & 1 & & & & & & \\
\hline Elogabalo & $218-222$ & 1 & & & & & & \\
\hline Gordiano III & $238-244$ & 27 & & & & & 5 & \\
\hline Filipo I & $244-249$ & 58 & & & & & 1 & \\
\hline Ota.Severa & & 8 & & & & & & \\
\hline Filipo II & 244-249 & 14 & & & & & 3 & \\
\hline T. Decio & $249-251$ & 63 & 4 & & & & 3 & \\
\hline Etruscilla & & 46 & & & & & 2 & \\
\hline Em. Consecratio & & & 11 & & & & & \\
\hline H. Etrusco & $250-251$ & 18 & & & & & 1 & \\
\hline Hostiliano & 251 & 5 & & & & & 6 & \\
\hline T. Galo & $251-253$ & 144 & 46 & & & & 191 & \\
\hline Volusiano & $251-253$ & 179 & 16 & & & & 41 & \\
\hline Emiliano & 253 & 34 & & & & & & \\
\hline Cornelia Supera & & 1 & & & & & & \\
\hline Valeriano I & $253-260$ & 1414 & 196 & & 39 & & & 190 \\
\hline Mariniana & & 104 & & & & & & \\
\hline Galieno & $\begin{array}{l}253-260 \\
260-268\end{array}$ & $\begin{array}{c}690 \\
15482\end{array}$ & $\begin{array}{c}167 \\
1894\end{array}$ & & 78 & 363 & 1 & 44 \\
\hline Salonina & $\begin{array}{l}253-260 \\
260-268\end{array}$ & $\begin{array}{c}700 \\
2534\end{array} \mid$ & $\begin{array}{c}63 \\
173\end{array}$ & & 40 & 57 & $\begin{array}{l}1 \\
1\end{array}$ & \\
\hline Valeriano II & $256-257$ & 171 & & & 29 & & & \\
\hline Salonino & $257-259$ & 82 & 99 & & 10 & & & \\
\hline Postumo & $260-268$ & & & 73 & & & & \\
\hline Macriano & $260-261$ & & & & & & 597 & \\
\hline \multirow[t]{3}{*}{ Quieto } & $260-261$ & & & & & & 501 & \\
\hline & Total & 21776 & 2669 & 73 & 196 & 420 & 1354 & 234 \\
\hline & $\%$ & 72,88 & 8,94 & 0,24 & 0,65 & 1,40 & 4,54 & 0,78 \\
\hline
\end{tabular}

Continúa 
Inv. (48) [1] Jimena de la Frontera-1 (Cádiz)

\begin{tabular}{|c|c|c|c|c|c|c|}
\hline Emperador & Cronol. & Asi & Sam & Inc & Total & $\%$ \\
\hline Diva Paulina & $235-238$ & & & & 1 & - \\
\hline Elogabalo & $218-222$ & & & & 1 & $\ldots$ \\
\hline Gordiano III & $238-244$ & & & & 32 & 0,11 \\
\hline Filipo I & $244-249$ & & & & 59 & 0,20 \\
\hline Ota.Severa & & & & & 8 & 0,03 \\
\hline Filipo II & 244-249 & & & & 17 & 0,06 \\
\hline T. Decio & $249-251$ & & & & 70 & 0,23 \\
\hline Etruscilla & & & & & 48 & 0,16 \\
\hline Em. Consecratio & & & & & 11 & 0,04 \\
\hline H. Etrusco & $250-251$ & & & & 19 & 0,06 \\
\hline Hostiliano & 251 & & & & 11 & 0,04 \\
\hline T. Galo & $251-253$ & & & & 381 & 1,27 \\
\hline Volusiano & $251-253$ & & & & 236 & 0,79 \\
\hline Emiliano & 253 & & & & 34 & 0,11 \\
\hline Cornelia Supera & & & & & 1 & - \\
\hline Valeriano I & $253-260$ & 777 & & 2 & 2618 & 8,77 \\
\hline Mariniana & & & & & 104 & 0,35 \\
\hline Galieno & $\begin{array}{l}253-260 \\
260-268\end{array}$ & $\begin{array}{c}646 \\
1159\end{array}$ & & & 20524 & 68,69 \\
\hline Salonina & $\begin{array}{l}253-260 \\
260-268\end{array}$ & $\begin{array}{l}209 \\
111\end{array}$ & & & 3898 & 13,02 \\
\hline Valeriano II & $256-257$ & 55 & & & 255 & 0,85 \\
\hline Salonino & $257-259$ & 154 & & & 345 & 1,15 \\
\hline Postumo & $260-268$ & & & & 73 & 0,24 \\
\hline Macriano & $260-261$ & & 14 & & 611 & 2,05 \\
\hline \multirow[t]{3}{*}{ Quieto } & $260-26$ & & 32 & & 533 & 1,78 \\
\hline & Total & 3111 & 46 & 2 & 29881 & 100 \\
\hline & $\%$ & 10,42 & 0,15 & -- & & \\
\hline
\end{tabular}


Inv. (49) [45] Tarragona-1888

\begin{tabular}{|c|c|c|c|c|c|c|c|c|c|c|c|c|}
\hline Emperador & Cronol. & Rom & $\mathrm{Col}$ & Med & Vim & Sis & Sam & Ant & SóA & $?$ & Total & $\%$ \\
\hline Gordiano III & $\begin{array}{c}238-239 \\
239 \\
241-243 \\
243-244 \\
242-244 \\
\ldots-\end{array}$ & $\begin{array}{l}1 \\
1 \\
8 \\
4 \\
1\end{array}$ & & & & & & 3 & & & 18 & 17,14 \\
\hline Filipo I & $244-249$ & 10 & & & & & & & & & 10 & 9,52 \\
\hline Ota. Severa & & 2 & & & & & & & & & 2 & 1,90 \\
\hline Filipo II Caes. & $\begin{array}{l}244-249 \\
244-246\end{array}$ & $\begin{array}{l}1 \\
1\end{array}$ & & & & & & & & & 2 & 1,90 \\
\hline T. Decio & $249-251$ & 5 & & & & & & & & & 5 & 4,76 \\
\hline Etruscilla & $249-251$ & 1 & & & & & & & & & 1 & 0,95 \\
\hline T. Galo & $251-253$ & 1 & & & 2 & & & 1 & & & 4 & 3,81 \\
\hline Volusiano & $\begin{array}{l}253 \\
-\end{array}$ & $\begin{array}{l}2 \\
6\end{array}$ & & & 1 & & & & & & 9 & 8,57 \\
\hline Valeriano I & $\begin{array}{c}253-254 \\
254-258 \\
\text { pos } 258 \\
256-259 \\
\ldots-\end{array}$ & $\begin{array}{l}8 \\
8 \\
1 \\
1\end{array}$ & & & $1 ?$ & & 5 & 1 & & & 25 & 23,81 \\
\hline Galieno & $\begin{array}{c}254 \\
253-254 \\
254-256 \\
256 \\
257-258 \\
258 \\
259 \\
261 \\
267-268\end{array}$ & $\begin{array}{l}1 \\
4 \\
1\end{array}$ & 1 & & & & $\begin{array}{l}1 \\
1 \\
1\end{array}$ & 1 & 1 & & 14 & 13,33 \\
\hline Salonino & $-\cdots$ & 1 & & & & & & & & 6 & 7 & 6,66 \\
\hline $\begin{array}{l}\text { Valeriano II } \\
\text { Consecratio }\end{array}$ & $\begin{array}{c}256-257 \\
258 \\
258-259\end{array}$ & 1 & 1 & & & 1 & & & & & 3 & 2,86 \\
\hline Salonina & $\begin{array}{c}256 \\
258-259 \\
259-260 \\
267\end{array}$ & 1 & & 1 & 1 & 1 & I & & & & 5 & 4,76 \\
\hline & Total & 72 & 2 & 1 & 6 & 1 & 9 & 7 & 1 & 6 & 105 & 100 \\
\hline & $\%$ & 68,57 & 1,90 & 0,95 & 5,71 & 0,91 & 8,57 & 6,66 & 0,95 & 5,71 & & \\
\hline
\end{tabular}


Inv. (60) [37] Valsadornin (Palencia)

\begin{tabular}{|l|c|c|c|c|c|c|c|c|c|c|}
\hline Emperador & Cronol. & Rom & Med & Sis & Lug & Ant & Col & lle & Total & $\%$ \\
\hline T. Galo & & 1 & & & & & & & 1 & 0,04 \\
\hline Emiliano & & 2 & & & & & & & 2 & 0,08 \\
\hline Valeriano I & $253-260$ & 62 & 3 & & 2 & 9 & & 2 & 78 & 3,22 \\
\hline Mariniana & & 5 & & & & & & 64 & 5 & 0,20 \\
\hline Galieno & $253-260$ & 1384 & 43 & 118 & 7 & & & 2 & 1616 & 66,80 \\
\hline Salonina & & 200 & 29 & 4 & 3 & 2 & & & 240 & 9,91 \\
\hline Valeriano II & & 12 & & & & & & & 12 & 0,50 \\
\hline Salonino & & 6 & & & & & & & 6 & 0,24 \\
\hline Postumo & $259-268$ & & & & & & 11 & & 11 & 0,45 \\
\hline Macriano & $260-261$ & & & & & 1 & & & 1 & 0,04 \\
\hline Quieto & $260-261$ & & & & & 4 & & & 4 & 0,16 \\
\hline Claudio II & $268-270$ & 443 & 1 & & & & & 1 & 445 & 8,38 \\
\hline & Total & 2115 & 76 & 122 & 12 & 16 & 11 & 69 & 2421 & 100 \\
\hline
\end{tabular}

Inv. (61) [20] Aldeia Das Dez (Conc. de Oliveira Do Hospital, Portugal)

\begin{tabular}{|l|c|c|c|c|c|c|c|c|c|}
\hline Emperador & Cronol. & Rom & Med & Sis & Asi & Dud & Ina & Total & $\%$ \\
\hline Volusiano & $251-253$ & 1 & & & & & & 1 & 0,37 \\
\hline Valeriano I & $253-260$ & 5 & 1 & & & & & 6 & 2,22 \\
\hline Galieno & $253-260$ & 5 & & & 1 & & & & \\
\hline Salonina & $260-268$ & 138 & 15 & 1 & & 11 & 3 & 174 & 64,44 \\
\hline Valeriano II & $253-260$ & 8 & & & & & & & \\
\hline Claudio II & $260-268$ & 21 & 1 & & & & 1 & 31 & 11,48 \\
\hline & Total & 236 & 17 & 1 & 1 & 11 & 4 & 270 & 100 \\
\hline & $\%$ & 87,41 & 6,30 & 0,37 & 0,37 & 4,07 & 1,48 & & \\
\hline
\end{tabular}


Inv. (63) [--] Terra Cha (Lugo)

\begin{tabular}{|l|c|c|c|c|c|c|c|c|}
\hline Emperador & Cronol. & Rom & Sis & Asia & Med & Ind & Total & $\%$ \\
\hline Galieno & $\begin{array}{c}263 \\
266 \\
267-268 \\
268\end{array}$ & 2 & & & & & & \\
\hline Salonina & $\begin{array}{c}267 \\
-267\end{array}$ & & & 1 & & & 1 & 8,33 \\
\hline Claudio II & $\begin{array}{c}269 \\
269-270\end{array}$ & 2 & & & 2 & & & \\
\hline & Total & 7 & 1 & 1 & 2 & 1 & 12 & 100 \\
\hline
\end{tabular}

Inv. (64) [--] Grandas de Salime (Asturias)

\begin{tabular}{|c|c|c|c|c|c|c|c|c|}
\hline Emperador & Cronol. & Rom & Sis & Asia & Med & Ant & Total & $\%$ \\
\hline T. Galo & $251-253$ & & & & & 1 & 1 & 4,35 \\
\hline Emiliano & 253 & 1 & & & & & 1 & 4,35 \\
\hline Valeriano & $\begin{array}{c}254 \\
254-255 \\
255-256\end{array}$ & $\begin{array}{l}1 \\
1\end{array}$ & & & & $\begin{array}{l}1 \\
1\end{array}$ & 4 & 17,39 \\
\hline Galieno & $\begin{array}{c}257-258 \\
259-268 \\
260-268 \\
263 \\
266 \\
267-268\end{array}$ & $\begin{array}{l}2 \\
1 \\
3\end{array}$ & 1 & 1 & & & 9 & 39,12 \\
\hline Salonina & $\begin{array}{c}260-268 \\
262-263 \\
263\end{array}$ & $\begin{array}{l}1 \\
1 \\
1\end{array}$ & & & & & 3 & 13,04 \\
\hline Quieto & $260-261$ & & & & & 1 & 1 & 4,35 \\
\hline Macriano & $260-261$ & & & & & 1 & 1 & 4,35 \\
\hline Claudio II & $\begin{array}{l}268 \\
269\end{array}$ & $\begin{array}{l}1 \\
1\end{array}$ & & & & & 2 & 8,70 \\
\hline \multirow[t]{3}{*}{ Divo Claudio } & pos 270 & & & & 1 & & 1 & 4,35 \\
\hline & Total & 15 & 1 & 1 & I & 5 & 23 & 100 \\
\hline & $\%$ & 65,21 & 4,35 & 4,35 & 4,35 & 21,74 & & \\
\hline
\end{tabular}


Inv. (65) [--] Son Hereu-1 (Lluchmajor, Mallorca)

\begin{tabular}{|c|c|c|c|c|c|c|c|}
\hline Emperador & Cronol. & Rom & Sis & Med & $\mathrm{Gal}$ & Total & $\%$ \\
\hline \multirow[t]{3}{*}{ Galieno } & 263 & 4 & & \multirow{3}{*}{1} & & \multirow[b]{3}{*}{60} & \multirow[b]{3}{*}{58,82} \\
\hline & 266 & 16 & 8 & & & & \\
\hline & $267-268$ & 27 & 4 & & & & \\
\hline \multirow[t]{3}{*}{ Claudio II } & $268-269$ & 2 & & \multirow[b]{3}{*}{1} & & \multirow[b]{3}{*}{40} & \multirow[b]{3}{*}{39,22} \\
\hline & 269 & 31 & & & & & \\
\hline & $269-270$ & 5 & 1 & & & & \\
\hline \multirow[t]{5}{*}{ Divo Claudio } & post 270 & & & & & & \\
\hline & Aguila & 1 & & & & & \\
\hline & Pira & & & & 1 & 2 & 1,96 \\
\hline & Total & 86 & 13 & 2 & 1 & 102 & 100 \\
\hline & $\%$ & 84,32 & 12,74 & 1,96 & 0,98 & & \\
\hline
\end{tabular}

Inv. (67) [23] Conimbriga D (Condeixa A Velha, Portugal)

\begin{tabular}{|l|c|c|c|c|c|c|c|}
\hline Emperador & Cronol. & Rom & Med & Sis & RoL & Total & $\%$ \\
\hline Galieno & 261 & 1 & & & & & \\
263 & 1 & & & & & \\
& 264 & 1 & & & & & \\
& 266 & 12 & & & & & \multirow{2}{*}{62,07} \\
\hline Salonina & $267-268$ & 3 & & & & 18 & \\
& 263 & 1 & & & & & \multirow{2}{*}{1} \\
\hline Claudio II & 268 & 2 & & & & & \\
& 269 & 3 & 1 & & & & 27,90 \\
\hline Divo Claudio & pos 270 & & & & 1 & 1 & 3,45 \\
\hline & Total & 25 & 1 & 2 & 1 & 29 & 100 \\
\hline & $\%$ & 86,20 & 3,45 & 6,90 & 3,45 & & \\
\hline
\end{tabular}


Inv. (70) [22] Conimbriga B (Condeixa a Velha, Portugal)

\begin{tabular}{|l|c|c|c|c|c|c|c|c|}
\hline Emperador & Cronol. & Rom & Med & Sis & Tre & RoL & Total & $\%$ \\
\hline Galieno & 261 & 2 & & & & & & \\
& 263 & 2 & & & & & & \\
& 266 & 10 & 2 & & & & & \\
& $267-268$ & 8 & & & & & 25 & 44,66 \\
\hline Sábrido & 1 & & & & & & \\
\hline Claudio II & 266 & 1 & & & & & & 3,57 \\
\hline Divo Claudio & $267-268$ & 1 & & & & & 2 & \\
\hline Victorino & 268 & & 1 & & & & & \\
\hline Quintilio & $268-270$ & 17 & & & & & & \\
\hline & pibrido & 1 & & 2 & & & & 37,50 \\
\hline & 269 & & & & & 6 & 6 & 10,71 \\
\hline
\end{tabular}

Inv. (72) [--] Vila Caiz (Amarante, Portugal)

\begin{tabular}{|l|c|c|c|c|c|c|c|}
\hline Emperador & Cronol. & Rom & Cyz & Tre & Ind & Total & $\%$ \\
\hline Galieno & 263 & 1 & & & & & \\
& 264 & 1 & & & & & \\
& 265 & & 1 & & & & \\
& 266 & 14 & & & & & \\
& $267-268$ & 5 & & & & 23 & 42,60 \\
\hline Salonina & 266 & 1 & & & & & \\
\hline Claudio II & $267-268$ & 1 & & & & 2 & 3,70 \\
\hline Divo Claudio & 268 & 2 & & & & & \\
\hline Quintilo & 269 & 17 & & & & & \\
\hline Aureliano & 270 & 4 & & & & 4 & 7,41 \\
\hline Victorino & $274-275$ & 2 & & & & 2 & 3,70 \\
\hline Tetrico & 269 & & & 1 & & 1 & 1,85 \\
\hline & 272 & & & 1 & & 1 & 1,85 \\
\hline & Total & 49 & 1 & 2 & 2 & 54 & 100 \\
\hline & $\%$ & 90,75 & 1,85 & 3,70 & 3,70 & & \\
\hline
\end{tabular}


Inv. (73) [--] Reguengo (Vila Pouca de Aguiar, Portugal)

\begin{tabular}{|l|c|c|c|c|c|c|c|c|c|c|c|c|}
\hline Emperador & Cronol. & Rom & Med & Sis & Col & Lug & Tre & Cyz & Reg & Inc & Total & $\%$ \\
\hline Valeriano & $253-260$ & 7 & $1 ?$ & & & & & & 1 & & 9 & 1,20 \\
\hline Mariniana & (Diva) & 1 & & & & & & & & & 1 & 0,13 \\
\hline Galieno & $253-268$ & 329 & 31 & 7 & & & & 1 & & & 368 & 40,10 \\
\hline Salonina & & 42 & 4 & 2 & & & & & & & 48 & 6,40 \\
\hline Valeriano II & $256-258$ & 1 & & & & & & & & & 1 & 0,13 \\
\hline Salonino & 258 & 1 & & & & 1 & & & & & 2 & 0,26 \\
\hline Postumo & $260-268$ & & 1 & & 1 & & & & & & 2 & 0,26 \\
\hline Claudio II & $268-270$ & 286 & 2 & 2 & & & & & 4 & 4 & 298 & 39,73 \\
\hline Tetrico I & $270-273$ & & & & & & 1 & & & & 1 & 0,13 \\
\hline Quintilo & 270 & 16 & 1 & 1 & & & & & & 1 & 19 & 2,53 \\
\hline Aureliano & $270-275$ & & & 1 & & & & & & & 1 & 0,13 \\
\hline & Total & 683 & 40 & 13 & 1 & 1 & 1 & 1 & 5 & 5 & 750 & 100 \\
\hline & $\%$ & 91,10 & 5,33 & 1,73 & 0,13 & 0,13 & 0,13 & 0,13 & 0,66 & 0,66 & & \\
\hline
\end{tabular}


Inv. (74) [--] Clunia-3 (Coruña del Conde, Burgos)

\begin{tabular}{|c|c|c|c|c|c|c|c|c|c|c|}
\hline Emperador & Cronol. & Rom & Med & $\mathrm{Col}$ & Tre & Sis & Ant & Occ & Total & $\%$ \\
\hline Domiciano & $90-91$ & I* & & & & & & & 1 & 1,85 \\
\hline Trajano & $114-117$ & $1 * *$ & & & & & & & 1 & 1,85 \\
\hline Adriano & $134-138$ & $1^{*}$ & & & & & & & 1 & 1,85 \\
\hline Gordiano & 239 & $1^{* * * *}$ & & & & & & & 1 & 1,85 \\
\hline Filipo I & 249 & & & & & & 1 & & 1 & 1,85 \\
\hline Galieno & $\begin{array}{c}263 \\
266 \\
267-268 \\
268\end{array}$ & $\begin{array}{l}1 \\
6 \\
3\end{array}$ & & & & 1 & & & 11 & 20,37 \\
\hline Postumo & $\begin{array}{l}263 \\
267\end{array}$ & & & $\begin{array}{l}1 \\
1\end{array}$ & & & & & 2 & 3,70 \\
\hline Claudio II & $\begin{array}{c}269 \\
269-270 \\
-\end{array}$ & $\begin{array}{l}2 \\
2 \\
1\end{array}$ & & & & & 1 & & 6 & 11,11 \\
\hline Victorino & $\begin{array}{l}269 \\
270\end{array}$ & & & $\begin{array}{l}1 \\
4\end{array}$ & 1 & & & & 6 & 11,11 \\
\hline Quintilo & 270 & 1 & & & & & & & 1 & 1,85 \\
\hline Divo Claudio & pos 270 & & & & & & & 9 & 9 & 16,66 \\
\hline Aureliano & $271-272$ & & 1 & & & & & & 1 & 1,85 \\
\hline Tetrico I & $\begin{array}{c}270 \\
271 \\
272 \\
273 \\
\text { Imit. }\end{array}$ & & & 1 & 1 & & & 4 & 10 & 18,51 \\
\hline \multirow[t]{3}{*}{ Tetrico II } & $\begin{array}{l}273 \\
274\end{array}$ & & & $\begin{array}{l}1 \\
1\end{array}$ & 1 & & & & 3 & 5,55 \\
\hline & Total & 20 & 1 & 12 & 5 & 1 & 2 & 13 & 54 & 100 \\
\hline & $\%$ & 37,04 & 1,85 & 22,22 & 9,26 & 1,85 & 3,70 & 24,08 & & \\
\hline
\end{tabular}

$(*)=$ As

$(* *)=$ Sestercio 
Inv. (76) [13] Borba (o en su región, Portugal)

\begin{tabular}{|c|c|c|c|c|c|c|c|c|c|}
\hline Emperador & Cronol. & Rom & Med & Sis & $\mathrm{Col}$ & Tre & Ina & Total & $\%$ \\
\hline Galieno & $253-268$ & 130 & 1 & 1 & & & 3 & 136 & 50,75 \\
\hline Salonina & & 11 & & & & & & 11 & 4,10 \\
\hline Claudio II & $268-270$ & 94 & 2 & 2 & & & 2 & 100 & 37,31 \\
\hline Divo Claudio & $\begin{array}{c}\text { pos } 270 \\
\text { Aguila } \\
\text { Altar }\end{array}$ & $\begin{array}{l}1 \\
3\end{array}$ & & & & & & 4 & 1,49 \\
\hline Quintilo & 270 & 7 & & 1 & & & & 8 & 2,99 \\
\hline Tetrico I & $270-274$ & & & & 1 & 2 & & 3 & 1,12 \\
\hline Aureliano & $270-275$ & 2 & & & & & & 2 & 0,75 \\
\hline Inatrib. & & & & & & & 4 & 4 & 1,49 \\
\hline & Total & 248 & 3 & 5 & 1 & 2 & 9 & 268 & 100 \\
\hline & $\%$ & 92,54 & 1,12 & 1,86 & 0,37 & 0,75 & 3,36 & & \\
\hline
\end{tabular}


Inv. (77) [--] Sierra Pitillos (Valdepeñas, Jaén)

\begin{tabular}{|c|c|c|c|c|c|c|c|c|c|c|c|}
\hline Emperador & Cronol. & Rom & Ant & Med & $\mathrm{CoI}$ & Sis & RóS & RoM & Imit & Tot. & $\%$ \\
\hline Gordiano III & $238-244$ & 3 & 1 & & & & & & & 4 & 1,6 \\
\hline Filipo I & $244-249$ & 4 & & & & & & & & 4 & 1,6 \\
\hline Filipo II & $244-247$ & 1 & & & & & & & & 1 & 0,4 \\
\hline T. Decio & $249-251$ & 2 & & & & & & & & 2 & 0,8 \\
\hline H. Etrusco & 250 & 1 & & & & & & & & 1 & 0,8 \\
\hline H. Etruscilla & 250 & 1 & & & & & & & & 1 & 0,4 \\
\hline Hostiliano & 251 & 1 & & & & & & & & 1 & 0,4 \\
\hline T. Galo & $251-253$ & 6 & 3 & & & & & & & 9 & 3,6 \\
\hline Volusiano & $251-253$ & 3 & 1 & & & & & & & 4 & 1,6 \\
\hline Emiliano & 253 & 1 & & & & & & & & 1 & 0,4 \\
\hline Valeriano I & $253-260$ & 2 & 3 & 2 & & & & & & 7 & 2,8 \\
\hline Mariniana Diva & pos 254 & 1 & & & & & & & & 1 & 0,4 \\
\hline Galieno & $\begin{array}{l}253-260 \\
260-268\end{array}$ & $\begin{array}{c}2 \\
66^{*}\end{array}$ & $\begin{array}{c}7 \\
11\end{array}$ & $\begin{array}{l}7 \\
8\end{array}$ & & 9 & 3 & 4 & & 117 & 46,6 \\
\hline Salonina & $\begin{array}{l}253-260 \\
260-268\end{array}$ & $\begin{array}{l}1 \\
7\end{array}$ & $\begin{array}{l}1 \\
1\end{array}$ & $\begin{array}{l}1 \\
1\end{array}$ & 1 & & & & & 13 & 5,2 \\
\hline Valeriano II Divo & $\begin{array}{r}255-258 \\
\text { pos } 258\end{array}$ & & 2 & & 2 & & & & & 4 & 1,6 \\
\hline Salonino & $258-260$ & & 1 & & & & & & & 1 & 0,4 \\
\hline Macriano & $260-261$ & & 2 & & & & & & & 2 & 0,8 \\
\hline Quieto & $260-261$ & & 3 & & & & & & & 3 & 1,2 \\
\hline Postumo & $260-268$ & & & & 1 & & & & & l & 0,4 \\
\hline Claudio II Divo & $\begin{array}{r}268-270 \\
\operatorname{pos} 270\end{array}$ & $\begin{array}{c}53 \\
10 \mathrm{Ag} \\
6 \mathrm{Al}\end{array}$ & & & & & & & & 69 & 27,5 \\
\hline Quintilo & 270 & 1 & & & & & & & & 1 & 0,4 \\
\hline Aureliano & $270-271$ & 1 & 1 & & & & & & & 2 & 0,8 \\
\hline \multirow[t]{3}{*}{ Tétrico I } & $270-273$ & & & & 1 & & & & 1 & 2 & 0,8 \\
\hline & Total & 173 & 37 & 19 & 5 & 9 & 3 & 4 & 1 & 251 & 100 \\
\hline & $\%$ & 68,8 & 14,7 & 7,6 & 2,0 & 3,6 & 1,2 & 1,6 & 0,4 & & \\
\hline
\end{tabular}


Inv. (78) [28] Fragas Do Piago (Freg. de Salto, Conc. de Montalegre, Portugal)

\begin{tabular}{|c|c|c|c|c|c|c|c|c|}
\hline Emperador & Cronol. & Lug & Col & Med & Rom & Sis & Vim & Cyz \\
\hline Filipo I & $244-249$ & & & & 1 & & & \\
\hline T. Galo & $251-253$ & & & & 1 & & & \\
\hline Volusiano & $251-253$ & & & 1 & 1 & & & \\
\hline Emiliano & 253 & & & & 1 & & & \\
\hline Valeriano I & $253-260$ & & & & 29 & & 2 & \\
\hline Mariniana & & & & & 2 & & & \\
\hline Galieno & $253-268$ & & & 148 & 1252 & 146 & & \\
\hline Salonina & & 1 & & 28 & 144 & 3 & & \\
\hline Salonino & & 1 & & 2 & 7 & & & \\
\hline Macriano II & $260-261$ & & & & & & & \\
\hline Postumo & $260-268$ & 2 & 1 & & & & & \\
\hline Victorino & $269-271$ & & 2 & & & & & \\
\hline Claudio II* & $268-270$ & & & 130 & 762 & 17 & & 2 \\
\hline Quintilo & 270 & & & 1 & 51 & 3 & & \\
\hline Aureliano & $270-275$ & & & 8 & 8 & 1 & & 3 \\
\hline \multicolumn{9}{|l|}{ Severina } \\
\hline Tacito & $275-276$ & & & & & & & $\overline{1}$ \\
\hline \multicolumn{9}{|l|}{ Inatribui. } \\
\hline & Total & 4 & 3 & 318 & 2259 & 170 & 2 & 6 \\
\hline & $\%$ & $0, \overline{14}$ & 0,10 & 11,07 & 78,63 & 5,92 & 0,07 & 0,21 \\
\hline
\end{tabular}

\section{Continúa}


Inv. (78) [28] Fragas Do Piago (Freg. de Salto, Conc. de Montalegre, Portugal)

\begin{tabular}{|c|c|c|c|c|c|c|c|}
\hline Emperador & Cronol. & Ant & Asi & Dud & Inc & Total & $\%$ \\
\hline Filipo I & $244-249$ & & & & & 1 & 0,03 \\
\hline T. Galo & $251-253$ & 1 & & & & 2 & 0,07 \\
\hline Volusiano & $251-253$ & & & & & 2 & 0,07 \\
\hline Emiliano & 253 & & & & & 1 & 0,03 \\
\hline Valeriano I & $253-260$ & 3 & & 3 & & 37 & 1,29 \\
\hline Mariniana & & & & & & 2 & 0,03 \\
\hline Galieno & $253-268$ & & 6 & 22 & 15 & 1589 & 55,31 \\
\hline Salonina & & & 3 & & & 179 & 6,23 \\
\hline Salonino & & 1 & & & & 11 & 0,38 \\
\hline Macriano II & $260-261$ & 2 & & & & 2 & 0,07 \\
\hline Postumo & $260-268$ & & & & & 3 & 0,10 \\
\hline Victorino & $269-271$ & & & 1 & & 3 & 0,10 \\
\hline Claudio II* & $268-270$ & 1 & & 6 & 24 & 942 & 32,79 \\
\hline Quintilo & 270 & & & 1 & 1 & 57 & 1,98 \\
\hline Aureliano & $270-275$ & & & & & 20 & 0,70 \\
\hline Severina & & & & 2 & & 2 & 0,07 \\
\hline Tacito & $275-276$ & & & & & 1 & 0,03 \\
\hline \multirow[t]{3}{*}{ Inatribui. } & & & & & 19 & 19 & 0,66 \\
\hline & Total & 8 & 9 & 35 & 59 & 2873 & 100 \\
\hline & $\%$ & 0,28 & 0,31 & 1,22 & 2,05 & & \\
\hline
\end{tabular}

(*) Incluye varios ejemplares DIVO CLAVDIO 
Inv. (79) [-- Clunia-2 (Coruña del Conde, Burgos)

\begin{tabular}{|c|c|c|c|c|c|c|c|c|c|c|}
\hline Emperador & Cronol. & Rom & Sis & Ant & Occ & $\mathrm{Cel}$ & Cal & $\mathrm{Cae}$ & Total & $\%$ \\
\hline Augusto & $\begin{array}{c}33-28 \text { a.C } \\
23-13 \text { a.C } \\
28 \text { a.C. }\end{array}$ & & & & & $1 *$ & $1 "$ & $1 *$ & 3 & 12,60 \\
\hline Claudio I & $41-54$ & $1 *$ & & & & & & & 1 & 4,16 \\
\hline Domiciano & $90-91$ & $1 *$ & & & & & & & 1 & 4,16 \\
\hline Adriano & $125-128$ & 1' & & & & & & & 1 & 4,16 \\
\hline Valeriano I & $254-255$ & 1 & & & & & & & 1 & 4,16 \\
\hline Galieno & $\begin{array}{l}266 \\
268\end{array}$ & 2 & 1 & & & & & & 3 & 12,60 \\
\hline Claudio II & 269 & 2 & & & & & & & 2 & 8,35 \\
\hline Divo Claudio & post 270 & & & & 9 & & & & 9 & 37,60 \\
\hline Tetrico I & Imitac. & & & & 1 & & & & 1 & 4,16 \\
\hline Probo & 280 & & & 1 & & & & & 1 & 4,16 \\
\hline Indet. & & & & & 1 & & & & 1 & 4,16 \\
\hline & Total & 8 & 1 & 1 & 11 & 1 & 1 & 1 & 24 & 100 \\
\hline & $\%$ & 33,35 & 4,16 & 4,16 & 45,85 & 4,16 & 4,16 & 4,16 & & \\
\hline
\end{tabular}
(*) $=$ As
(") = Sestercio
(" c) = Denario 
Inv. (83) [--] Monte do Cavaleiro (Algarve, Portugal)

\begin{tabular}{|c|c|c|c|c|c|c|c|c|}
\hline Emperador & Cronol. & Rom & Sis & Mil & Cyz & Ind & Total & $\%$ \\
\hline Galieno & $\begin{array}{c}261 \\
262-264 \\
263 \\
266 \\
267-268 \\
268\end{array}$ & $\begin{array}{c}2 \\
1 \\
14 \\
11\end{array}$ & 1 & & & & 30 & 34,48 \\
\hline Salonina & 266 & 2 & & & & & 2 & 2,30 \\
\hline Claudio II & $\begin{array}{c}268 \\
268-269 \\
269 \\
269-270\end{array}$ & $\begin{array}{c}4 \\
24 \\
7\end{array}$ & $\begin{array}{l}1 \\
1\end{array}$ & $\begin{array}{l}3 \\
2\end{array}$ & & & 42 & 48,27 \\
\hline Divo Claudio & p. 270 & & & & & $\begin{array}{l}3 \text { Alt. } \\
2 \text { Agu. }\end{array}$ & 5 & 5,75 \\
\hline Quintilo & 270 & 4 & & & & & 4 & 4,60 \\
\hline Aureliano & $\begin{array}{c}270 \\
271-272\end{array}$ & & 1 & & 1 & & 2 & 2,30 \\
\hline Severina & $274-275$ & 1 & & & & & 1 & 1,15 \\
\hline \multirow[t]{3}{*}{ Probo } & 281 & $1 *$ & & & & & 1 & 1,15 \\
\hline & Total & 71 & 5 & 5 & 1 & 5 & 87 & \\
\hline & $\%$ & 81,60 & 5,75 & 5,75 & 1,15 & 5,75 & 87 & \\
\hline
\end{tabular}

*: Denario. 
Inv. (85) [--] Chaves (Portugal)

\begin{tabular}{|c|c|c|c|c|c|c|c|c|}
\hline Emperador & Cronol. & Rom & Lug & Med & Tic & Sis & Ser & Cyz \\
\hline Valeriano & $253-260$ & 2 & & & & & & \\
\hline Galieno & $\begin{array}{l}253-260 \\
260-268\end{array}$ & $\begin{array}{c}2 \\
90\end{array}$ & & 1 & & 1 & & \\
\hline Salonina & $\begin{array}{l}253-260 \\
260-268\end{array}$ & $\begin{array}{l}1 \\
8\end{array}$ & & & & & & \\
\hline Macriano & $260-261$ & & & & & & & \\
\hline Claudio II & $268-270$ & 50 & & 2 & & 4 & & 1 \\
\hline Divo Claudio & pos 270 & 5 & & & & & & \\
\hline Victorino & $268-270$ & & & & & & & \\
\hline Tetrico & $270-274$ & & & & & & & \\
\hline Quintilo & 270 & 4 & & 1 & & & & \\
\hline Aureliano & $270-275$ & 2 & & 1 & & 1 & 1 & \\
\hline Severina & $270-275$ & $3^{*}$ & & & & & & \\
\hline Tacito & $275-276$ & & 1 & & & & & \\
\hline Probo & $276-282$ & 1 & & & & 1 & & \\
\hline Caro & $282-283$ & & & & 1 & & & \\
\hline Imitaciones & $\begin{array}{c}\text { Claud. II } \\
\text { Div. Claud. } \\
\text { Tet. VII }\end{array}$ & & & & & & & \\
\hline \multicolumn{9}{|l|}{ Ilegibles } \\
\hline & Total & 168 & 1 & 5 & 1 & 7 & 1 & 1 \\
\hline & $\%$ & 79,25 & 0,47 & 2,36 & 0,47 & 3,30 & 0,47 & 0,47 \\
\hline
\end{tabular}

Continúa 
Inv. (85) [--] Chaves (Portugal)

\begin{tabular}{|c|c|c|c|c|c|c|c|}
\hline Emperador & Cronol. & Ant & Eme & Tre & $?$ & Total & $\%$ \\
\hline Valeriano & $253-260$ & & & & & 2 & 0,94 \\
\hline Galieno & $\begin{array}{l}253-260 \\
260-268\end{array}$ & & 1 & & 1 & 96 & 45,29 \\
\hline Salonina & $\begin{array}{l}253-260 \\
260-268\end{array}$ & & & & & 9 & 4,25 \\
\hline Macriano & $260-261$ & & 1 & & & 1 & 0,47 \\
\hline Claudio II & $268-270$ & & & & 1 & 58 & 27,37 \\
\hline Divo Claudio & $\operatorname{pos} 270$ & & & & & 5 & 2,36 \\
\hline Victorino & $268-270$ & & & 3 & & 3 & 1,41 \\
\hline Tetrico & $270-274$ & & & 1 & & 1 & 0,47 \\
\hline Quintilo & 270 & & & & & 5 & 2,36 \\
\hline Aureliano & $270-275$ & & & & & 5 & 2,36 \\
\hline Severina & $270-275$ & & & & & 3 & 1,41 \\
\hline Tacito & $275-276$ & & & & & 1 & 0,47 \\
\hline Probo & $276-282$ & 1 & & & & 3 & 1,41 \\
\hline Caro & $282-283$ & & & & & 1 & 0,47 \\
\hline Imitaciones & $\begin{array}{c}\text { Claud. II } \\
\text { Div. Claud } \\
\text { Tet. I/II }\end{array}$ & & & & $\begin{array}{c}1 \\
11 \\
4\end{array}$ & 16 & 7,55 \\
\hline \multirow[t]{3}{*}{ Ilegibles } & & & & & 3 & 3 & 1,41 \\
\hline & Total & 1 & 2 & 4 & 21 & 212 & 100 \\
\hline & $\%$ & 0,47 & 0,94 & 1,98 & 9,91 & & \\
\hline
\end{tabular}


Inv. (86) [39] Clunia-1 (Coruña del Conde, Burgos)

\begin{tabular}{|l|c|c|c|c|c|c|c|c|c|}
\hline Emperador & Cronol. & Rom & Sis & Lug & Tic & Cyz & Asi & Total & $\%$ \\
\hline Galieno & $255-256$ & & & & & & 1 & 1 & 2,94 \\
\hline Aureliano & $274-275$ & & & & & 2 & & 2 & 5,88 \\
\hline Floriano & 276 & & & 1 & & & & 1 & 2,94 \\
\hline Probo & $277-278$ & & & 1 & & & & & \\
& 278 & 1 & & & 2 & & & & \\
& $278-279$ & 1 & & 1 & & & & & \\
& 279 & 1 & & & 3 & & & & \\
& 280 & 1 & 2 & & & & & & \\
\hline Carino & 281 & 5 & & 1 & 2 & & & 25 & 73,54 \\
\hline Numeriano & $282-283$ & 1 & & & & & & & \\
\hline Divo Caro & $283-284$ & 1 & & & & & & 2 & 5,88 \\
\hline Magna Urbica & $282-283$ & 1 & & & & & & 1 & 2,94 \\
\hline & $284-284$ & 1 & & & & & & 1 & 2,94 \\
\hline
\end{tabular}


Inv. (89) [-- Coimbra (Portugal)

\begin{tabular}{|l|c|c|c|c|c|c|c|}
\hline Emperador & Cronol. & Lug & Col & Tic & Med & Rom & Sis \\
\hline Valeriano & $253-258$ & & 1 & & & 1 & \\
\hline Galieno & $262-268$ & & & & 2 & 5 & \\
\hline Salonina & 264 & & & & & 2 & \\
\hline Claudio II & 268.270 & & & & & 6 & \\
\hline Divo Claudio & pos 270 & & & & & 1 & \\
\hline Quintilo & 270 & & & & & 2 & \\
\hline Aureliano & $\begin{array}{l}270-275 \\
\text { pre ref. } \\
\text { pos ref. }\end{array}$ & & & & & & \\
\hline Tacito & $275-276$ & & & 1 & & 3 & \\
\hline Floriano & 276 & & & & & 1 & \\
\hline Probo & $276-282$ & 4 & & 8 & & 9 & 7 \\
\hline Caro & 282 & 1 & & & & & 1 \\
\hline Carino Caes. & 283 & & & & & 1 & \\
\hline Numeriano & 283 & & & & & 1 & \\
\hline Diocleciano & $285-292$ & & & & & 4 & \\
\hline Maximiano & $286-291$ & 2 & & & & 8 & \\
\hline & Total & 7 & 1 & 9 & 3 & 44 & 9 \\
\hline
\end{tabular}

Continúa 
Inv. (89) [--] Coimbra (Portugal)

\begin{tabular}{|c|c|c|c|c|c|c|c|}
\hline Emperador & Cronol. & Ser & $\mathrm{Biz}$ & Cyz & Ant & Total & $\%$ \\
\hline Valeriano & $253-258$ & & & & & 2 & 2,53 \\
\hline Galieno & $262-268$ & & & 1 & & 8 & 10,13 \\
\hline Salonina & 264 & & & & & 2 & 2,53 \\
\hline Claudio II & 268.270 & & & & & 6 & 7,59 \\
\hline Divo Claudio & $\operatorname{pos} 270$ & & & & & 1 & 1,26 \\
\hline Quintilo & 270 & & & & & 2 & 2,53 \\
\hline Aureliano & $\begin{array}{l}270-275 \\
\text { pre ref. } \\
\text { pos ref. }\end{array}$ & 1 & 1 & 1 & 1 & 6 & 7,59 \\
\hline Tacito & $275-276$ & & & & & 4 & 5,06 \\
\hline Floriano & 276 & & & & & 1 & 1,26 \\
\hline Probo & $276-282$ & 1 & & & & 29 & 36,70 \\
\hline Caro & 282 & & & & & 2 & 2,53 \\
\hline Carino Caes. & 283 & & & & & 1 & 1,26 \\
\hline Numeriano & 283 & & & & & 1 & 1,26 \\
\hline Diocleciano & $285-292$ & & & & & 4 & 5,06 \\
\hline \multirow[t]{3}{*}{ Maximiano } & $286-291$ & & & & & 10 & 12,65 \\
\hline & Total & 2 & 1 & 2 & 1 & 79 & 100 \\
\hline & $\%$ & 2,53 & 1,26 & 2,53 & 1,26 & & \\
\hline
\end{tabular}

